\title{
CARACTERIZAÇÃO HIDRÁULICA DE DOIS MODELOS DE MICROASPERSORES ASSOCIADOS A TRÊS REGULADORES DE \\ FLUXO E UM MECANISMO DE PULSO.
}

\section{Maristélio da Cruz Costa}

Engenheiro Agrônomo

Orientador: Prof. Dr. José Antonio Frizzone

Dissertação apresentada à Escola Superior de Agricultura "Luiz de Queiroz", da Universidade de São Paulo, para obtenção do título de Mestre em Agronomia, área de concentração: Irrigação e Drenagem.

PIRACICABA

ESTADO DE SÃO PAULO - BRASIL

DEZEMBRO - 1994 
Ficha catalogrtica preparada pela seça de Livos da Divisă de Biblioteca e Dacumentagád - FCLDLGP

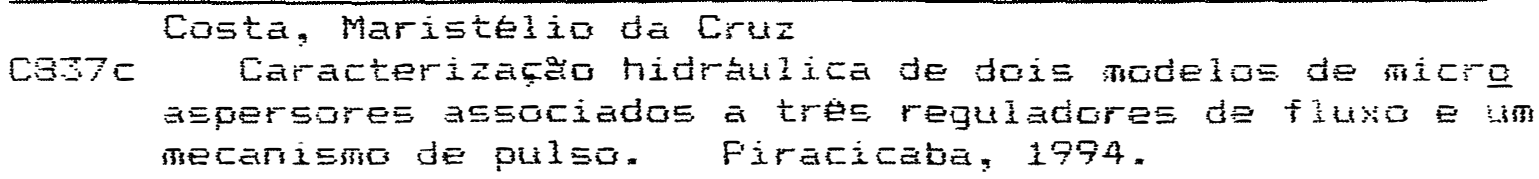

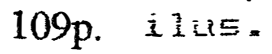

DiES-(NeStre) - ESALQ

Bìliografia.

1. Irpigapao lacalizada 2. Microaspersor - Daracteristica I. EEcGia Suferior de Agricultura luiz de Ruei Fö, Firacicaba

CDD G. 631.7 
CARACTERIZAÇÃO HIDRÁULICA DE DOIS MODELOS DE MICROASPERSORES ASSOCIADOS A TRÊS REGULADORES DE

FLUXO E UM MECANISMO DE PULSO.

\section{MARISTÉLIO DA CRUZ COSTA}

Aprovada em: 02121994.

Comissão julgadora:

Prof. Dr. João Carlos Cury Saad

FCA/UNESP

Prof. Dr. Tarlei Arriel Botrel

ESALQ/USP

Prof. Dr. José Antonio Frizzone

ESALQ/USP

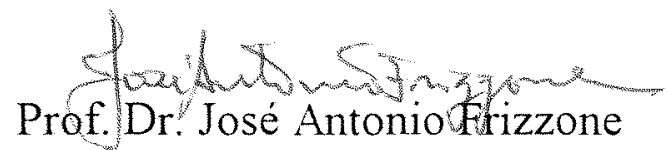

Orientador 
À minha esposa Marly pela compreensão, entusiasmo e apoio durante todo o decorrer do curso.

à minha mãe Cétura,

à meu pai Adauto (In memorian)

e a todos meus familiares. 


\section{AGRADECIMENTOS}

À Deus pela fé e perseverança concedidos em todos os momentos.

Ao Governo do Estado do Rio Grande do Norte, através da Fundação Idec pela oportunidade oferecida e concessão de recursos financeiros, para a realização deste curso de mestrado.

À Escola Superior de Agricultura de Mossoró pela formação acadêmica.

À Escola Superior de Agricultura "Luiz de Queiroz", por intermédio do Departamento de Engenharia Rural, pela acolhida e efetivo apoio concedido.

À Coordenadoria de Aperfeiçoamento de Pessoal de Ensino Superior CAPES, pela contribuição financeira durante a realização do curso.

À empresa Fortilit pela concessão dos equipamentos para realização deste trabalho.

Ao Professor Dr. José Antonio Frizzone, pela orientação e amizade no decorrer do curso e realização deste trabalho.

Aos Professores Dr. Tarlei Arriel Botrel e Dr. João Carlos Cury Saad, pelas valiosas sugestões e colaborações apresentadas durante a defesa da dissertação.

Aos funcionários do Departamento de Engenharia Rural José Figueiredo (Zezinho), Márcio, Gilmar e Hélio pela ajuda nos trabalhos durante a fase experimental.

Enfim, a todos aqueles que, direta ou indiretamente, tenham contribuído para o êxito deste trabalho. 


\section{SUMÁRIO}

Página

LISTA DE FIGURAS ...............................................................................

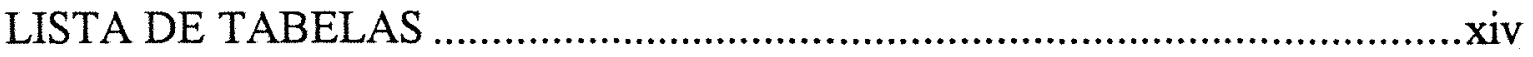

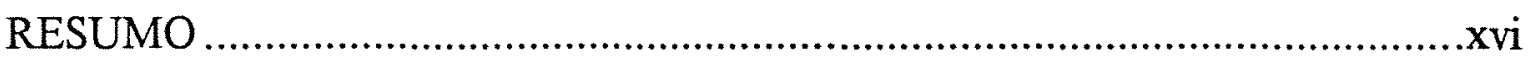

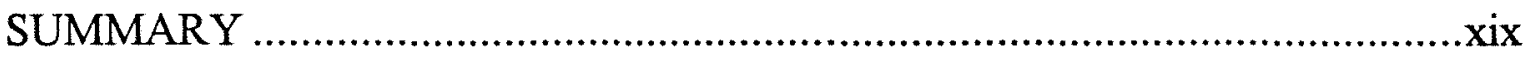

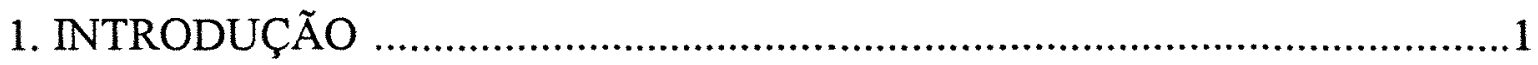

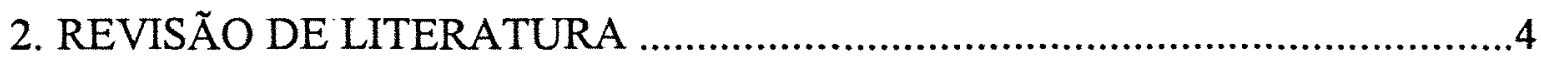

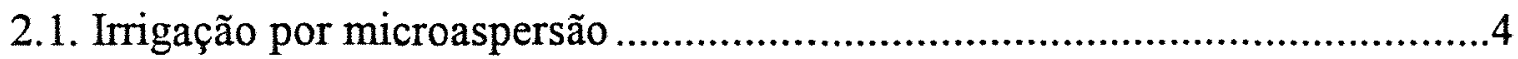

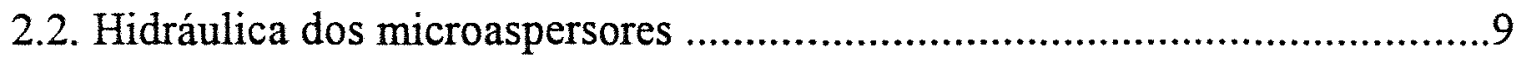

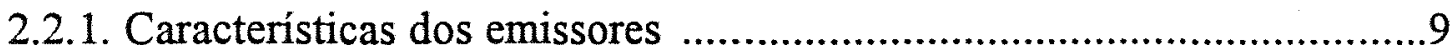

2.2.2. Características hidráulicas dos emissores ........................................10

2.2.3. Coeficiente de variação de fabricação dos emissores..........................14

2.2.4. Uniformidade de distribuição dos microaspersores............................18

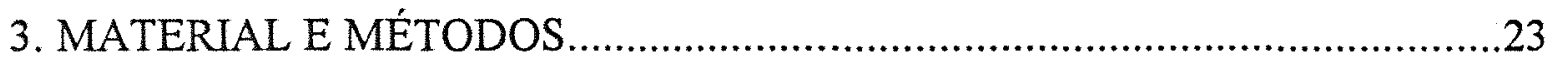

3.1. Determinação da equação característica vazão-Pressão..............................28

3.2. Determinação da uniformidade de vazão.................................................33

3.3. Determinação do perfil de distribuição de água........................................33

3.4. Determinação da superfície de distribuição de água pelos microaspersores..36 
4.1. Determinação da equação característica vazão-pressão .40

4.2. Determinação da uniformidade de vazão. .53

4.3. Determinação do perfil de distribuição de água........................................64

4.4. Determinação da superfície de distribuição de água pelos microaspersores .71

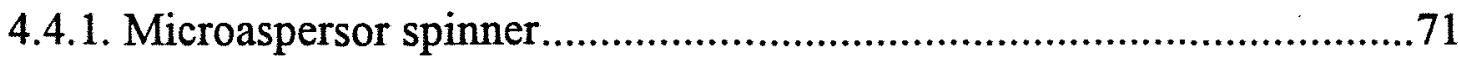

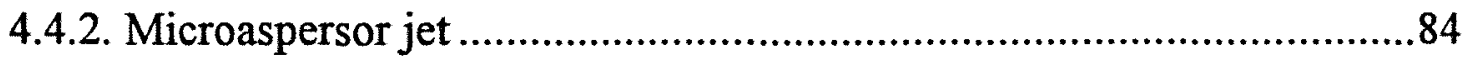

5. CONCLUSÕES

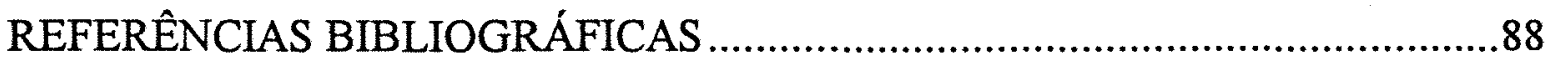

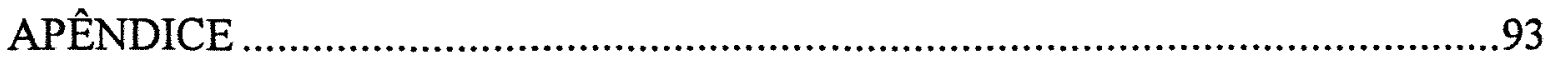




\section{LISTA DE FIGURAS}

Figura $\mathrm{n}^{\mathrm{O}}$

página

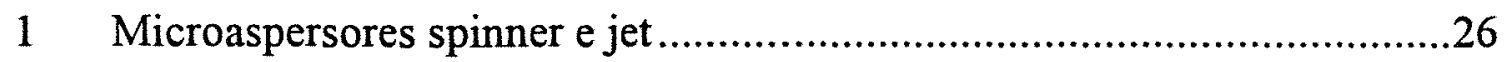

2 Detalhes do pulsator e de sua montagem. com os bocais .......................26

3 Vista da filtragem e alimentação da bancada de testes...........................29

$4 \quad$ Vista da coleta de água pelos microaspersores ....................................32

5 Vista da conexão dos microaspersores na linha lateral .........................32

6 Disposição de coletores para perfil de distribuição

e superficie molhada pelos microaspersores ....................................38

7 Distribuição dos coletores para ensaio com o microaspersor jet ...............38

8 Posição relativa dos jatos do microaspersor jet.......................................39

9 Curvas características dos microaspersores spinner .............................44

10 Curvas características dos microaspersores jet....................................45

11 Curvas características dos microaspersores spinner com regulador de

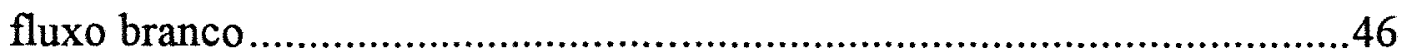

12 Curvas características dos microaspersores jet com regulador de fluxo branco

13 Curvas Características dos microaspersores spinner com regulador de fluxo verde.

14 Curvas Características dos microaspersores jet com regulador de 
fluxo verde

15 Curvas características dos microaspersores spinner com regulador de

fluxo preto

16 Curvas Características dos microaspersores jet com regulador

de fluxo preto.

17 Curvas Características dos reguladores de fluxo branco, verde e preto. ...52

18 Perfil de distribuição da precipitação dos Microaspersores spinner

19 Perfil de distribuição da precipitação dos Microaspersor spinner com regulador de fluxo branco 68

20 Perfil de distribuição da precipitação dos Microaspersor spinner com regulador de fluxo verde

21 Perfil de distribuição da precipitação dos Microaspersor spinner com regulador de fluxo preto 70

22 Distribuição espacial da água apresentada pelo microaspersor spinner com bocal vermelho operando $151,06 \mathrm{kPa}$ - (A) vista tridimensional; (B) vista superior 72

23 Distribuição espacial da água apresentada pelo microaspersor spinner com bocal violeta operando $151,06 \mathrm{kPa}$ - (A) vista tridimensional ; (B) vista superior 
24 Distribuição espacial da água apresentada pelo microaspersor spinner com bocal azul operando $151,06 \mathrm{kPa}$ - (A) vista tridimensional ; (B) vista superior 74

25 Distribuição espacial da água apresentada pelo microaspersor spinner com bocal vermelho e regulador de fluxo branco operando a $151,06 \mathrm{kPa}-(\mathrm{A})$ vista tridimensional ; (B) vista superior

26 Distribuição espacial da água apresentada pelo microaspersor spinner com bocal violeta e regulador de fluxo branco operando a $151,06 \mathrm{kPa}$ - (A) vista tridimensional ; (B) vista superior 76

27 Distribuição espacial da água apresentada pelo microaspersor spinner com bocal azul e regulador de fluxo branco operando a $151,06 \mathrm{kPa}$ - (A) vista tridimensional ; (B) vista superior

28 Distribuição espacial da água apresentada pelo microaspersor spinner com bocal vermelho e regulador de fluxo verde operando a $151,06 \mathrm{kPa}$ - (A) vista tridimensional ; (B) vista superior. 78

29 Distribuição espacial da água apresentada pelo microaspersor spinner com bocal violeta e regulador de fluxo verde operando a $151,06 \mathrm{kPa}$ - (A) vista tridimensional ; (B) vista superior 79 
30 Distribuição espacial da água apresentada pelo microaspersor spinner com bocal azul e regulador de fluxo verde operando a $151,06 \mathrm{kPa}-(\mathrm{A})$ vista tridimensional ; (B) vista superior

31 Distribuição espacial da água apresentada pelo microaspersor spinner com bocal vermelho e regulador de fluxo preto operando a $151,06 \mathrm{kPa}-(\mathrm{A})$ vista tridimensional ; (B) vista superior .81

32 Distribuição espacial da água apresentada pelo microaspersor spinner com bocal violeta e regulador de fluxo preto operando a $151,06 \mathrm{kPa}-(\mathrm{A})$ vista tridimensional ; (B) vista superior

33 Distribuição espacial da água apresentada pelo microaspersor spinner com bocal azul e regulador de fluxo preto operando a $151,06 \mathrm{kPa}$ - (A) vista tridimensional ; (B) vista superior 83

34 Distribuição espacial da água apresentada por três jatos do microaspersor jet com bocal vermelho operando a $151,06 \mathrm{kPa}$. -

(A) vista tridimensional; (B) vista superior 94

35 Distribuição espacial da água apresentada por três jatos do microaspersor jet com bocal violeta operando a $151,06 \mathrm{kPa}$. (A) vista tridimensional; (B) vista superior 95 
36 Distribuição espacial da água apresentada por três jatos do microaspersor jet com bocal azul operando a $151,06 \mathrm{kPa}$. - (A) vista tridimensional; (B) vista superior .96

37 Distribuição espacial da água apresentada por três jatos do microaspersor jet com bocal laranja operando a $151,06 \mathrm{kPa}$. (A) vista tridimensional; (B) vista superior .97

38 Distribuição espacial da água apresentada por três jatos do microaspersor jet com bocal vermelho e regulador de fluxo branco operando a $151,06 \mathrm{kPa}$ - (A) vista tridimensional; (B) vista superior .98

39 Distribuição espacial da água apresentada por três jatos do microaspersor jet com bocal violeta e regulador de fluxo branco operando a $151,06 \mathrm{kPa}$ - (A) vista tridimensional; (B) vista superior 99

40 Distribuição espacial da água apresentada por três jatos do microaspersor jet com bocal azul e regulador de fluxo branco operando a $151,06 \mathrm{kPa}$ - (A) vista tridimensional; (B) vista superior. 100

41 Distribuição espacial da água apresentada por três jatos do microaspersor jet com bocal laranja e regulador de fluxo branco 
operando a $151,06 \mathrm{kPa}$ - (A) vista tridimensional; (B) vista superior.

42 Distribuição espacial da água apresentada por três jatos do microaspersor jet com bocal vermelho e regulador de fluxo verde operando a $151,06 \mathrm{kPa}$ - (A) vista tridimensional; (B) vista superior

43 Distribuição espacial da água apresentada por três jatos do microaspersor jet com bocal violeta e regulador de fluxo verde operando a $151,06 \mathrm{kPa}$ - (A) vista tridimensional; (B) vista superior

44 Distribuição espacial da água apresentada por três jatos do microaspersor jet com bocal azul e regulador de fluxo verde operando a $151,06 \mathrm{kPa}$ - (A) vista tridimensional; (B) vista superior. 104

45 Distribuição espacial da água apresentada por três jatos do microaspersor jet com bocal laranja e regulador de fluxo verde operando a $151,06 \mathrm{kPa}$ - (A) vista tridimensional; (B) vista superior 105

46 Distribuição espacial da água apresentada por três jatos do microaspersor jet com bocal vermelho e regulador de fluxo 
preto operando a $151,06 \mathrm{kPa}-(\mathrm{A})$ vista tridimensional; (B)

vista superior

47 Distribuição espacial da água apresentada por três jatos do microaspersor jet com bocal violeta e regulador de fluxo preto operando a $151,06 \mathrm{kPa}$ - (A) vista tridimensional; (B) vista superior

48 Distribuição espacial da água apresentada por três jatos do microaspersor jet com bocal azul e regulador de fluxo preto operando a $151,06 \mathrm{kPa}$ - (A) vista tridimensional; (B) vista superior 108

49 Distribuição espacial da água apresentada por três jatos do microaspersor jet com bocal laranja e regulador de fluxo preto operando a $151,06 \mathrm{kPa}$ - (A) vista tridimensional; (B) vista superior 


\section{LISTA DE TABELAS}

Tabela $\mathrm{n}^{\mathrm{o}}$

página

1 Classificação dos emissores, segundo coeficiente de variação de fabricação

2 Vazões e diâmetros de alcance nominais dos bocais operando à 147,13

$\mathrm{kPa}(15$ m.c.a. $)$

3 Combinações entre bocais e reguladores de fluxo.

4 Relação vazão-pressão dos emissores estudados

5 Vazão média observada para os bocais spinner a diferentes

pressões e respectivos coeficientes de variação

6 Dados de vazão média observada para os bocais jet a diferentes pressões e respectivos coeficientes de variação

7 Vazão média observada para os bocais spinner com reguladores

de fluxo branco a diferentes pressões e respectivos coeficientes

de variação

8 Vazão média observada para os bocais jet com reguladores

de fluxo branco a diferentes pressões e respectivos coeficientes de variação. 
9 Vazão média observada para os bocais spinner com reguladores de fluxo verde a diferentes pressões e respectivos coeficientes de variação 59

10 Vazão média observada para os bocais jet com reguladores de fluxo verde a diferentes pressões e respectivos coeficientes de variação

11 Vazão média observada para os bocais spinner com reguladores de fluxo preto a diferentes pressões e respectivos coeficientes de variação 61

12 Dados de vazão média observada para os bocais jet com reguladores de fluxo preto a diferentes pressões e respectivos coeficientes de variação

13 Vazão média observada para os reguladores de fluxo branco, verde e preto a diferentes pressões e respectivos coeficientes de variação 63

14 Diâmetro de alcance para os microaspersores spinner 65

15 Diâmetro de alcance para os microaspersores jet. 85 


\author{
CARACTERIZAÇÃO HIDRÁULICA DE DOIS MODELOS DE \\ MICROASPERSORES ASSOCIADOS A TRÊS REGULADORES DE \\ FLUXO E UM MECANISMO DE PULSO.
}

Autor: Maristélio da Cruz Costa

Orientador: Prof. Dr. Antonio José Frizzone

RESUMO

O propósito do presente trabalho é a caracterização hidráulica de dois modelos de microaspersores associados a três reguladores de fluxo e um mecanismo de pulso com o intuito de dar subsídios ao adequado dimensionamento de sistemas de irrigação por microaspersão. Nesse sentido, foi desenvolvido um trabalho no laboratório de irrigação do Departamento de Engenharia Rural da Escola Superior de Agricultura "Luiz de Queiroz", na cidade de Piracicaba - SP, onde foram estudados os seguintes aspectos: equação Características da relação vazão-pressão, uniformidade de vazão de microaspersores, perfil e a superfície de distribuição pluviométrica dos microaspersores. 
O objeto de nosso trabalho são dois tipos de microaspersores comercializados no Brasil pela Irridelco-Fortilit, o spinner e o jet; os microaspersores spinner com três bocais, e o jet com quatro bocais foram associados a um pulsator com três reguladores de fluxo diferentes. Dessa associação resultaram 28 combinações distintas.. Além dessas combinações procurou-se determinar a equação Características dos três reguladores de fluxo.

As equações encontradas para os microaspersores sem reguladores de fluxo foram do tipo potencial semelhantes as sugeridas por KELLER \& KARMELI (1974)

Entretanto como os microaspersores com reguladores de fluxo operando na faixa 120 a $400 \mathrm{kPa}$ não se ajustaram ao modelo potencial, utilizou-se de suas curvas características observadas como forma de definir a relação vazão-pressão.

Os coeficientes de variação de vazão obtidos segundo a classificação do projeto de normas 12:02.08-022 da ASSOCIAÇÃO BRASILEIRA DE NORMAS E TÉCNICAS variaram de médio a bom.

Os reguladores de fluxo branco, verde e preto estabilizaram os valores de vazão em $13 \mathrm{l} / \mathrm{h}, 9 \mathrm{l} / \mathrm{h}$ e $41 / \mathrm{h}$ respectivamente, quando associados aos microaspersores spinner ou jet independentemente dos bocais utilizados.

Os diâmetros de alcance para os microaspersores spinner variaram de 5,00 a 6,60 m, variação esta que dependia do bocal utilizado e do regulador de 
fluxo, ao qual, o bocal estava associado. Por sua vez, o microaspersor do tipo jet com ângulo de cobertura de $360^{\circ}$ proporcionou um diâmetro de alcance médio variando de 3,76 a $6,66 \mathrm{~m}$.

Os perfis de distribuição mostraram-se variados entre microaspersores e a distribuição pluviométrica por sua vez apresentou-se concentrada próximo ao microaspersor. 


\title{
HYDRAULIC CHARACTERIZATION OF TWO MICROSPRINKLERS
}

\author{
MODELS ASSOCIATED TO A FLOW CONTROL
}

AND A PULSE MECHANISM.

Author: Maristélio da Cruz Costa

Adviser: Prof. Dr. Antonio José Frizzone

SUMMARY

In order to provide support to dimension an irrigation system by microsprinklers, a study was conducted at the "Laboratório de Hidráulica" of the Escola Superior de Agricultura "Luiz de Queiroz", USP, Piracicaba-SP.

The characteristics studied were the discharge - pressure equation; the microsprinklers discharge uniformity; profile and the microsprinklers pluviometric surface distribution.

Two types of microsprinklers are commercialized in Brazil by IrridelcoFortilit, the spinner and the jet. The first one with three nozzles and the jet with four, were associated to a pulsator with three regulators of different flow. It resulted 28 distinct combinations from this association, 
It was also determined the characteristic equation of the three flow controls.

Similar equation were found from microsprinklers without flow control and those suggested by Keller and Karmeli (1974)

However, like microsprinklers with flow control operating the 120 to 400 $\mathrm{kPa}$ band, did not adjusted to the above models, wich utilized its caracteristics curves like the way of define the relation discharge-pressure.

The discharge pressure variation coefficient obtained according to Associação Brasileira de Normas Técnica were from medium to good.

The white flow control, green and black reached the values of discharge in $12 \mathrm{lph}$, 9lph and $4 \mathrm{lph}$ respectively, when associated to the spinner or jet microsprinklers indepently of the nozzle utilized.

The spinner reached a diameter of 5,00 to $6,60 \mathrm{~m}$, depending on the nozzles and flow control; while the jet type got to 3,76 to $6,66 \mathrm{~m}$ covering $360^{\circ}$. There was a significant microsprinklers variation on the profile distribution; as the pluviometric concentration occurred near them. 


\section{INTRODUÇÃO}

A água pelo seu comportamento físico é fator imprescindível à vida. Sua importância reside no fato, da mesma, constituir-se como parte integrante dos vegetais e animais, por conseguinte dos próprios alimentos indispensáveis à vida humana.

Ciente da importância do uso da água na produção de alimentos, o homem procurou desenvolver meios e equipamentos adequados para uma agricultura eficiente e rentável. Uma das técnicas desenvolvidas com esse intuito foi a irrigação.

O uso da irrigação tem por finalidade a aplicação de água no solo, em quantidades adequadas e nos momentos oportunos, de forma econômica e eficiente.

O processo de utilização da água envolve técnicas e equipamentos com custos significativos, tornando o controle contra o desperdício, fator de primordial importância para a garantia do retorno dos investimentos, principalmente na atual crise econômica que vive o mundo.

Além dos prejuízos econômicos que podem causar diretamente ao homem, o uso irracional da água pode gerar degradação do meio ambiente (salinidade, erosões, etc...). Acrescente-se a isso, o fato de algumas regiões não disporem de recursos 
hídricos suficientes para atender a crescente demanda. Todos esses fatores contribuíram para que, no decorrer dos últimos anos, se desse preferência para sistemas de irrigação que economizassem o máximo de água, é o caso da irrigação localizada.

Irrigação localizada é o processo pelo qual se aplica água no solo, de forma a molhar apenas parte do volume ocupado pelo sistema radicular das plantas, através de pequenas vazões e curtos intervalos de irrigação, mantendo-se, desta forma, o solo sempre com alto teor de umidade.

A microaspersão é um sistema de irrigação localizada, que surgiu a partir do método de gotejamento, principalmente para atender áreas com solos muito permeáveis onde a distribuição de água pelos gotejadores causava bulbos molhados desenvolvidos pouco em largura e muito em profundidade.

A água é levada da fonte até as plantas por meios de tubos, eliminando totalmente as perdas por condução e minimizando as perdas por percolação, uma vez que se aplica água somente em parte da área e sob a copa das plantas (KELLER \& KARMELI, 1974). A aplicação de água é feita por meio de dispositivos especiais denominados microaspersores, que são pequenos aspersores conectadas às linhas laterais capazes de dissipar a pressão disponível na linha lateral e aplicar vazões pequenas e constantes.

Após a implantação do sistema de irrigação localizada, deve-se proceder a avaliação para verificar as características de distribuição de água e a eficiência da 
irrigação; procurando-se assim, corrigir falhas, por ventura existentes, melhorando estes sistemas e adquirindo subsidios para o desenvolvimento e aperfeiçoamento dos sistemas de irrigação localizada.

Considerando a importância do conhecimento das características hidráulicas dos emissores e da avaliação da distribuição de água na otimização do sistema de irrigação como um todo, o presente trabalho teve os seguintes objetivos:

a) Estudar dois modelos de microaspersores comercializados no Brasil, associados a três reguladores de fluxo e um mecanismo de pulsos, estabelecendo relações entre pressão e vazão para cada uma das combinações existentes.

b) Determinar a relação entre pressão e vazão de três reguladores de fluxo

c) Determinar o perfil e a superficie de distribuição pluviométrica apresentados pelos microaspersores estudados. 


\section{REVISÃO DE LITERATURA}

\subsection{Irrigação por microaspersão:}

De acordo com SAN JUAN (1981) a irrigação localizada começou a ser ensaiada na Alemanha (1899) e USA (1918) mediante o uso de tubos perfurados e enterrados. O sistema era muito caro, em função do tipo de tubos utilizados e apresentou problemas de obstrução, porque as raizes das plantas acabavam tampando as saídas de oxigênio existentes nos tubos.

Segundo o mesmo autor, pode-se dizer que a irrigação localizada tal como conhecemos hoje, surgiu na Inglaterra (1940), após a segunda grande guerra mundial, com a utilização de gotejadores na irrigação de casas de vegetação. E no campo, por volta de 1950 no Estado de Israel. Sendo que sua utilização comercial se desenvolveu na década de sessenta, com a expansão da indústria na área de tubos e conexões de PVC.

A irrigação por microaspersão é uma variação recente da irrigação localizada, desenvolvida inicialmente na África do Sul na década de setenta para fruteiras, sendo hoje utilizada na irrigação de diversas culturas. 
Esse sistema vem suprir alguns pontos onde o gotejamento não vinha suprindo adequadamente, é o caso de entupimentos devido a utilização de água com certo nivel de sedimentos.

Segundo PUEYA \& FORCADA (1982) as diferenças fundamentais entre a irrigação por gotejamento e a microaspersão são as seguintes:

- o gotejamento faz a irrigação puntual enquanto que microaspersão molha geralmente em faixas.

- o gotejamento utiliza vazões mais baixas (4-6 l/h, por cada emissor), enquanto a microaspersão utiliza-se de vazões mais elevadas. $(20-40 \mathrm{l} / \mathrm{h})$

- as pressões de serviço usadas em microaspersão são em geral mais elevadas do que as usadas em gotejamento.

- o sistema de irrigação por gotejamento exige uma filtragem mais rígida, pois é mais susceptivel ao entupimento do que o sistema de microaspersão.

SILVA (1989) considera a técnica da irrigação por microaspersão como sendo intermediária entre a irrigação por aspersão, propriamente dita, e a irrigação por gotejo, pelo que a microaspersão participa de grande parte das vantagens dos ditos sistemas, tais como: economia de água (menor área irrigada); eliminação do nivelamento do solo; economia de mão-de-obra; possibilidade do uso de água mais salina; boa distribuição de adubos líquidos e produtos solúveis.

Outros aspectos que contrastam a microaspersão com o gotejamento de acordo com TELLES (s/d) é que a distribuição de umidade lateralmente pouco 
depende (ou independe) das caracteristicas do solo quando se usa irrigação por microaspersão, o que possibilita um melhor ajuste da área úmida à área do sistema radicular.

MARTÍ (1993) afirma que as maiores vazões por unidade de superficie irrigada por microaspersão permitem reduzir o tempo de irrigação, quando comparadas por gotejo. Isto Deve-se ao fato da área de abrangência da irrigação ser maior na microaspersão, podendo-se reduzir o número de emissores por unidade, diminuindo-se, desta forma, também, as necessidades de filtragem por operar com orificios de maior diâmetros.

Esse autor enfatiza, ainda, que a microaspersão é mais indicada para irrigação localizada de solos de baixa capacidade de infiltração, já que a quantidade aplicada de água por superficie é sensivelmente menor do que a aplicada por gotejo.

RODRIGUEZ \& LOZANO (1991) trabalhando em uma região árida do México, compararam três métodos de irrigação (microaspersão, gotejo e inundação) por um período de 6 anos e usando três niveis de irrigação para cada método, chegaram as seguintes conclusões: quando se limitava o uso de água o peso dos frutos e o crescimento das árvores eram muito mais afetados pelo sistema de irrigação por inundação do que pelos sistemas pressurizados e que os métodos de microaspersão e gotejo, tendo maiores eficiências de aplicação de água, seriam os sistemas mais indicados para áreas onde o nível de água disponível é baixo. 
RENQUIST (1987), trabalhando com irrigação de pêssego [Prumus persica,( l.) batsch, cv. Glohaven] comparou a irrigação por microaspersão, com dois níveis de aplicação de água (1,0 e 1,5 vezes a evapotranspiração da cultura, irrigada semanalmente) com a irrigação por sulcos $(1,0$ vez a Etc, com intervalos de 4 semanas), observou-se que as médias dos diâmetros dos troncos irrigados por sulco foram $42 \%$ e $64 \%$ menores que as irrigadas por microaspersão depois da primeira e segunda estações respectivamente.

ZEKRI \& PARSONS (1989) comparando os métodos de irrigação por aspersão, microaspersão e gotejamento na cultura do grapefruit (Citmıs paradisi Macf.) concluíram que com relação aos aspectos estudados: desenvolvimento da parte aérea, número de folhas e frutos, tiveram melhores desempenhos os sistemas de aspersão, microaspersão e gotejamento, respectivamente. Os autores atribuem o baixo desempenho do sistema de gotejamento, devido ao fato de boa parte, do sistema radicular ter ficado fora da área molhada pelo gotejo.

PLANAS E SOLANELLES (1993), trabalhando com irrigação por microaspersão no combate a geadas em fruteiras, concluíram que o sistema de microaspersão, apresenta importantes vantagens sobre a aspersão convencional, tais como: economia de água energia, versatilidade das instalações, maiores garantias sanitárias e operacionais para as plantações, bem como economia na execução das instalações. 
PIZARRO (1990), comenta que em solos muito permeáveis, em que os bulbos úmidos se desenvolvem muito em profundidade e pouco em largura, deve-se dar preferência ao sistema de microaspersão em relação ao de gotejo, sob pena de fazermos uma irrigação ineficiente em termos de bulbo úmido minimo necessário para as culturas.

A irrigação por microaspersão tem se desenvolvido bastante nos últimos anos, estendendo sua aplicação à irrigação de pomares, hortaliças, viveiros e estufas. 


\subsection{Hidráulica dos microaspersores}

\subsubsection{Características dos emissores}

Os microaspersores se constituem, nos elementos de maior importância dos sistemas de irrigação por microaspersão. São dispositivos que possibilitam a distribuição de um fluxo de água, recebidos pelas tubulações as quais estão conectados, sofre uma dissipação de energia tal que resulte na sua saída pelos bocais sob a forma de jatos de água. No caso dos microaspersores rotativos (Spinner), a resistência do ar faz com que o jato seja fracionado em gotas que precipitam sobre o terreno, como uma chuva. Nos microaspersores fixos (jet), o fracionamento em gotas ocorre pelo impacto d'água contra uma placa defletora colocada na parte superior do emissor.

Para PIZARRO (1990) as maiores dificuldades nos projetos construtivos dos emissores reside no problema de que eles devem proporcionar uma vazão baixa, com o objetivo de que os diâmetros das tubulações, especialmente as laterais e derivações sejam reduzidas. Por outro lado, a pressão de serviço dos emissores não deve ser alta, para reduzir o consumo de energia; também não deve ser muito baixa, para minimizar o efeito dos desníveis dos terrenos e da perda de carga sobre a uniformidade de irrigação. Estas condições conduzem a emissores com reduzido 
diâmetro da seção de passagem da água. Em contra partida, há uma condição oposta a ser cumprida: o diâmetro da seção de passagem de água do emissor deve ser o maior possível, com o objetivo de evitar obstruções, que se apresentam como o principal problema no manejo dos sistemas de irrigação localizada. Esta condição é resolvida de forma muito variada e, em conseqüência, existem no mercado muitos tipos de emissores.

Os emissores devem atender, de uma forma geral, três requisitos básicos: vazão pequena, uniforme e constante; orificio de saída relativamente grande, para reduzir a possibilidade de entupimento; compacto e de baixo custo. (VERMEIREN \& JOBLING, 1984).

\subsubsection{Características hidráulicas dos emissores.}

A vazão de um emissor relaciona-se diretamente com a carga hidráulica atuante na entrada do emissor e pode ser representada segundo KELLER \& KARMELI (1975), pela seguinte equação:

$q=k d \cdot H^{x}$

onde:

$q$ - Vazão do emissor $(1 / h)$;

$\mathrm{kd}$ - constante de proporcionalidade que caracteriza cada emissor;

$\mathrm{H}$ - pressão de serviço do emissor $(\mathrm{kPa})$. 
$\mathrm{x}$ - é o expoente de descarga do emissor que caracteriza o regime de fluxo.

Para determinar $k d$ e $\mathrm{x}$, faz-se necessário que se conheça pelo menos dois valores de vazão operando a duas diferentes pressões. $O$ expoente $x$ pode ser determinado pela medida de inclinação da reta em papel log-log, plotando-se vazão $\mathrm{x}$ pressão, ou analiticamente por:

$x=\log \left(\mathrm{q}_{1} / \mathrm{q}_{2}\right) / \log \left(\mathrm{H}_{1} / \mathrm{H}_{2}\right)$

O valor de $\mathrm{x}$ pode ser usado na equação (1) para determinar o valor de $\mathrm{kd}$.

De acordo com a equação (1) podemos verificar que a redução na vazão é menos influenciado pela variação de pressão, à medida que o valor de $\mathrm{x}$ decresce. $\mathrm{O}$ valor de $\mathrm{x}$ caracteriza o regime de escoamento do emissor. No escoamento totalmente turbulento $(\operatorname{Re}>10.000), x=0,5$; no regime parcialmente turbulento $(4.000<\operatorname{Re} \leq$ $10.000) ; 0,5<x \leq 0,7$; para fluxo instável $(2.000<\operatorname{Re}<4.0000), 0,7<x 1,0 ;$ e no regime laminar $(\operatorname{Re}<2000), x=1,0$. Alguns emissores possuem mecanismos reguladores de pressão e $\mathrm{x}$ pode ser menor do que 0,5 . Com regulação absoluta de vazão, $x=0$.

Os emissores com dispositivos autoreguláveis, que apresentam vazões relativamente constantes frente às variações de pressão, possuem teoricamente, um comportamento ideal, aproximando-se dos requisitos básicos desejados para um emissor de acordo com KELLER \& KARMELI (1975). Tal fato pode resultar em maiores comprimentos para os ramais e menores diâmetros para as tubulações, trazendo como conseqüência sistemas economicamente mais baratos. Entretanto 
fatores relacionados principalmente com o processo de fabricaçăo destes emissores, podem acarretar mudanças no seu funcionamento hidráulico.

De acordo com BRALTS et al. $(1981)^{1}$, citado por NUEVO (1992), o termo kd envolve fatores ligados a construção do emissor, tais como coeficientes de descarga e área da seção transversal. Qualquer variação na vazão do emissor advinda do processo de fabricação será considerada no termo $\mathrm{kd}$. Os termos $\mathrm{H} \mathrm{e} \mathrm{x}$, por outro lado, são variáveis hidraulicamente dependentes. Assim qualquer variação na vazão dos emissores ocasionadas pela variação hidráulica será considerada no termo $\mathrm{H}^{x}$.

Ainda segundo o mesmo autor, quando se considera o entupimento dos emissores (total ou parcial) a equação (1) se apresenta da seguinte forma:

$q=(1-\alpha) \cdot k d \cdot H^{X}$

onde $\alpha$ é o grau de entupimento do emissor.

BOTREL (1984) estudou as características de dois microaspersores fabricados no Brasil: Dantas MA120 e Irtec rotativo. Os microaspersores foram submetidos a testes sob pressões constantes e variáveis visando a determinação da equação vazão-pressão, coeficiente de variação de vazão decorrente do processo de fabricação, perfil de distribuição da precipitação, alcance do jato e perda localizada na inserção do microaspersor na linha lateral.

${ }^{1}$ BRALTS, V.F.;EDWARDS, D.M. Drip irrigation design and evaluation based on statisticaluniformity concept. In: Hillel, D. Advences in irrigation, Orlando, Academic Press, 1987, v.4, p. $67-117$ 
As equações vazão-pressão obtidas para o microaspersor Dantas MA120 e o Irtec rotativo foram respectivamente: $\mathrm{q}=18,54 \mathrm{H}^{0.54}$ e $\mathrm{q}=12,78 \mathrm{H}^{0,55}$; onde $\mathrm{q}=$ Vazão do emissor ( $(/ / h) ; H=$ pressão de serviço do emissor (m.c.a.).

Os coeficientes de variação de vazão dos microaspersores foram $2,7 \%$ para o Dantas MA120 e 12,18\% para o Irtec rotativo. Tais valores, de acordo com os parâmetros SOIL CONSERVATION SERVICE - USDA, classificam o microaspersor Dantas MA120 como excelente uniformidade e o Irtec rotativo como uniformidade pobre.

Estudo semelhante ao anterior foi realizado por PAES (1985), utilizando-se dos mesmos modelos de microaspersores testados por BOTREL (1984). Sob pressão constante, procurou-se analisar a variação entre os microaspersores decorrentes do processo de fabricação, e sob pressão variável, determinou-se as equações caracteristicas de vazão-pressão dos microaspersores, o perfil de distribuição de água, o alcance do jato e a uniformidade de aplicação de água pelos microaspersores.

Esse autor chegou as seguintes conclusões:

- existência de pequenas variações dos microaspersores, cujos coeficientes de variação foram de $6,42 \%$ e 9,14\% para o Dantas MA120 e Irtec respectivamente.

- as equações características de vazão-pressão dos microaspersores foram:

$\mathrm{q}=22,21 \mathrm{H}^{0.55}$ para Dantas MA120 e $\mathrm{q}=17,32 \mathrm{H}^{0.50}$ para Irtec.

- Esses dois tipos de microaspersores apresentam uma grande variedade no perfil de distribuição e no diâmetro molhado, quando submetidos a mesma pressão. 


\subsubsection{Coeficiente de variação de fabricação dos emissores.}

Os microaspersores são dispositivos que aplicam pequenas vazões e por conseguinte tem orificios com diâmetros bastante reduzidos. Por mais esmerilhados que sejam os processos de fabricação sempre ocorrem variações mínimas e como a área de escoamento dos emissores é da ordem de milímetros quadrados, qualquer pequena variação poderá afetar, de forma bastante representativa, as vazões dos emissores a uma mesma pressão.

Acrescente-se a isso, como assinala SOLOMON (1979), o fato de alguns emissores utilizarem membrana elástica para atingir uma compensação de pressão ou capacidade de expulsar a água em forma de jato. Tais materiais são essencialmente dificeis de serem obtidos com características e dimensões consistentes. É o caso da membrana usada no corpo do PULSATOR com a finalidade de provocar os pulsos (jatos)

SOLOMON (1979) enfatiza, também, que existe um grande número de variáveis a serem controladas no processo de fabricação nas máquinas de moldes, dentre as quais: pressão e temperatura de injeção, velocidade de injeção, temperatura dos moldes, tempo do ciclo e operação dos moldes. Todas essas características afetam o produto final quanto ao tamanho, forma, peso, resistência e superficie do emissor. 
KELLER \& KARMELI (1974)², citados por BOMAN (1989), introduziram o coeficiente de variação de fabricação (CV) como uma medida estatística da variação de fabricação dos emissores para irrigação. O CV descreve a variação no item que é fabricado como supostamente "idêntico", o CV é um valor admensional calculado pela divisão do desvio padrão de uma taxa de fluxo (vazão) de uma amostra adequada de emissores pela média da taxa de fluxo de uma amostra testada.

O desvio padrão se define como a raiz quadrada da média aritmética dos quadrados dos desvios em relação a média.

$\delta=\sqrt{\frac{\sum_{i=1}^{n}\left(\mathrm{q}_{\mathrm{e}}-\overline{\mathrm{q}}\right)^{2}}{n}}$

onde:

$\delta$ - desvio padrão

$\mathrm{q}_{e}$ - vazão do emissor

$\bar{q}$ - vazão média dos emissores testados a uma mesma pressão de operação $\left(\frac{\sum q_{e}}{n}\right)$

$\mathrm{n}$ - número de emissores

No entanto, para PIZARRO (1990), O desvio padrão tem o inconveniente de ser uma medida de dispersão absoluta, sendo que a dispersão relativa se adequaria

\footnotetext{
${ }^{2}$ KELLER \& KARMELI, Trickle irrigation design parameters. Transactions of ASAE 17(4); 678-4, 1974.
} 
melhor ao coeficiente de variação (CV), que se define como o quociente entre o desvio padrão e o valor médio da vazão.

$\mathrm{CV}=\delta / \overline{\mathrm{q}}$

O coeficiente de variação é um termo estatístico. Na tecnologia de irrigação localizada, o termo utilizado é Coeficiente de Variação de Fabricação (CVF).

Para HERNÁNDEZ ABRÉU et al., o significado estatístico do coeficiente de variação de fabricação é o seguinte: i) praticamente todos as vazões observadas no ensaio estão compreendidas em torno de $(1 \pm 3 \mathrm{CVF}) . \overline{\mathrm{q}}$; ii) aproximadamente $95 \%$ das observações se encontram compreendidas em torno de ( $1 \pm 2$ CVF). $\bar{q}$; iii) se tomarmos $25 \%$ das observações de valor mais baixo, sua média será, aproximadamente, igual a $(1-1,2+\mathrm{CVF}) \cdot \overline{\mathrm{q}}$; iv) $68 \%$ das observações realizadas estavam no intervalo de $(1 \pm \mathrm{CVF}) \cdot \overline{\mathrm{q}}$.

SOLOMON (1979) faz diversas considerações sobre as taxas de fluxo dos emissores em uma dada pressão apresentarem uma distribuição normal: i) as distribuições observadas assemelham-se à distribuição normal; ii) as variações envolvidas no processo de fabricação tendem a ser normalmente distribuidas; iii) embora não obrigatória, a suposição da normalidade é computacionalmente conveniente, à distribuição normal é completamente caracterizada pela média e desvio padrão, suas propriedades analíticas são bem conhecidas, e os valores tabulados são facilmente obtidos; iv) devido a incertezas e imprecisões inerentes a 
outros aspectos do problema, não é garantido o ajuste a outras distribuições estatísticas, mesmo que reconhecida sua superioridade em relação a distribuição normal.

Tabela 1 - Classificação dos emissores segundo o coeficiente de variação de fabricação $(*)$.

\begin{tabular}{|c|c|c|c|c|c|}
\hline $100 \%$ & BUA Y YMA & IRRIGATION & NORMAS & UNITED STIFTES & 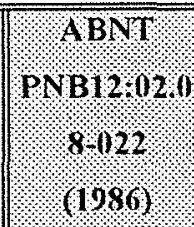 \\
\hline$<0,05$ & bom & bom & categoria $\mathrm{A}$ & $\begin{array}{l}\text { excelente } \\
(<0,05)\end{array}$ & $\begin{array}{c}\text { bom } \\
(<0,10)\end{array}$ \\
\hline $0,05-0,1$ & médio & médio & categoria $B$ & $\begin{array}{c}\text { média } \\
(0,05-0,07)\end{array}$ & $\begin{array}{c}\text { média } \\
(0,1-0,2)\end{array}$ \\
\hline $0,1-0,15$ & marginal & marginal & $\begin{array}{c}\text { nào } \\
\text { qualificável }\end{array}$ & $\begin{array}{c}\text { marginal } \\
(0,08-0,11)\end{array}$ & $\begin{array}{l}\text { marginal } \\
(0,2-0,3)\end{array}$ \\
\hline$>0,15$ & inaceitável & ruim & $\begin{array}{c}\text { não } \\
\text { qualificável }\end{array}$ & $\begin{array}{c}\text { ruim } \\
(0,12-0,15)\end{array}$ & $\begin{array}{c}\text { inaceitável } \\
(>0,30)\end{array}$ \\
\hline OUTROS & & & & $\begin{array}{c}\text { inaceitável } \\
(>0,15)\end{array}$ & \\
\hline
\end{tabular}

* Adaptado de Aguilá 1993. 


\subsubsection{Uniformidade de distribuição dos microaspersores}

Para AGUILÁ (1993) ${ }^{3}$, o emprego correto de difusores (microaspersores) numa instalação de irrigação por microaspersão supõe o conhecimento prévio das características e desempenho dos mesmos.

Pela própria definição de difusor se deduz a importância do conhecimento da área molhada, raio de alcance efetivo, e uniformidade de distribuição de precipitação dos emissores antes mesmo da elaboração dos projetos agronômico (pois afeta as necessidades totais de água) e hidráulico (pois é em função dele que se definem os limites da variação na vazão dos emissores) de toda a instalação do sistema.

O ensaio de distribuição pluviométrica é o que caracteriza e determina o funcionamento do microaspersor sobre uma superficie irrigada. As curvas isoietas delimitam a área molhada pelo microaspersor e as curvas pluviométricas nos indicam a precipitação horária que recebe o terreno.

A mais popular medida da uniformidade de irrigação é o coeficiente de uniformidade de Christiansen, proposto pelo autor em 1942, e amplamente utilizada em irrigação por aspersão. No entanto de acordo com PIZARRO (1990), em irrigação localizada se utilizam critérios mais exigentes e se define um novo coeficiente de uniformidade (CU), segundo a seguinte expressão:

\footnotetext{
${ }^{3}$ AGUILÁ, F.J.G.; MARTI, S.P.; BENEDICTO, C.R. (Estación de Mecánica Agricola, Lleida)Determinación de la distribuición pluviometrica en difusores de microirrigación; apostila de aula 1993
} 


$$
C U=\frac{q}{\bar{q}}
$$

onde $\bar{q}$ - vazão média dos emissores; e $q_{25}$ - vazão mínima coletada - é considerada como a média do menor quartil ( $1 / 4$ dos menores valores obtidos).

O coeficiente de uniformidade pode ser utilizado na avaliação de instalações em funcionamento ou para o projeto de novas instalações.

SAVALDI, (1991), faz a seguinte classificação, dos fatores que influenciam na uniformidade de distribuição de água em microaspersão:

\section{Posição vertical do microaspersor}

Para se obter uma distribuiçăo ótima em microaspersão, deve-se levar em conta que o microaspersor deve ser colocado sobre um suporte vertical a uma altura de $20 \mathrm{~cm}$ do solo e a uma distância de $60 \mathrm{~cm}$ do tronco das árvores com o dorso da ponte dirigido no sentido do tronco.

\section{O ângulo de irrigação}

Quanto maior for o ângulo de aplicação de água, menor será a uniformidade de distribuição, por isso recomenda-se a aplicação o mais horizontal possivel. 


\section{O tronco e a folhagem da árvore}

O tronco constitui em um obstáculo permanente. Em plantas jovens, o microaspersor pode ser colocado perto do tronco, mas depois de algum tempo mudase para uma distância de $60 \mathrm{~cm}$. Quanto à folhagem, deve-se cortar todos os ramos que estejam no caminho do jato.

\section{O elemento distribuidor (defletor)}

Em geral, a uniformidade de distribuição do microaspersor com elemento giratório dinâmico tem uma forma trapezoidal, sendo melhor que a do difusor com elemento de distribuição estático, o qual tem uma forma triangular.

\section{Pressão de serviço}

Uma pressão maior que a pressão nominal de trabalho, pulveriza o jato, causando acúmulo de água próximo ao emissor e déficit no perimetro molhado. Por outro lado, quando a pressão de trabalho é menor que a nominal, as gotas d'água são maiores, alcançando maiores distâncias, causando maior acumulação de água no perímetro e déficit de água perto do microaspersor.

\section{Reguladores e amortecedores}

Os reguladores têm a função de manter as pressões e vazões constantes e controlar assim o tamanho das gotas de água na saída do emissor, como também o diâmetro de umidade. 
O amortecedor mantém uma velocidade adequada no bocal e evita o efeito de nebulização. Em ambos os casos, obtém-se uma melhora na uniformidade de distribuição de água

\section{Vazão nominal}

Em geral, microaspersores com vazões menores têm deficiência na distribuição de água. Microaspersores com vazão entre 70 e $90 \mathrm{l} / \mathrm{h}$ tem melhor uniformidade do que de 35 a $90 \mathrm{l} / \mathrm{h}$.

LIMA \& ALVES $(1994)^{4}$ avaliando as características de distribuição de água dos principais microaspersores e microdifusores fabricados no Brasil, Estados Unidos e Israel, concluíram que os resultados da uniformidade de Christiansen dos microdifusores foram inferiores a $25 \%$, enquanto que nos microaspersores os valores variaram de 27 a $62 \%$. Esses coeficientes, calculados a partir de lâminas coletadas abaixo da superficie do solo, elevaram-se para 40 a 50\% (microdifusores) e 52 a $57 \%$ (microaspersores), devido, provavelmente, a redistribuirão de água no solo. Observaram também que o volume de água aplicado por microaspersores, uma fração de até $9 \%$ escorre junto a haste, tendo sido interceptado pelo corpo do microaspersor.

NOGUEIRA (1989), estudando as características hidráulicas de cinco modelos de um microaspersor de fabricação brasileira (DANTAS MA-70, DANTAS

\footnotetext{
${ }^{4}$ LIMA, L.A. \& ALVES, D.R.B. Avaliação da uniformidade de distribuição de água demicroaspersores e microdifusores. $17 p, 1994$.
} 
MA-120, DUTOFLEX, ASBRASIL com asa giratória e ASBRASIL com difusor), visando a determinação da equação característica vazão-pressão, coeficiente de variação de vazão e perfil de distribuição de água, chegou aos seguinte resultados:

- os diâmetros médios de cobertura variavam de 3,0 a 4,1m para os microaspersores DANTAS MA-70 e DANTAS MA-120; 2,0 a 2,6 para o microaspersor ASBRASIL com asa giratória e 3,7 a 3,9 para o microaspersor ASBRASIL com difusor.

- Os coeficientes de uniformidade de distribuição obtidos apresentaram-se extremamente baixos, o que inviabiliza, segundo esse autor, a recomendação de utilização desses microaspersores com sobreposição, para uma aplicação uniforme de água. Tal ocorrência confirma a utilização desses microaspersores apenas como fontes pontuais de aplicação de água. 


\section{MATERIAL E MÉTODOS}

Este trabalho foi desenvolvido no laboratório de irrigação do Departamento de Engenharia Rural da Escola Superior de Agricultura "Luiz de Queiroz ", da Universidade de São Paulo, na cidade de Piracicaba-SP.

Os modelos de microaspersores estudados foram o Spinner e o Jet da linha irridelco (Figura 1). O modelo Jet é do tipo fixo, com ângulo de cobertura de $360^{\circ} \mathrm{e}$ com bocais nas cores laranja, azul, violeta e vermelho, enquanto o modelo spinner é do tipo rotativo, com ângulo de cobertura de $360^{\circ}$ e com bocais nas cores azul, violeta e vermelho. Os' dados de vazão e diâmetros de alcance nominais dos bocais encontram-se na Tabela 2.

Tabela 2 - Vazão e diâmetros de alcance nominais dos bocais operando à $\quad$ 147,13 $\mathrm{kPa}(15$ m.c.a.)

\begin{tabular}{|c|c|c|}
\hline $\begin{array}{c}\text { BOCAIS } \\
\text { JET/SPINNER }\end{array}$ & $\begin{array}{c}\text { VAZÃO (I/h) } \\
\text { (A 15 } \mathbf{~ m a ) ~}\end{array}$ & $\begin{array}{c}\text { DIÂMETROS DE } \\
\text { ALCANCE } \mathbf{( m )}\end{array}$ \\
\hline \hline LARANJA & 37 & 5,0 \\
\hline AZUL & 48 & 6,0 \\
\hline VERMELHO & 61 & 6,2 \\
\hline VIOLETA & 109 & 7,6 \\
\hline
\end{tabular}


De acordo com os dados do fabricante, os bocais exigem uma filtragem com tela de no máximo 150 mesh.

Os microaspersores são feitos de plástico rígido podendo ser utilizados acoplados diretamente a uma haste de $30 \mathrm{~cm}$ que o sustenta a $20 \mathrm{~cm}$ do solo ou acoplados a um pulsator conectado na própria haste.

O pulsator é uma peça montada junto com o microaspersor Irridelco Jet ou Spinner, permitindo a operação desses a baixas vazões ( 4 a 12 l/h). Junto com o Pulsator é embutido um diafragma e um regulador de fluxo que asseguram vazão constante independente das variações de pressão do sistema. O pulsator funciona da seguinte maneira: um volume de água é acumulado numa câmara coletora de silicone (diafragma). Ao atingir o limite de elasticidade da câmara, a água é então descarregada, o processo se repete estabelecendo pequenos jatos sob a forma de pulsos (Figura 2)

Os reguladores de fluxo eram classificados nas cores preto, verde e branco. Para uma variação mínima de pressão de $137,32 \mathrm{kPa}$ (14 m.c.a.) até uma máxima de $343,31 \mathrm{kPa}$ (35 m.c.a.), os valores de vazão nominal para os pulsators com regulador de fluxo preto, verde e branco eram respectivamente: $4 \mathrm{l} / \mathrm{h} ; 8 \mathrm{l} / \mathrm{h}$ e $12 \mathrm{l} / \mathrm{h}$.

A caracterização hidráulica dos microaspersores foi feita utilizando-se 20 unidades de cada modelo. Tendo em vista a possibilidade de se trabalhar com os quatro bocais do tipo jet ou três bocais do tipo spinner combinados com os três 
reguladores de fluxo disponíveis, procurou-se analisar todas essas combinações diferentes, as quais estão apresentadas na Tabela 3: 


\section{SPINNER}

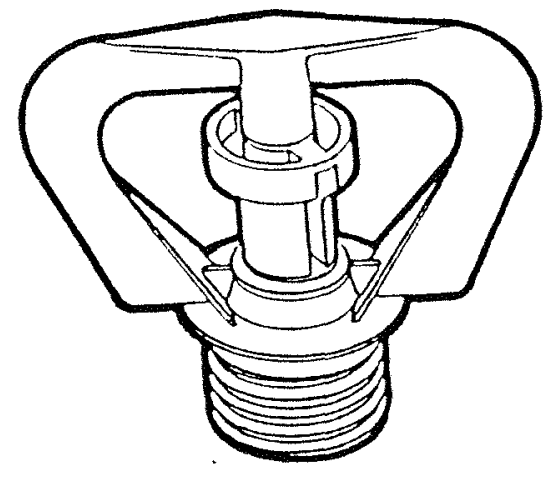

\section{JET}

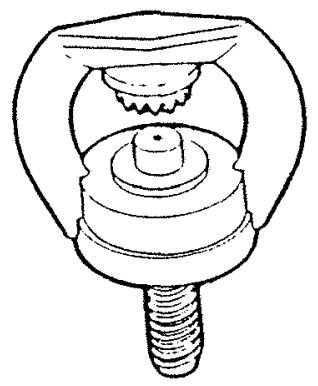

Figura 1- Microaspersores spinner e jet.

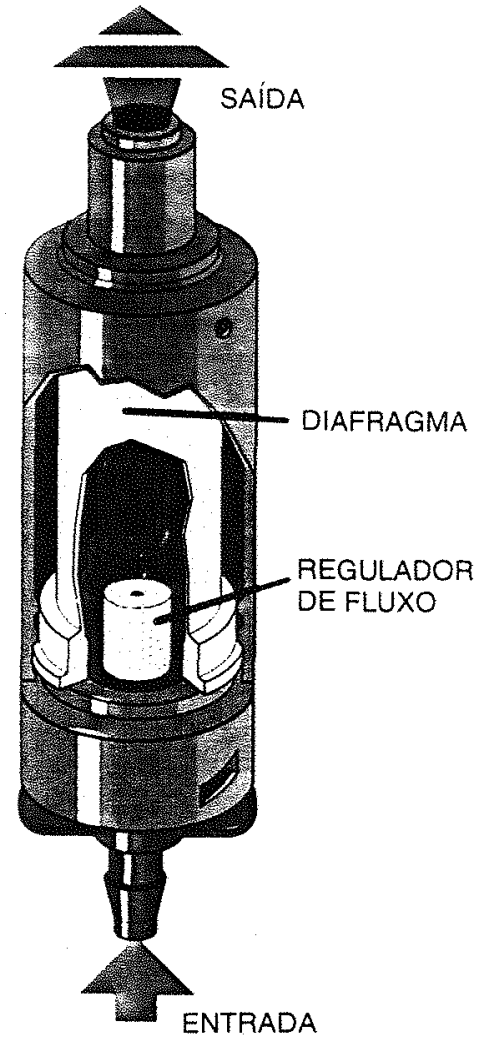

PULSATOR

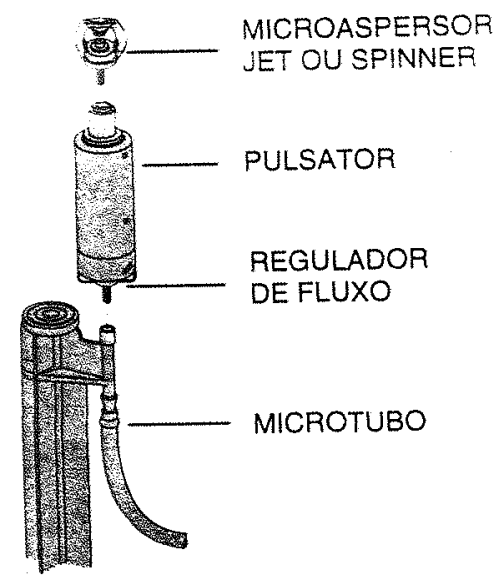

Figura 2 - Detalhes do pulsator e de sua montagem com os bocais. 
Tabela 3 - Combinações entre bocais e reguladores de fluxo

\begin{tabular}{|c|c|c|}
\hline MODELO & REG. DE FI UXO & BOCAI. \\
\hline SPINNER & $\ldots$ & vermelho \\
\hline SPINNER & - n & violeta \\
\hline SPINNER & -1 & azul \\
\hline SPINNER & preto & vermelho \\
\hline SPINNER & preto & violeta \\
\hline SPINNER & preto & azul \\
\hline SPINNER & verde & vermelho \\
\hline SPINNER & verde & violeta \\
\hline SPINNER & verde & azul \\
\hline SPINNER & branco & vermelho \\
\hline SPINNER & branco & violeta \\
\hline SPINNER & branco & azul \\
\hline JET & preto & vermelho \\
\hline JET & preto & violeta \\
\hline JET & preto & azul \\
\hline JET & preto & laranja \\
\hline JET & verde & vermelho \\
\hline JET & verde & violeta \\
\hline JET & verde & azul \\
\hline JET & verde & laranja \\
\hline JET & branco & vermelho \\
\hline JET & branco & violeta \\
\hline JET & branco & azul \\
\hline JET & branco & laranja \\
\hline JET & -............ & vermelho \\
\hline JET & --.---.--- & violeta \\
\hline JET & $-\ldots$ & azul \\
\hline JET & -.......... & laranja \\
\hline - - - - - - & preto & 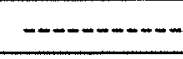 \\
\hline …-.---- & verde & -........- \\
\hline -...-.--.-- & branco & -........... \\
\hline
\end{tabular}




\subsection{DETERMINAÇÃO DA EQUAÇÃO CARACTERÍSTICA VAZÃo- PRESSÃO}

Este teste foi realizado no laboratório de irrigação da Escola Superior de Agricultura "Luiz de Queiroz" da Universidade de São Paulo, na cidade de Piracicaba -SP.

Foram utilizadas 20 unidades de cada modelo, obtidos aleatoriamente na linha de produção, testando-se cada uma das 31 combinações descrita na Tabela 3.

Esses ensaios tiveram como objetivos determinar uma equação que relacione a vazão com a pressão na entrada do microaspersor.

O abastecimento de água foi obtido proveniente de um reservatório na parte inferior do próprio laboratório sendo bombeada por uma eletrobomba KSB tipo ETABLOC 32-125.1, ф rotor $144 \mathrm{~mm}$ e motor elétrico WEG mod. 90L $128760 \mathrm{hz}, 4$ cr.

A água era recalcada da bomba através de uma tubulação de 2" (50 mm) até um filtro de tela de 200 mesh na entrada da bancada. A partir do filtro a tubulação era reduzida para $26 \mathrm{~mm}(3 / 4$ ") e antes de chegar nos microaspersores era precedida por um registro de esfera; outro filtro de 155 mesh e uma válvula reguladora de pressão NIAGARA tipo 152 série 604 com diafragma. (Figura 3). 


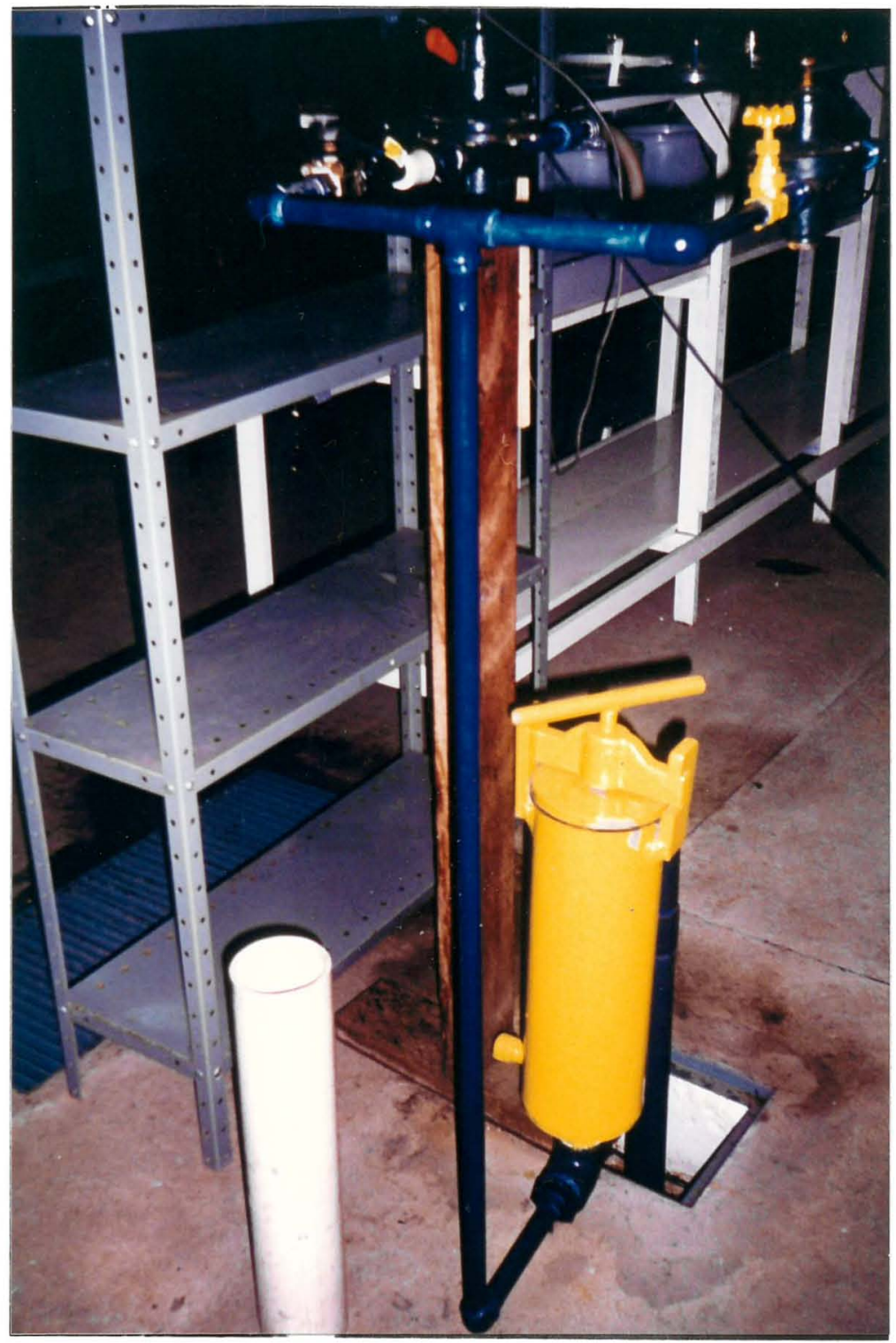

Figura 3 -Vista da filtragem e alimentação da bancada de testes. 
A pressão na entrada dos microaspersores foi monitorada através de um INDICADOR MICROPROCESSADO PARA TRANSDUTORES DE PRESSÃO (INTERFACE); previamente calibrado. O qual recebia os dados de pressão através de um tubo de $6,35 \mathrm{~mm}\left(1 / 4^{\prime \prime}\right)$ conectado na linha dos emissores por intermédio de uma célula modelo PT5 No 726 com capacidade de 5 bar.

Para determinação da vazão, os microaspersores foram conectados à linha de alimentação, num total de 10 (dez) emissores, espaçados de $25 \mathrm{~cm}$, colocados para funcionar simultaneamente. Foi colocado sob cada emissor, uma cuba de acrílico que interceptava o jato d'água, a qual era coletada através de baldes com capacidade para 15 litros para posterior pesagem, a fim de encontrar o volume a intervalos de tempos predeterminados. (Figuras 4 e 5 )

Para a coleta da água os microaspersores ficaram ligados, colocando-se os baldes sob as cubas interceptoras ao mesmo tempo que se acionava o cronômetro. Para a colocação simultânea dos baldes, foi adaptado um suporte de madeira com 2 m de comprimento, com o qual se empurrava os baldes para debaixo das cubas.

O tempo de coleta foi de 6 minutos, cronometrados com precisão de centésimos de segundos, findo o qual os baldes eram pesados para se obter os valores de vazões. Os resultados das vazões apresentados referem-se às médias de três determinações.

As vazões foram determinadas trabalhando-se com as seguintes pressões de serviço: 29,$92 ; 49,34 ; 78,47 ; 98,38 ; 147,43 ; 196,57 ; 245,12$; e $294,66 \mathrm{kPa}$; para os 
bocais sem reguladores de fluxo e 120,$35 ; 140,85 ; 151,06 ; 202,16 ; 253,26 ; 304,37$; 355,57 e 406,67 $\mathrm{kPa}$, para os bocais com reguladores de fluxo.

A curva característica vazão-pressão foi obtida através de análise de regressão a partir dos dados obtidos nos testes, sendo os valores de vazão, a média das 20 unidades ensaiadas.

Durante estes ensaios foi feito o acompanhamento da temperatura da água, tendo-se o cuidado que essa não ultrapassasse a faixa de temperatura recomendada para ensaios, ou seja entre $20^{ \pm} 5^{\circ} \mathrm{c}$. 


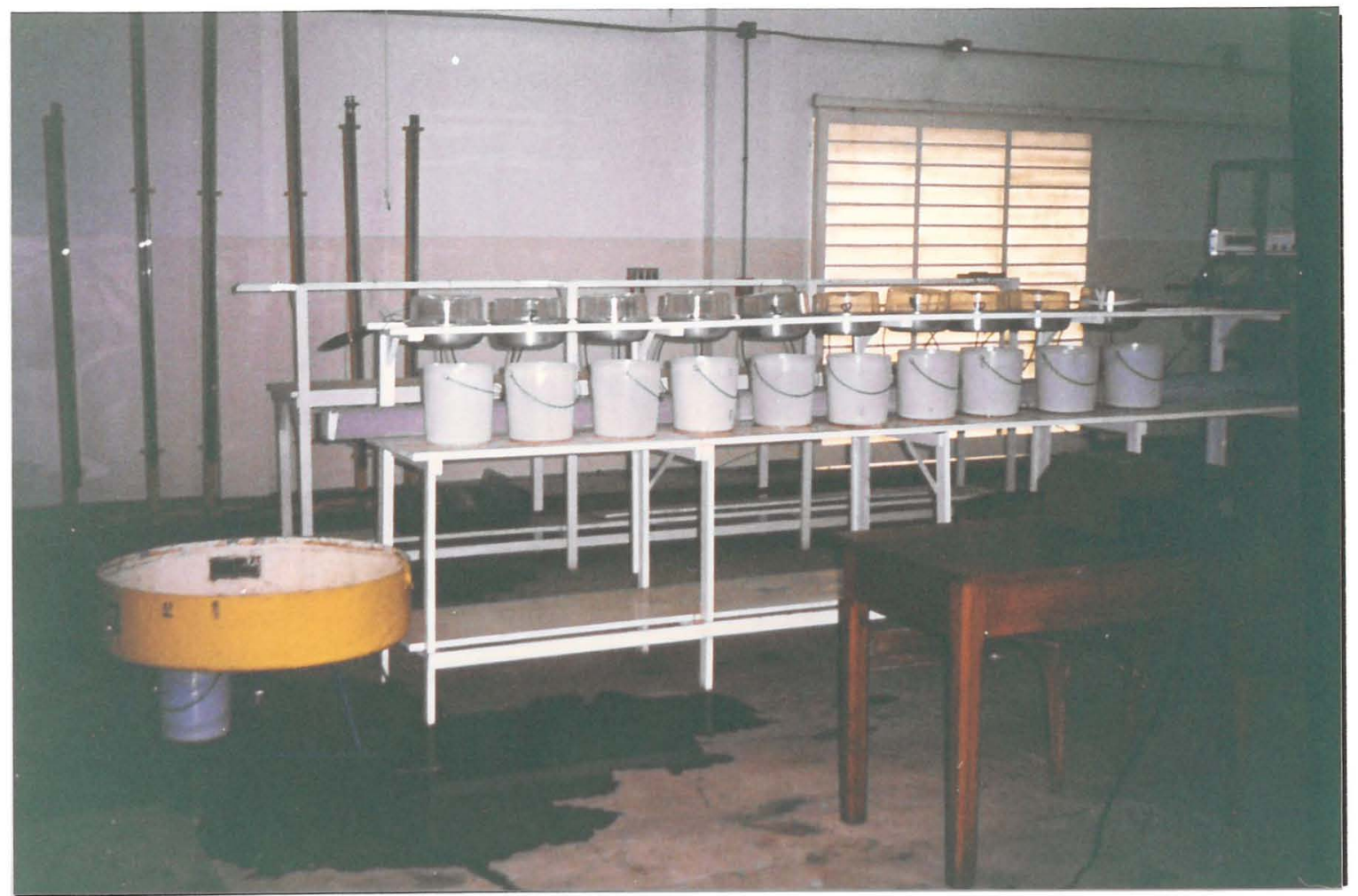

Figura 4 - Vista da coleta de água dos microaspersores.

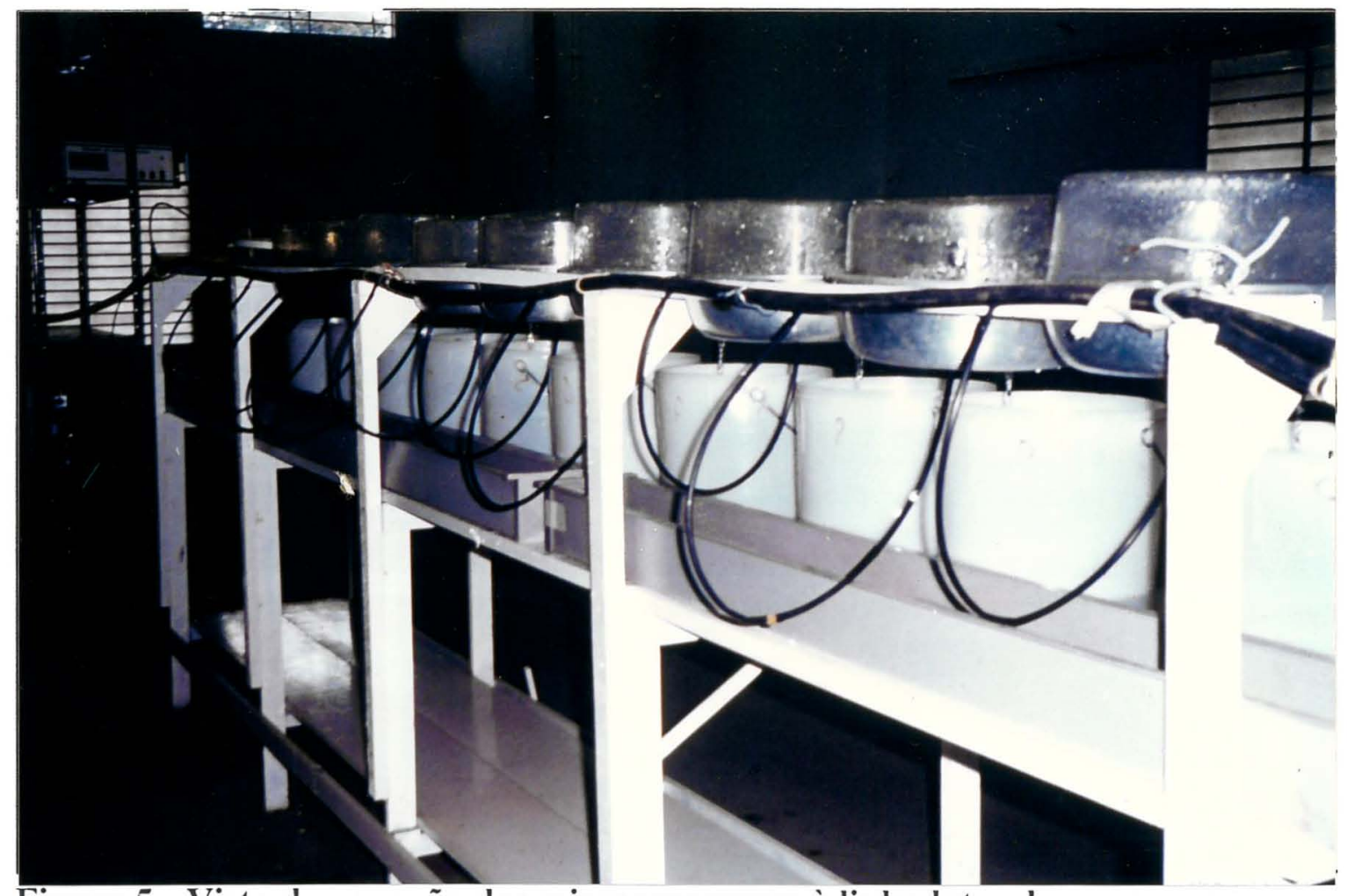

Figura 5 - Vista da conexão dos microaspersores à linha lateral. 


\subsection{DETERMINAÇ̃̃O DA UNIFORMIDADE DE VAZÃO.}

O presente teste teve como objetivo avaliar as diferenças que ocorrem na vazão entre os microaspersores em virtude de diferenças inerentes ao processo de fabricação.

Neste teste foram utilizados os dados de vazão obtidos na determinação da equação característica vazão-pressão (item 3.1). A partir dos dados de vazão, calculou-se o desvio padrão (equação 4 ) e a vazão média. Calculando-se então o coeficiente de variação de fabricação, dividindo-se o desvio padrão pela média da vazão (equação 5).

A uniformidade de vazão, representada pelo coeficiente de variação de vazão, foi a média dos coeficientes de variação de vazão obtidos a cada pressão ensaiada.

\subsection{DETERMINAÇÃO DO PERFIL DE DISTRIBUIÇÃO DA ÁGUA.}

Este teste foi determinado no laboratório de irrigação do Departamento de Engenharia Rural, sob ausência de ventos.

O objetivo foi a determinação do perfil de distribuição da água e o raio de alcance dos diversos modelos de bocais de microaspersores estudados, quando submetidos à pressão de $147,13 \mathrm{kPa}(15,03$ m.c.a. $)$. 
Utilizou-se, neste teste, três unidades de cada combinação de bocais, listadas na Tabela 3, exceção feita as três ultimas combinações, ou seja os reguladores de fluxo sem os bocais. O tempo de funcionando foi de duas horas.

O perfil de distribuição foi obtido com o auxílio de duas linhas de coletores dispostos ortogonalmente entre si no círculo de abrangência da água, com os coletores espaçados eqüidistantes a cada $20 \mathrm{~cm}$, entre eixos. (Figura 6).

Como coletores utilizaram-se recipientes cilíndricos metálicos de $9,5 \mathrm{~cm}$ de altura e $75,5 \mathrm{~mm}$ de diâmetro.

As leituras dos volumes de água contidas nos coletores foram feitas com o auxilio de duas provetas, com capacidade para $100 \mathrm{ml}$, graduadas a cada $1 \mathrm{ml}$, e a outra com capacidade para $10 \mathrm{ml}$, graduada a cada $0,1 \mathrm{ml}$ sendo as leituras convertidas em alturas de precipitações.

Os valores de precipitações para cada ponto foram obtidos através da média dos valores dos quatro coletores situados a uma mesma distância do microaspersor, sendo que para o traçado do perfil de distribuição, utilizou-se a média dos valores dos três microaspersores.

A base de cálculo para os valores de precipitação $(\mathrm{mm} / \mathrm{h})$ foi obtida mediante a utilização da seguinte expressão:

$P=(10 . V) /(A . t)$

onde: $\mathrm{P}$ - precipitação horária $(\mathrm{mm} / \mathrm{h})$

$\mathrm{V}$ - volume coletado em cada pluviômetro $\left(\mathrm{cm}^{3}\right)$ 


$$
\begin{aligned}
& \text { A - área do pluviômetro }\left(\mathrm{cm}^{2}\right) \\
& \mathrm{t} \text { - tempo de coleta (horas) }
\end{aligned}
$$

Os microaspersores com pulsator foram testados a uma altura de $30 \mathrm{~cm}$ acima da superficie dos coletores e os microaspersores sem pulsator a $22 \mathrm{~cm}$ dos coletores, alturas essas que por sua vez correspondem a altura das hastes que acompanham os microaspersores.

O suprimento de água foi semelhante ao descrito no teste 3.1 , utilizando-se dos mesmos equipamentos. 


\subsection{DETERMINAÇÃo DA SUPERFÍCIE DE DISTRIBUIÇÃO DE ÁGUA PELOS MICROASPERSORES:}

Este ensaio foi realizado simultaneamente ao teste de determinação do perfil de distribuição de água pelos microaspersores.

O objetivo do presente ensaio foi a determinação da distribuição pluviométrica dos microaspersores. Traçando-se as curvas isoietas, configurando desta forma a área molhada pelo emissor, e as curvas pluviométricas que nos indicam a precipitação média horária que recebe o terreno.

Levando-se em consideração as diferentes formas de distribuição de água pelos microaspersores, spinner (rotativo, num ângulo de $360^{\circ}$ ) e jet (fixo, num ângulo de $360^{\circ}$, com 12 jatos setoriais.), procurou-se distribuir os coletores em diferentes arranjos no solo com o intuito de adequar a área de captação (coletores) com a área efetivamente irrigada. (Figura 7)

Desta forma, no caso do microaspersor do tipo spinner, o mesmo foi colocado no centro geométrico de um reticulado de coletores espaçados eqüidistantes entre si, de maneira a formar quadrículas. O espaçamento entre coletores foi de $40 \mathrm{x}$ $40 \mathrm{~cm}$.

Por outro lado o microaspersor do tipo jet, apresentava uma distribuição em 12 jatos fixos ( 3 em cada quadrante., Figura 8 ). Foram escolhidos três jatos (2, 8 e 11) e procurou-se adaptar os coletores a área de precipitação dos mesmos. Os 
coletores foram dispostos desde o microaspersor até o ponto de alcance máximo do jato, espaçados eqüidistantes entre si, de maneira a formar uma área triangular de coletores com uma malha de coletores de $10 \times 10 \mathrm{~cm}$.(Figura 7)

O tempo de funcionamento dos microaspersores foi de 2 horas. Utilizou-se os mesmos equipamentos e a mesma metodologia descrita anteriormente para os cálculos das precipitações em cada pluviômetro. Com os resultados de precipitação horária, sendo representada pela média de três microaspersores ensaiados.

Com os valores de precipitações para cada ponto, fez-se a determinação gráfica das isoietas e a representação tridimensional da distribuição de água na superficie irrigada. Para tanto, utilizou-se a média dos valores de três microaspersores. 


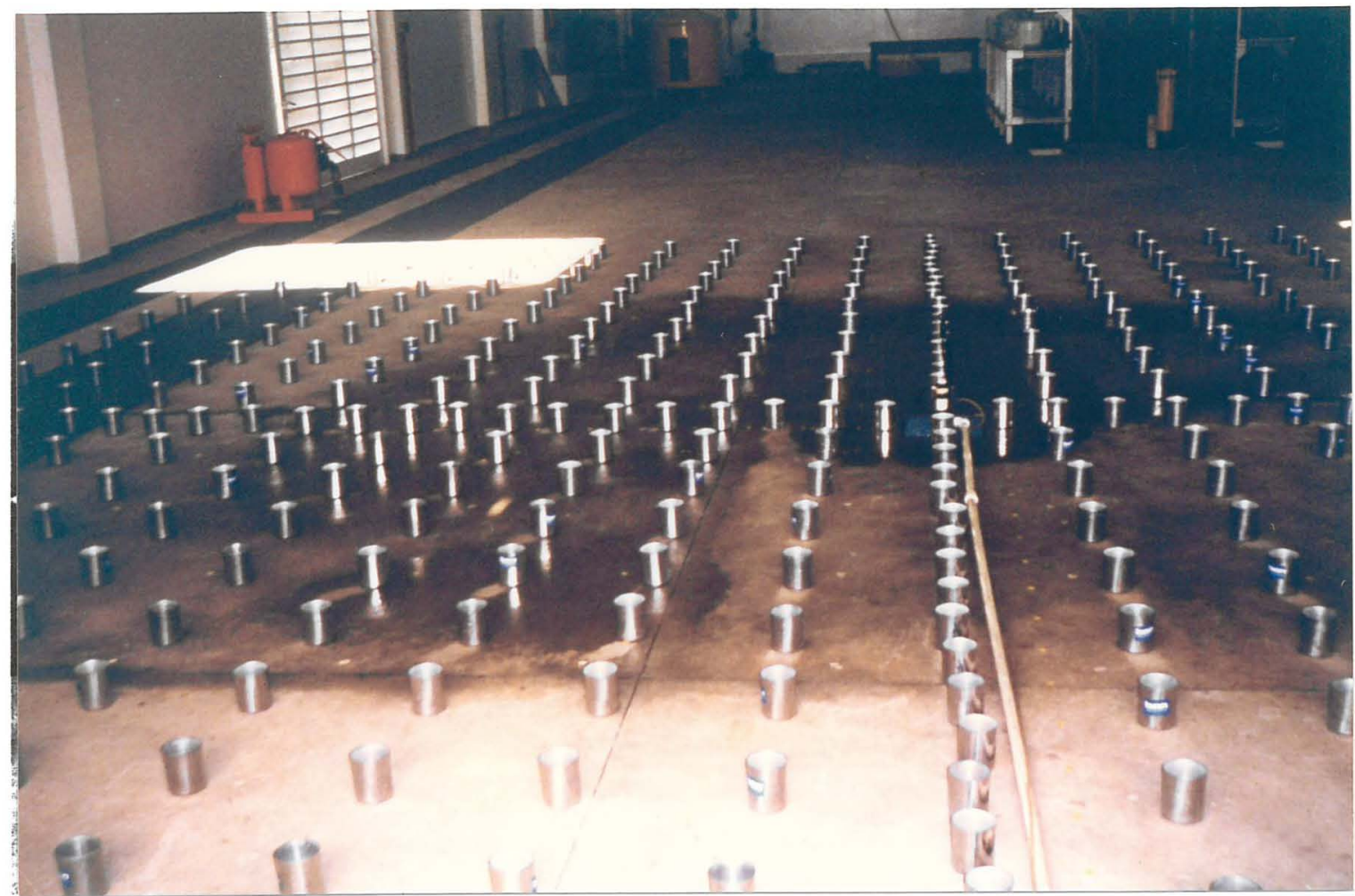

Figura 6 - Disposição de coletores para o perfil de distribuição e superfície molhada pelos microaspersores.

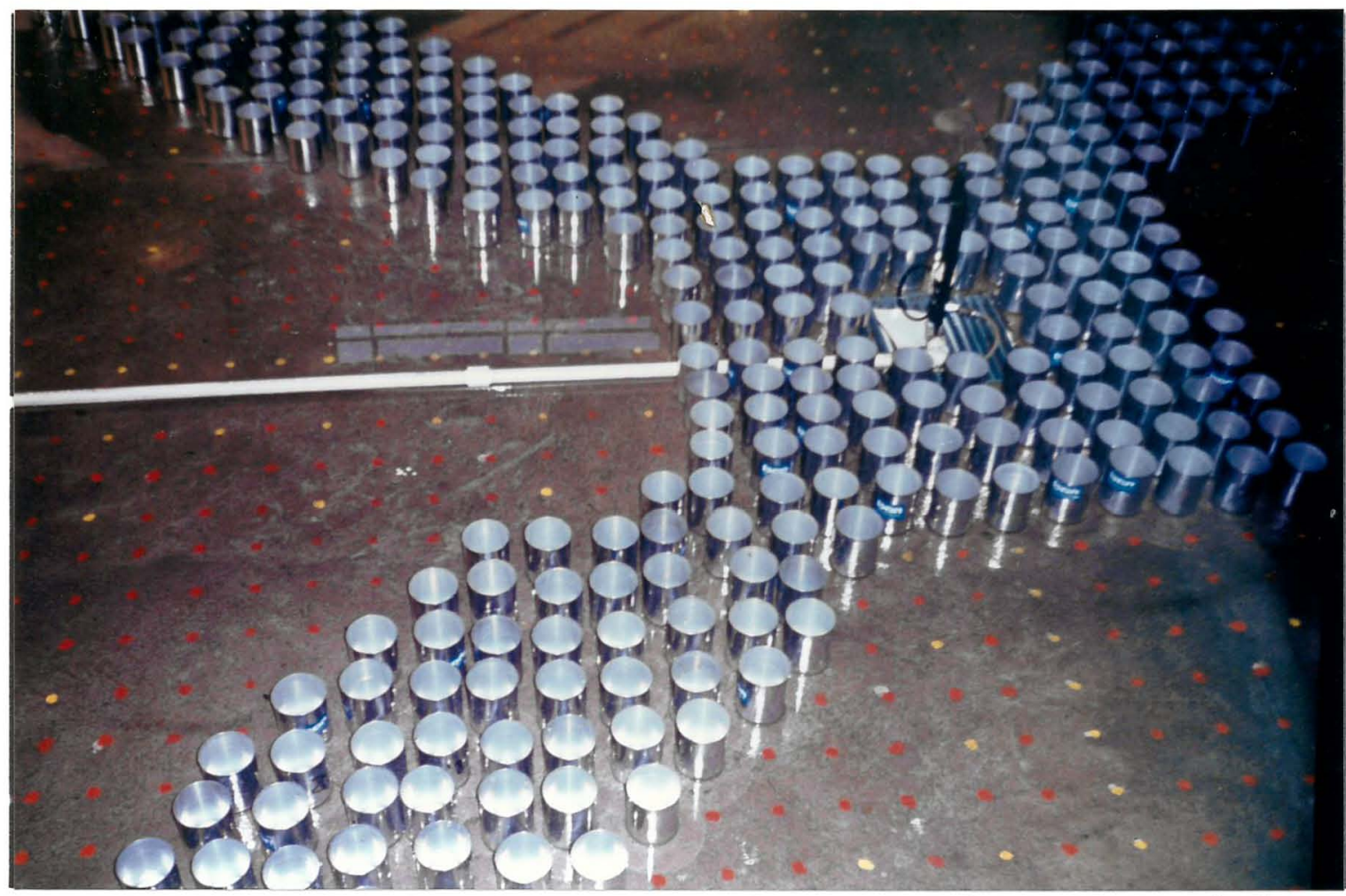

Figura 7 - Distribuição dos coletores com o microaspersor jet para o ensaio de distribuição de água. 


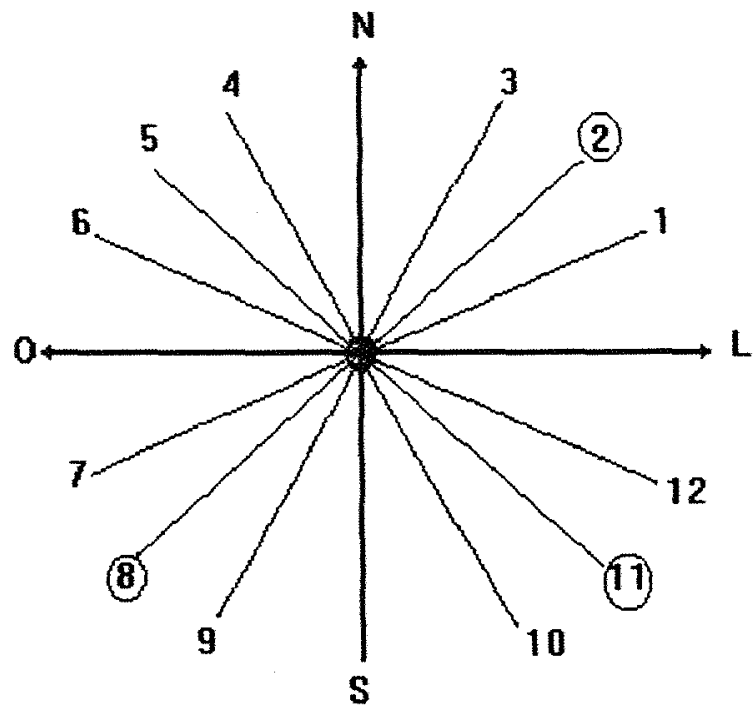

-Posição do microaspersor

Figura 8 - Posicão relativa dos jatos do microaspersor jet. Com destaque para os jatos ensaiados. 


\section{RESULTADOS E DISCUSSÃO}

\subsection{DETERMINAÇÃo DA EQUAÇÃO CARACTERÍSTICA VAZÃo- PRESSÃO}

Com o propósito de encontrar uma equação que melhor representasse a variação de vazão em função das pressões aplicadas aos microaspersores realizou-se o teste para determinação da equação caracteristica de vazão-pressão, foram utilizadas as médias aritméticas das três repetições das 20 (vinte) unidades de microaspersores de cada combinação da Tabela 3, a 8 (oito) diferentes pressões.

Com os dados de vazão e pressão e através de uma análise de regressão, estabeleceu-se uma equação característica semelhante a equação (1), sugerida por KELLER \& KARMELLI (1974). As equações obtidas para cada combinação com seus respectivos coeficientes de determinação encontram-se na Tabela 4. 
Tabela 4 - Relação vazão-pressão dos emissores estudados.

\begin{tabular}{|c|c|c|c|c|c|}
\hline MODELO & REG. & BOCAl. & EQUAGAO DE & $1^{0}$ & $\mathrm{R}^{2}$ \\
\hline SPINNER & 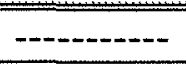 & vermelho & $q=7,0628 \mathrm{H}^{0,5051}$ & 8 & 1,0 \\
\hline SPINNER & $-\ldots$ & violeta & $q=4,4281 \mathrm{H}^{0,4986}$ & 9 & 0,9998 \\
\hline SPINNER & -.......- & azul & $q=3,3784 H^{0,5126}$ & 10 & 0,9997 \\
\hline SPINNER & branco & vermelho & $q=2,9277 \mathrm{H}^{0,2599}$ & 11 & 0,6517 \\
\hline SPINNER & branco & violeta & $q=2,6991 \mathrm{H}^{0,2702}$ & 12 & 0,5619 \\
\hline SPINNER & branco & azul & $q=4,5117 \mathrm{H}^{0,1791}$ & 13 & 0,5296 \\
\hline SPINNER & verde & vermelho & $q=1,8653 \mathrm{H}^{0,2816}$ & 14 & 0,6592 \\
\hline SPINNER & verde & violeta & $q=1,9166 \mathrm{H}^{0,2741}$ & 15 & 0,6574 \\
\hline SPINNER & verde & azul & $\mathrm{q}=2,0332 \mathrm{H}^{0,2631}$ & 16 & 0,66678 \\
\hline SPINNER & preto & vermelho & $q=5,6893 \mathrm{H}^{-0,0503}$ & 17 & 0,3063 \\
\hline SPINNER & preto & violeta & $\mathrm{q}=5,8643 \mathrm{H}^{-0,0632}$ & 18 & 0,2731 \\
\hline SPINNER & preto & azul & $q=6,4091 H^{-0,0749}$ & 19 & 0,4333 \\
\hline JET & - & vermelho & $\mathrm{q}=7,1363 \mathrm{H}^{0,4994}$ & 20 & 0,9999 \\
\hline JET & - - - - & violeta & $q=4,6709 \mathrm{H}^{0,4922}$ & 21 & 0,9999 \\
\hline JET & -......... & azul & $q=3,5554 \mathrm{H}^{0,5070}$ & 22 & 0,9999 \\
\hline JET & - & laranja & $q=2,7464 \mathrm{H}^{0,5015}$ & 23 & 0,9998 \\
\hline JET & branco & vermelho & $\mathrm{q}=1,8892 \mathrm{H}^{0,3355}$ & 24 & 0,7052 \\
\hline JET & branco & violeta & $q=1,9355 \mathrm{H}^{0,3325}$ & 25 & 0,7046 \\
\hline JET & branco & azul & $\mathrm{q}=2,4746 \mathrm{H}^{0,2876}$ & 26 & 0,6839 \\
\hline JET & branco & laranja & $q=2,2020 \mathrm{H}^{0,3107}$ & 27 & 0,6854 \\
\hline JET & verde & vermelho & $\mathrm{q}=1,6309 \mathrm{H}^{0,3013}$ & 28 & 0,6925 \\
\hline JET & verde & violeta & $q=1,8446 \mathrm{H}^{0,2803}$ & 29 & 0,6789 \\
\hline JET & verde & azul & $q=2,1206 \mathrm{H}^{0,2559}$ & 30 & 0,6650 \\
\hline JET & verde & laranja & $\mathrm{q}=2,5886 \mathrm{H}^{0,2211}$ & 31 & 0,6198 \\
\hline JET & preto & vermelho & $\mathrm{q}=5,1274 \mathrm{H}^{-0,0385}$ & 32 & 0,1288 \\
\hline JET & preto & violeta & $\mathrm{q}=5,9407 \mathrm{H}^{-0,0653}$ & 33 & 0,3398 \\
\hline JET & preto & azul & $\mathrm{q}=5,8929 \mathrm{H}^{-0,0634}$ & 34 & 0,2859 \\
\hline JET & preto & laranja & $\mathrm{q}=5,7341 \mathrm{H}^{-1,0591}$ & 35 & 0,2580 \\
\hline$-\cdots$ & branco & -......- & $\mathrm{q}=1,6567 \mathrm{H}^{0,3616}$ & 36 & 0,7567 \\
\hline - & verde & - & $\mathrm{q}=1,6995 \mathrm{H}^{0,3082}$ & 37 & 0,6999 \\
\hline -.........- & preto & $-\cdots$ & $q=1,5762 \mathrm{H}^{0,1702}$ & 38 & 0,6419 \\
\hline
\end{tabular}

obs: $q$ - vazão $(\mathrm{l} / \mathrm{h})$ e $\mathrm{H}$ - pressão $(\mathrm{kPa})$ 
Os testes $t$ foram significativos ao nivel de $1 \%$ de probabilidade para as equações ( 8 a 10 e 20 a 25). Para os microaspersores spinner - vermelho, violeta e azul - e os jets - vermelho, violeta, azul e laranja - (equações $8,9,10,20,21$ e 22), o coeficiente de determinação variou de 0,9997 a 1,0; o que significa dizer que cerca de 99 a $100 \%$ da variação ocorrida foi explicada pela suas respectivas equações, sendo que os valores obtidos de vazão média dos microaspersores testados, para cada pressão aplicada, tiveram um ajustamento adequado à equação determinada.

Por outro lado, os microaspersores spinner com bocais vermelho, violeta e azul associados ao regulador de fluxo preto (equações 17, 18 e 19), bem como o microaspersor tipo jet com bocais vermelho, violeta, azul e laranja, também associados ao regulador de fluxo preto (equações 32, 33, 34 e 35), apresentaram um coeficiente de determinação inferior a $43 \%$. Acrescente-se a isso o fato do teste $t$ não ter sido significativo, indicando que " $r$ " aproxima-se de " 0 ", em outras palavras, não há relação potencial entre a pressão e vazão. A vazão na faixa de pressão entre $120 \mathrm{a}$ $380 \mathrm{kPa}$ pouco variou devido o regulador de fluxo preto que a manteve estável em torno dos $4,0 \mathrm{l} / \mathrm{h}$

Os demais microaspersores, juntamente com os reguladores de fluxo branco, verde e preto apresentaram um coeficiente de determinação variando de 52 a $75 \%$, tendo um nível de significância de $5 \%$ de probabilidade quando da aplicação do teste $\mathrm{t}$. 
Quando as equações $8,9,10,20,21,22$ e 23 (bocais sem reguladores de fluxo) são comparadas com as demais (bocais com reguladores de fluxo) percebe-se que o valor do expoente $\mathrm{X}$ decresce com o uso do regulador de fluxo de menor vazão (branco $12 \mathrm{l} / \mathrm{h}$; verde $8 \mathrm{l} / \mathrm{h}$ e preto $4 \mathrm{l} / \mathrm{h}$ ). O baixo valor de $\mathrm{X}$ evidencia a pouca influência exercida pela variação de pressão nestes modelos com reguladores de fluxo, fato este devido a presença de um dispositivo compensador de pressão presente no seu interior.

Nas Figuras 9 e 10, estão apresentados graficamente as equações $8,9,10$, $20,21,22$ e 23 características de seus respectivos emissores.

Levando-se em consideração o fato das equações 11 a 19 e 24 a 38 não terem sido ajustadas adequadamente aos dados obtidos, foram considerados como representativos das relações vazão-pressão dos microaspersores para as condições nas quais os testes foram realizados, as respectivas curvas características apresentadas nas Figuras de números 11 a 17. 


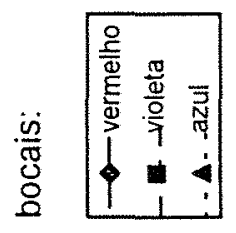

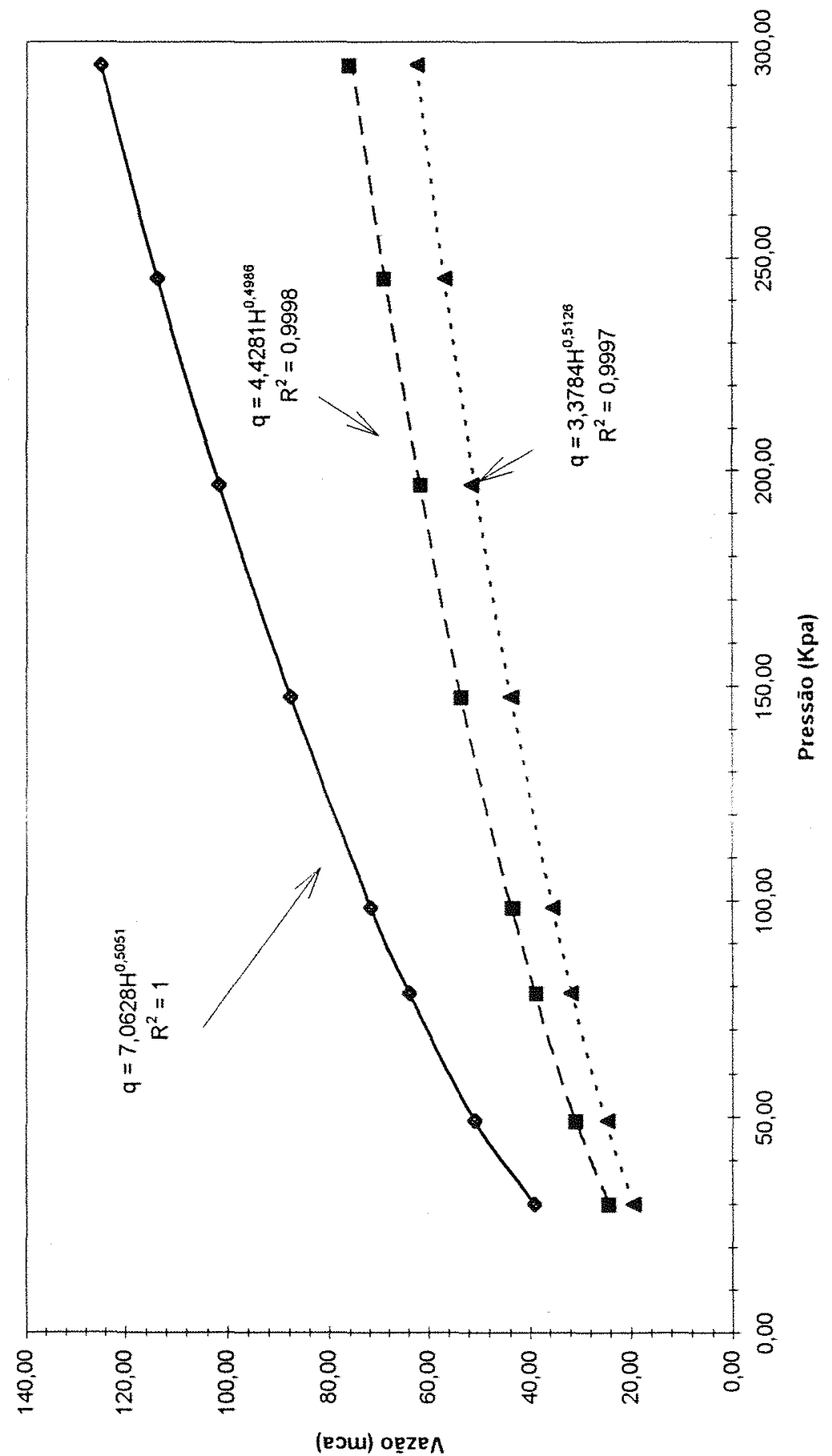

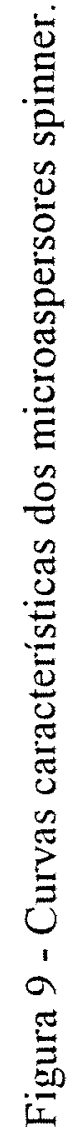



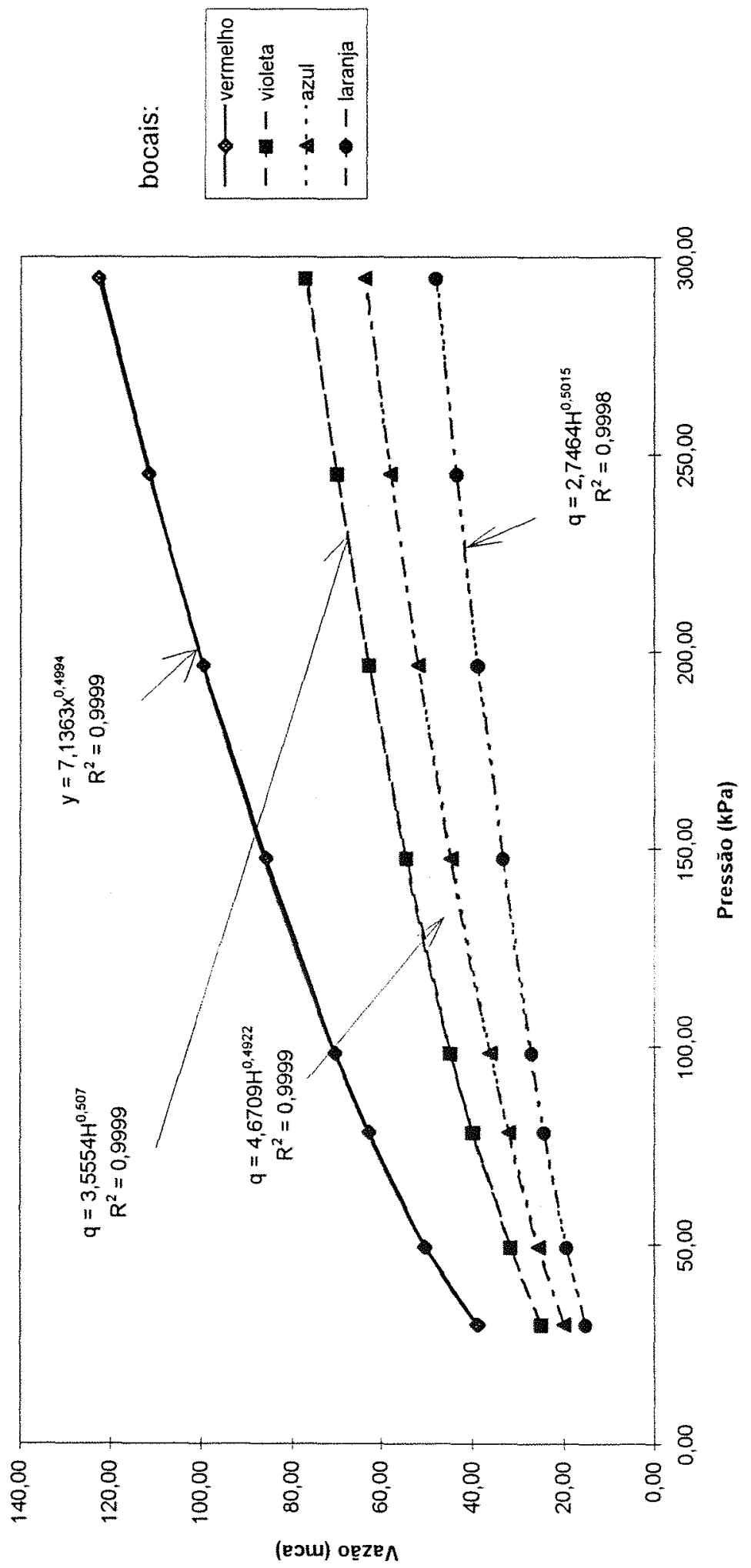

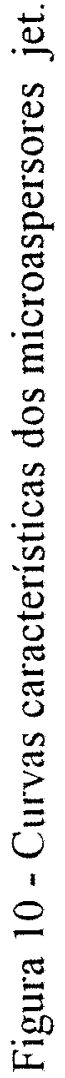




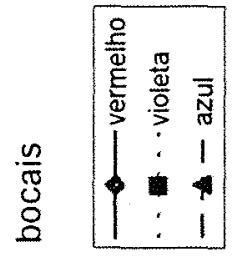

导

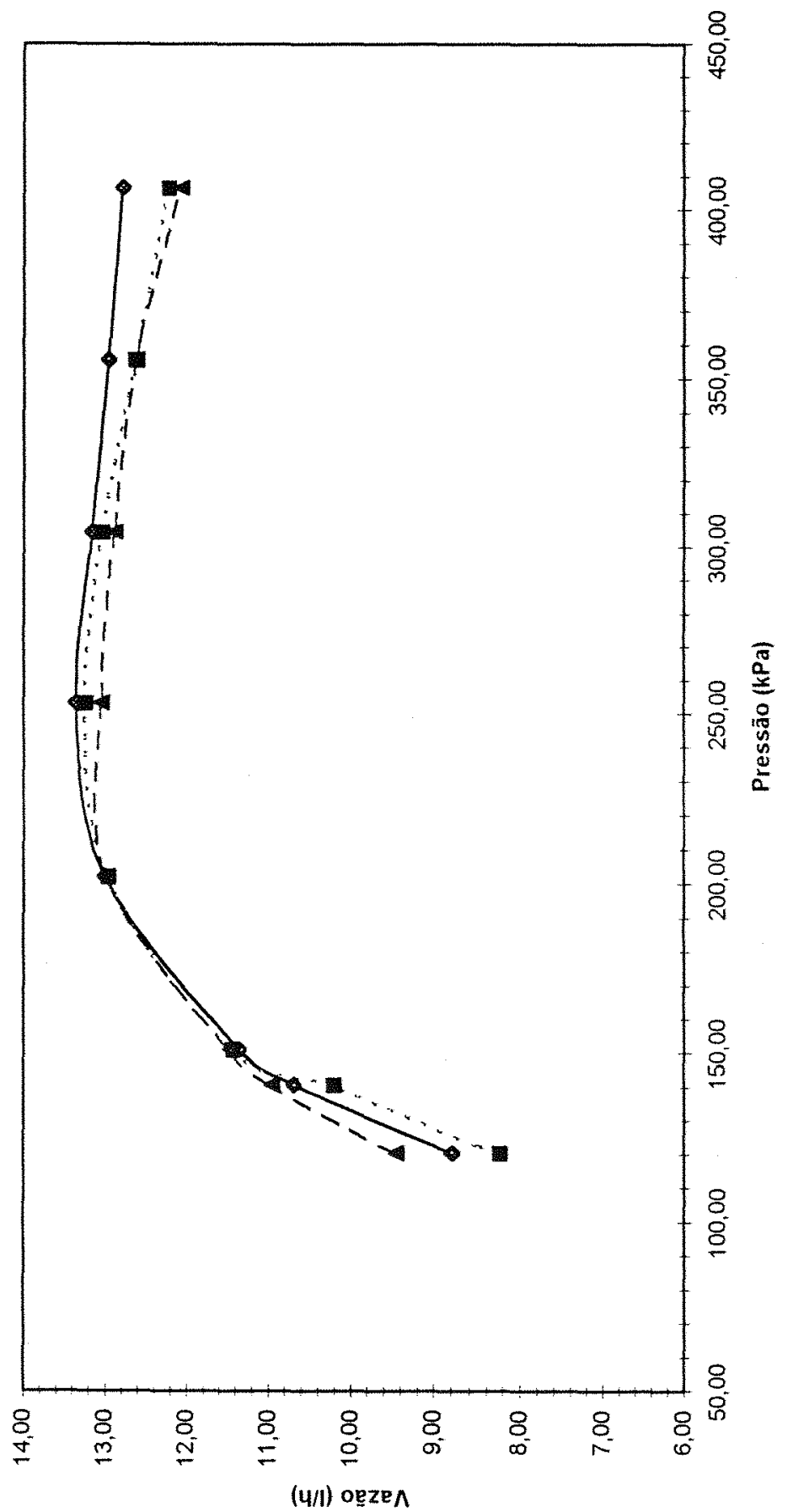

을

8

흘

U

छั

总

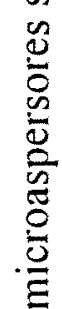

ฒ

范

告

$\stackrel{0}{\Xi}$

莫 

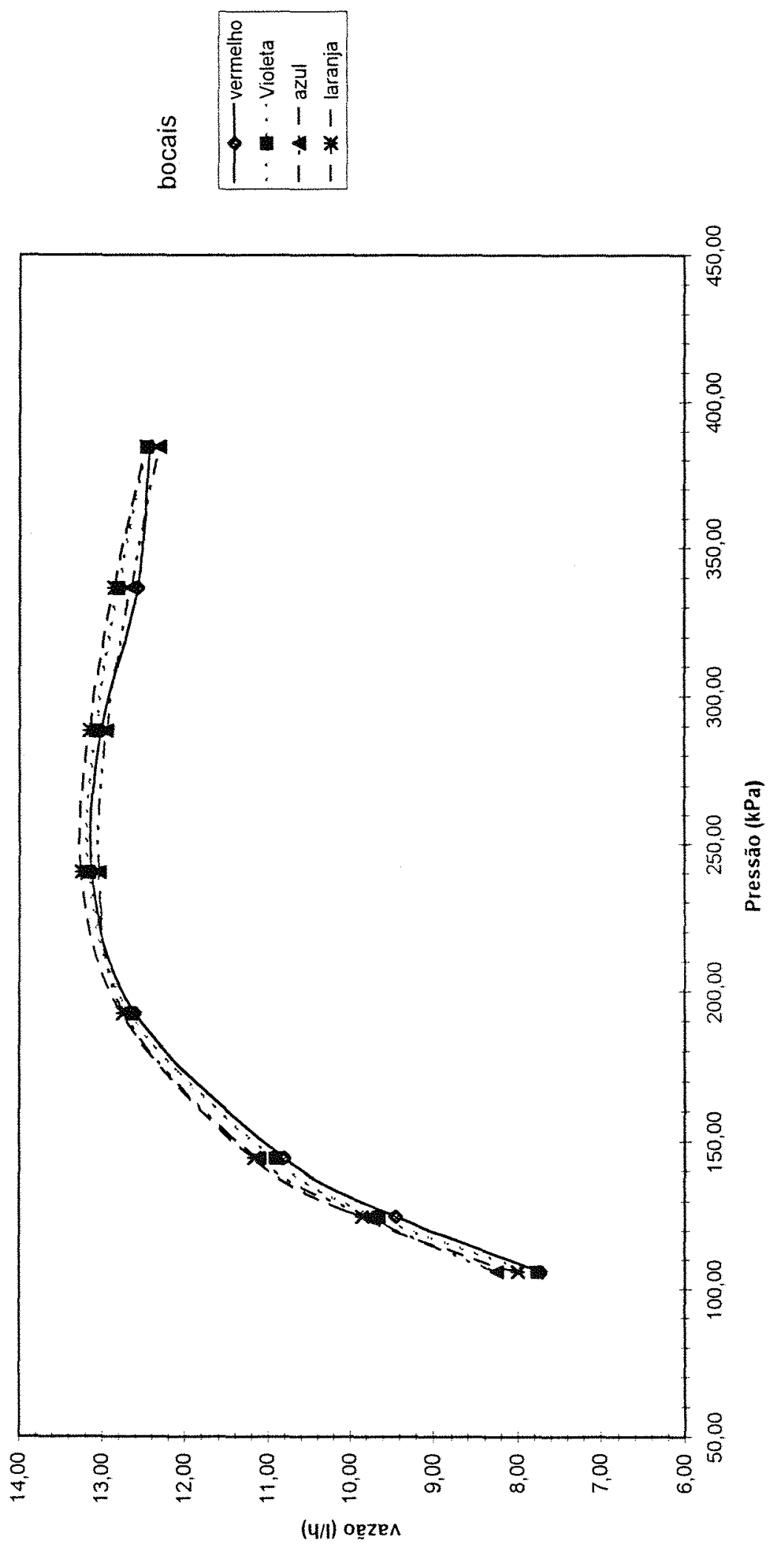

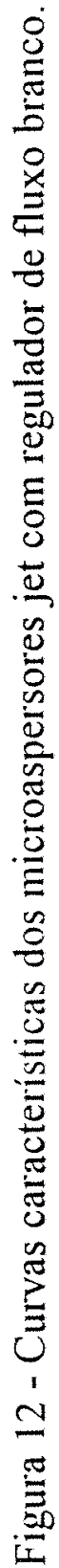



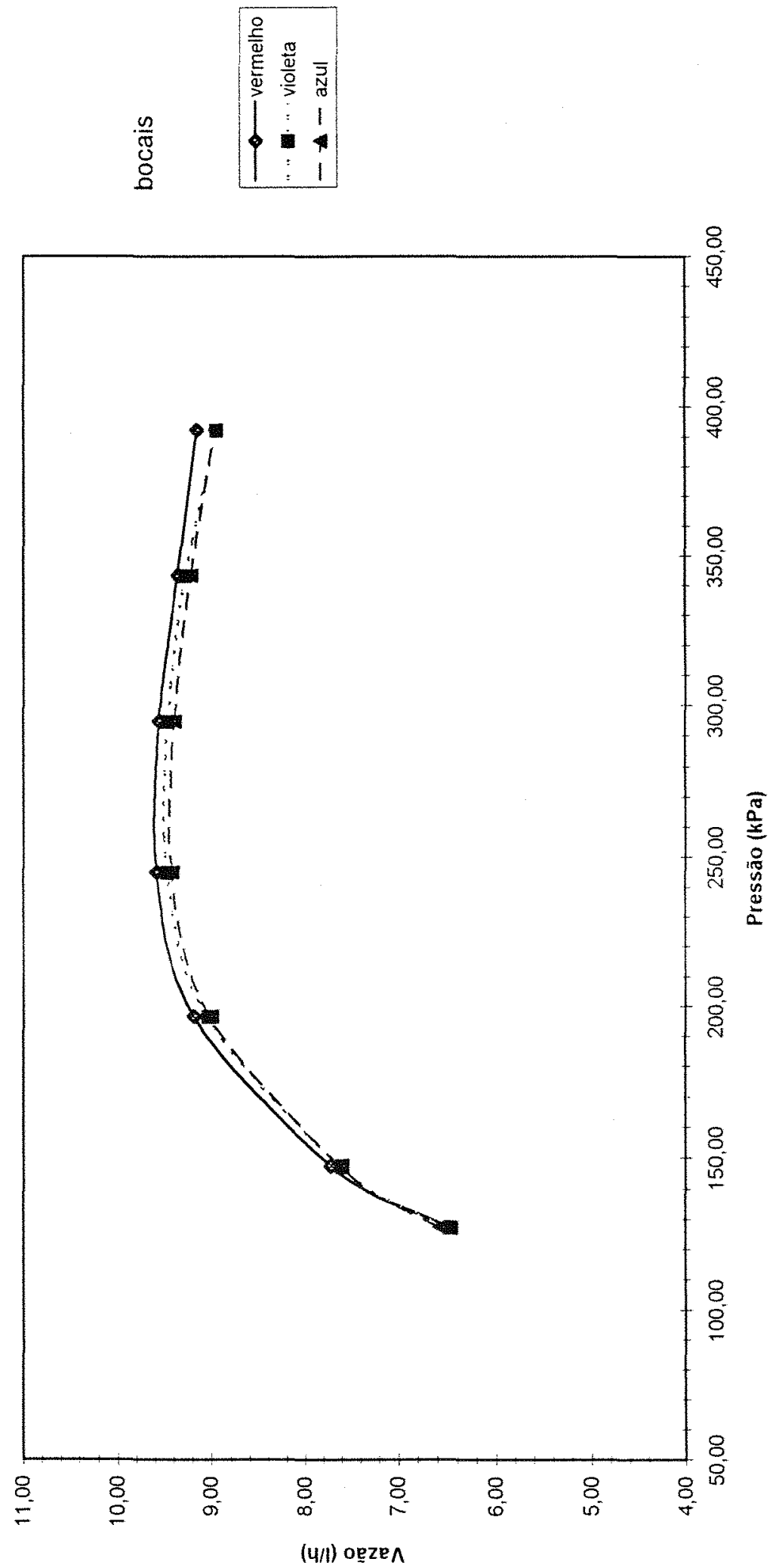

$\stackrel{0}{2}$

를

닝

$\frac{\overline{0}}{3}$

ह0

్ㅇ

$\overline{\bar{\sigma}}$

E

\&

o

क

○

$\Xi$

$\stackrel{\infty}{0}$

$=$

导

$\bar{E}$

可

告 


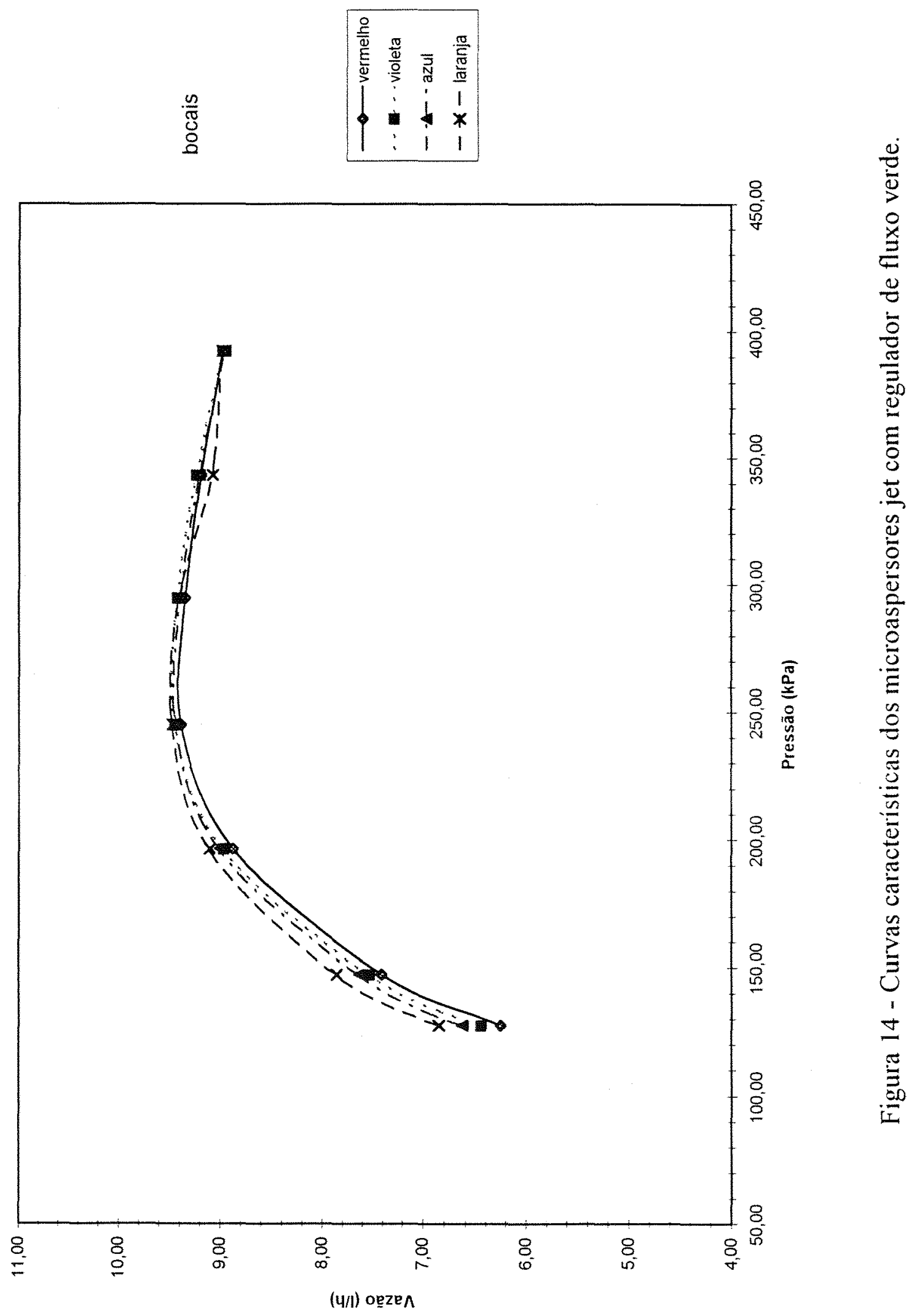




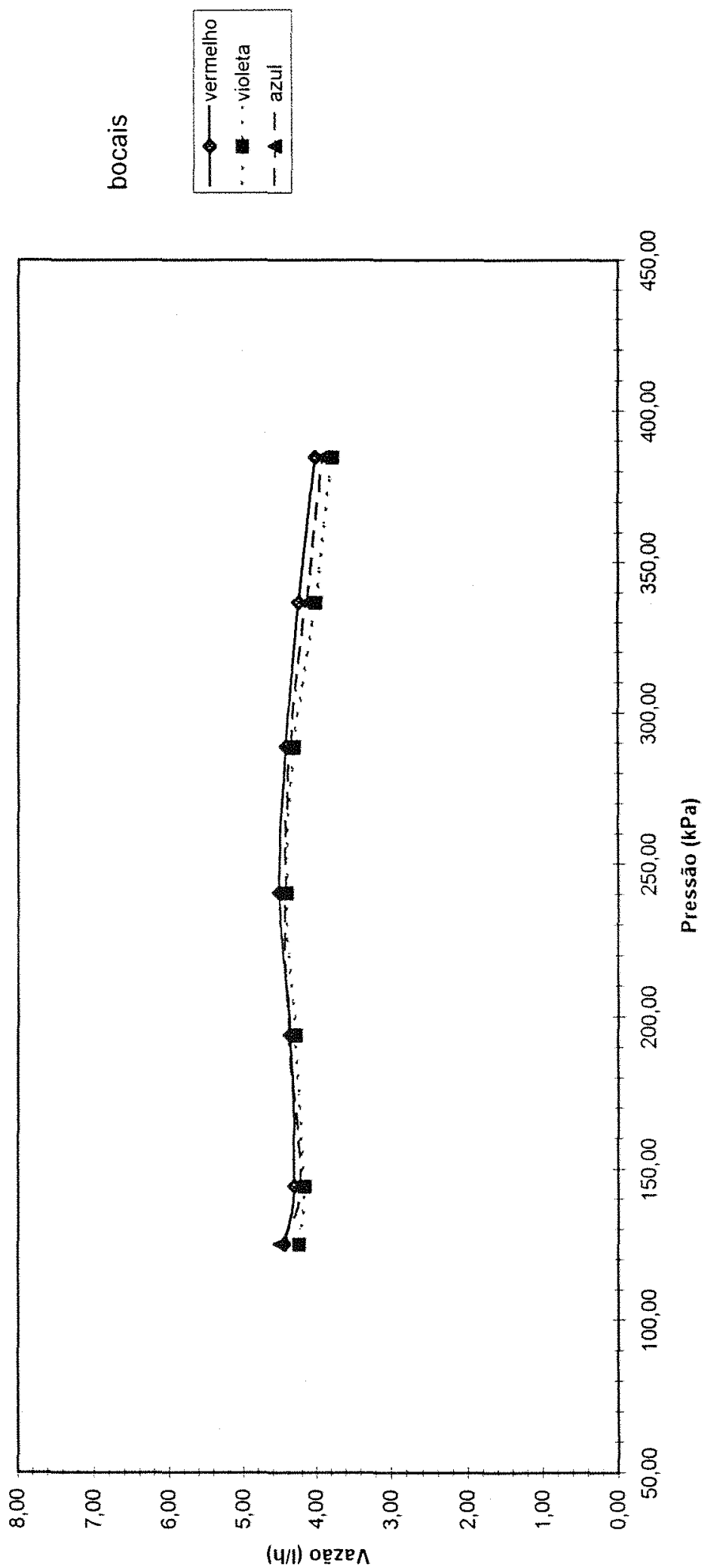

迷

을

0

它

छ

吕

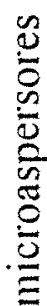

응

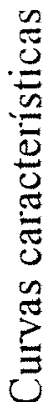

in

总 

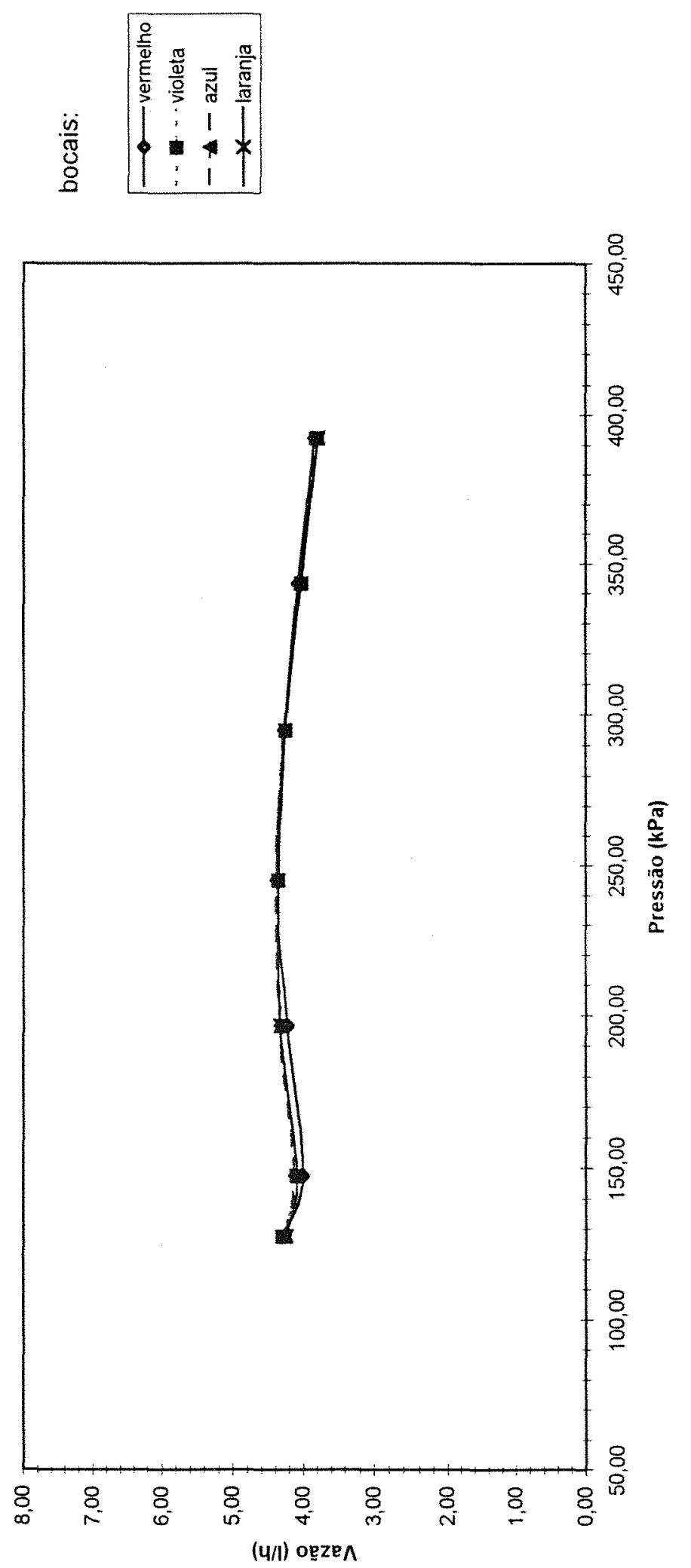

$\frac{0}{0}$

ֻ̊ํㅡ

0

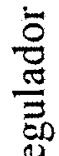

छ

. \pm

0
0
0
0
0
0
0
0
0
$\vdots$
0
0
0
0
0
0
0
0
0
0
0
0
0
0
0
0

它 

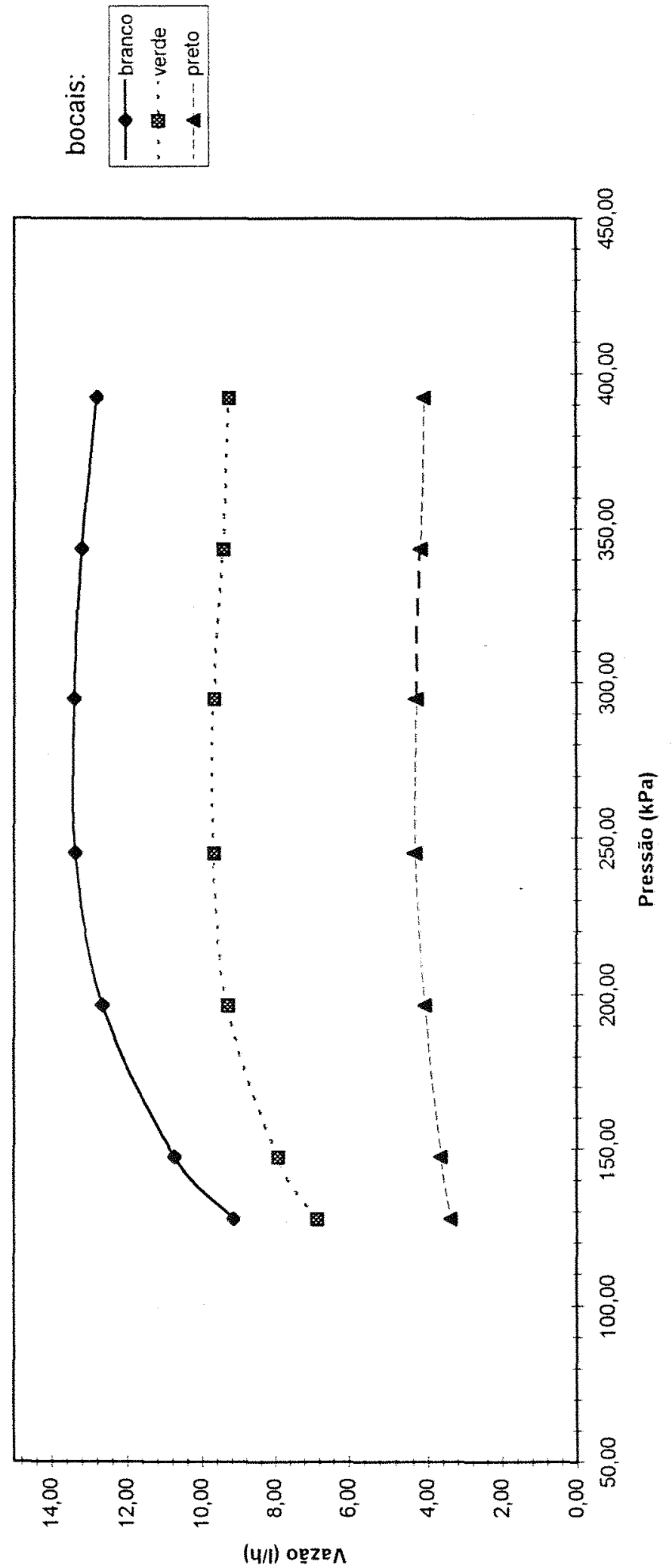

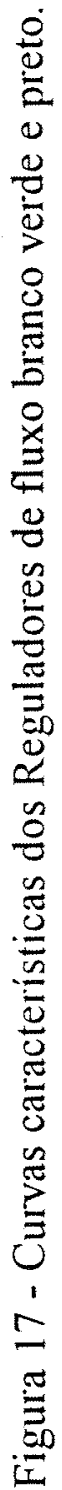




\subsection{DETERMINAÇÃO DA UNIFORMIDADE DE VAZÃO.}

Com a finalidade de analisar a variação de vazão entre os microaspersores, em função das diferenças decorrentes do processo de fabricação, os microaspersores do tipo spinner e jet (sendo o spinner nas cores vermelha, violeta, e azul e o jet nas mesmas cores mais a cor laranja) foram combinados com três reguladores de fluxo, com pulsator, nas cores branca, verde e preta. O que resultou em 31(trinta e uma) combinações listadas na Tabela 3.

Os microaspersores foram submetidos a 8 (oito) níveis de pressão, com três repetições para todos os modelos ensaiados.

A vazão média, o desvio padrão, o coeficiente de variação de fabricação bem como sua classificação segundo a $\mathrm{ABNT}$, dos dados observados de cada tipo de combinação, encontram-se nas Tabelas 5 a 13.

Com base nesses dados podemos verificar que os microaspersores do tipo spinner - com os bocais vermelho, violeta e azul, e o jet nos bocais vermelho, violeta, azul e laranja ambos com reguladores de fluxo preto além dos reguladores de fluxo verde e preto; apresentaram segundo a $A B N T$ um $\mathrm{cV}$ classificado como médio enquanto que as demais combinações apresentaram um cv bom.

Foram classificados como "marginais" o regulador de fluxo preto combinado tanto com o spinner (bocais vermelho, violeta e azul) quanto com o jet (vermelho, violeta, azul e laranja) nas pressões de 124,96 a 144,39 kPa. 
Verificou-se ainda, que quando os microaspersores do tipo spinner ou jet, independentemente do bocal utilizado, quando associados aos reguladores de fluxo branco e verde, para uma faixa de 200 a $400 \mathrm{kPa}$, mantiveram seus valores de vazão médio estáveis e próximos de $13 \mathrm{l} / \mathrm{h}$ e $9 \mathrm{l} / \mathrm{h}$ respectivamente para os reguladores de fluxo acima citados. Enquanto que estes mesmos bocais quando associados ao regulador de fluxo preto, mantiveram seus valores de vazão médio estáveis e próximos a 4 1/h para uma faixa de operação de 120 a $400 \mathrm{kPa}$ (Figuras 15 e 16). 
Tabela 5 - Vazão média observada para os bocais spinner a diferentes pressões e respectivos coeficientes de variação. Piracicaba 1993

\begin{tabular}{|c|c|c|c|c|}
\hline \multicolumn{5}{|c|}{ MODELO:SPINNER ANG.:(graus):360 BOCAL:VERMELHO } \\
\hline $\begin{array}{c}\text { Pressão } \\
\text { (Kpa) }\end{array}$ & $\begin{array}{c}\text { Vaz.Média } \\
(1 / h)\end{array}$ & $\begin{array}{l}\text { Desvió } \\
\text { padrão }\end{array}$ & C.V.F. & $\begin{array}{c}\text { Classificação } \\
\text { ABNT }\end{array}$ \\
\hline 29,92 & 39,27 & 1,264 & 0,032 & bom \\
\hline 49,34 & 50,74 & 1,377 & 0,027 & bom \\
\hline 78,47 & 63,94 & 1,764 & 0,028 & bom \\
\hline 98,38 & 71,69 & 1,993 & 0,028 & bom \\
\hline 147,43 & 87,73 & 2,582 & 0,029 & bom \\
\hline 196,57 & 101,59 & 3,076 & 0,030 & bom \\
\hline 245,12 & 113,80 & 3,199 & 0,028 & bom \\
\hline 294,66 & 124,98 & 4,022 & 0,032 & bom \\
\hline \multicolumn{5}{|c|}{ cv médio $=0,029 \quad$ bom } \\
\hline \multicolumn{5}{|c|}{ MODELO:SPINNER ANG:(graus):360 BOCAL:VIOLETA } \\
\hline $\begin{array}{c}\text { Pressão } \\
\text { (Kpa) }\end{array}$ & $\begin{array}{c}\text { Vaz.Média } \\
(I / h)\end{array}$ & $\begin{array}{l}\text { Desvió } \\
\text { padrão }\end{array}$ & C.V.F. & $\begin{array}{c}\text { Classificação } \\
\text { ABNT }\end{array}$ \\
\hline 29,92 & 24,33 & 0,722 & 0,030 & bom \\
\hline 49,34 & 30,90 & 1,288 & 0,042 & bom \\
\hline 78,47 & 38,73 & 1,593 & 0,041 & bom \\
\hline 98,38 & 43,32 & 2,053 & 0,047 & bom \\
\hline 147,43 & 53,28 & 2,261 & 0,042 & bom \\
\hline 196,57 & 61,51 & 2,612 & 0,042 & bom \\
\hline 245,12 & 69,01 & 2,956 & 0,043 & bom \\
\hline 294,66 & 75,96 & 3,264 & 0,043 & bom \\
\hline \multicolumn{5}{|c|}{ cv médio = } \\
\hline \multicolumn{5}{|c|}{ MODELO:SPINNER ANG:(graus):360 BOCAL :AZUL } \\
\hline $\begin{array}{c}\text { Pressão } \\
\text { (Kpa) }\end{array}$ & $\begin{array}{c}\text { Vaz.Média } \\
(1 / h)\end{array}$ & $\begin{array}{l}\text { Desvio } \\
\text { padrão }\end{array}$ & C.V.F. & $\begin{array}{c}\text { Classificação } \\
\text { ABNT }\end{array}$ \\
\hline 29,92 & 19,43 & 0,680 & 0,035 & bom \\
\hline 49,34 & 24,62 & 2,116 & 0,086 & bom \\
\hline 78,47 & 31,79 & 1,661 & 0,052 & bom \\
\hline 98,38 & 35,40 & 1,293 & 0,037 & bom \\
\hline 147,43 & 43,52 & 1,639 & 0,038 & bom \\
\hline 196,57 & 51,19 & 1,811 & 0,035 & bom \\
\hline 245,12 & 56,53 & 2,191 & 0,039 & bom \\
\hline 294,66 & 62,16 & 2,381 & 0,038 & bom \\
\hline \multicolumn{5}{|c|}{ cvmédio $=$} \\
\hline
\end{tabular}


Tabela 6 - Vazão média observada para os bocais jet a diferentes pressões e respectivos coeficientes de variação. Piracicaba 1993

\begin{tabular}{|c|c|c|c|c|}
\hline \multicolumn{5}{|c|}{ MODELO JET ANG (graUS) 360 BOCAL VERMELHO } \\
\hline Presogo & Vat Media & Desvio & 01\% & Classfficara \\
\hline 29,92 & 39,05 & 0,971 & 0,025 & bom \\
\hline 49,34 & 50,18 & 1,234 & 0,025 & bom \\
\hline 78,47 & 62,84 & 1,738 & 0,028 & bom \\
\hline 98,38 & 70,47 & 1,926 & 0,027 & bom \\
\hline 147,43 & 85,90 & 2,336 & 0,027 & bom \\
\hline 196,57 & 99,57 & 2,603 & 0,026 & bom \\
\hline 245,12 & 111,63 & 2,906 & 0,026 & bom \\
\hline 294,66 & 122,75 & 3,202 & 0,026 & bom \\
\hline \multicolumn{5}{|c|}{ cr médio $=$} \\
\hline \multicolumn{5}{|c|}{ MODELO 3 ET ANG (gIaUS) 360 BOCAL VIOLETA } \\
\hline pressaro & Wornedia & posvoro & 60 & Classificaro \\
\hline 29,92 & 25,02 & 0,387 & 0,015 & bom \\
\hline 49,34 & 31,78 & 0,558 & 0,018 & bom \\
\hline 78,47 & 39,86 & 0,649 & 0,016 & bom \\
\hline 98,38 & 44,62 & 0,640 & 0,014 & bom \\
\hline 147,43 & 54,38 & 0,876 & 0,016 & bom \\
\hline 196.57 & 62,79 & 0,984 & 0,016 & bom \\
\hline 245,12 & 70,12 & 0,977 & 0,014 & bom \\
\hline 294,66 & 77,14 & 1,104 & 0,014 & bom \\
\hline \multicolumn{3}{|c|}{ cv médio } & 0,015 & bom \\
\hline \multicolumn{5}{|c|}{ MODELO ONT } \\
\hline Prosoro & Worata & posuro. & 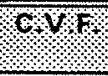 & Cassifras \\
\hline 29,92 & 20,07 & 0,724 & 0,036 & bom \\
\hline 49,34 & 25.56 & 1,051 & 0.041 & bom \\
\hline 78.47 & 32,30 & 1,358 & 0,042 & bom \\
\hline 98,38 & 36,34 & 1,522 & 0,042 & bom \\
\hline 147,43 & 44,58 & 1.908 & 0,043 & bom \\
\hline 196,57 & 51,73 & 2,269 & 0,044 & bom \\
\hline 245,12 & 57,95 & 2,580 & 0,045 & bom \\
\hline 294,66 & 63,76 & 2,878 & 0,045 & bom \\
\hline \multirow{2}{*}{\multicolumn{5}{|c|}{ 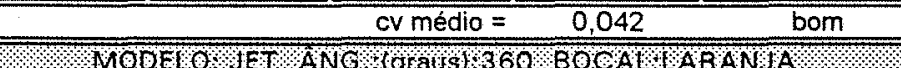 }} \\
\hline & & & & \\
\hline Pressoto & VazMedta & posvio & $\mathrm{COH}$ & CTassificacto \\
\hline 29,92 & 15,20 & 0,223 & 0,015 & bom \\
\hline 49,34 & 19,41 & 0,346 & 0,018 & bom \\
\hline 78,47 & 24,43 & 0,378 & 0,015 & bom \\
\hline 98,38 & 27,18 & 0,354 & 0,013 & bom \\
\hline 147,43 & 33,52 & 0,445 & 0,013 & bom \\
\hline 196,57 & 38,77 & 0,623 & 0,016 & bom \\
\hline 245,12 & 43,40 & 0,707 & 0,016 & bom \\
\hline 294,66 & 47,92 & 0,721 & 0.015 & bom \\
\hline \multicolumn{4}{|c|}{ cv médio = } & bom \\
\hline
\end{tabular}


Tabela 7 - Vazão média observada para os bocais spinner com reguladores de fluxo branco a diferentes pressões e respectivos coeficientes de variação. Piracicaba 1993

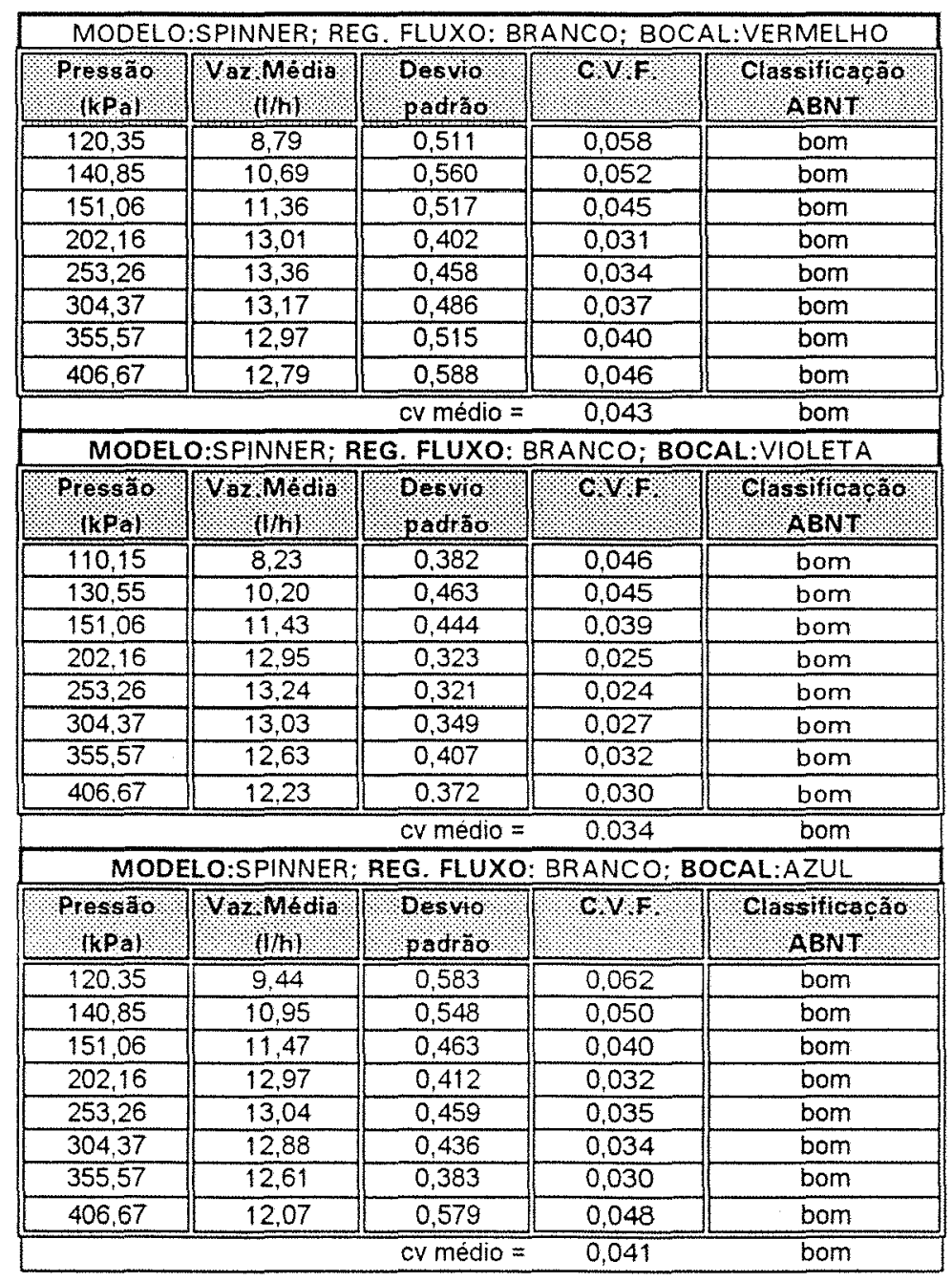


Tabela $\&$ - Vazão média observada para os bocais jet com reguladores de fluxo branco a diferentes pressões e respectivos coeficientes de variação. Piracicaba 1993

\begin{tabular}{|c|c|c|c|c|}
\hline \multicolumn{5}{|c|}{ MODELO:JET; REG. FLUXO: BRANCO; BOCAL:VERMELHO } \\
\hline $\begin{array}{l}\text { Pressão } \\
\text { (kPal }\end{array}$ & \begin{tabular}{|l} 
Vaz.Média \\
$((/ / h)$ \\
\end{tabular} & Desvio & C.V.F. & $\begin{array}{l}\text { Classificação } \\
\text { ABNT }\end{array}$ \\
\hline 106,03 & 7,72 & 0,575 & 0,075 & bom \\
\hline 124,96 & 9.45 & 0,444 & 0,047 & bom \\
\hline 144,39 & 10,81 & 0,448 & 0,041 & bom \\
\hline 192,45 & 12,60 & 0,375 & 0,030 & bom \\
\hline 240,51 & 13,13 & 0,354 & 0,027 & bom \\
\hline 288,57 & 13,01 & 0,327 & 0,025 & bom \\
\hline 336,64 & 12,58 & 0,429 & 0,034 & bom \\
\hline 384,70 & 12,43 & 0.303 & 0,024 & bom \\
\hline \multirow{2}{*}{\multicolumn{5}{|c|}{$\begin{array}{ccc}\text { cr médio }= & 0,038 & \text { bom } \\
\text { MODELO.JET: REG FLUXO: BRANCO : BOCAL VIOLETA }\end{array}$}} \\
\hline & & & & \\
\hline $\begin{array}{l}\text { Pressão } \\
\text { (kPa) }\end{array}$ & $\begin{array}{c}\text { Vaz.Média } \\
\text { (l/h) }\end{array}$ & $\begin{array}{l}\text { Desvió } \\
\text { padráo }\end{array}$ & CU.F. & $\begin{array}{c}\text { Classificação } \\
\text { ABNT }\end{array}$ \\
\hline 106,03 & 7,76 & 0,434 & 0,056 & bom \\
\hline 124,96 & 9,64 & 0,414 & 0,043 & bom \\
\hline 144,39 & 10.91 & 0.420 & 0,038 & bom \\
\hline 192.45 & 12.65 & 0,354 & 0,028 & bom \\
\hline 240.51 & 13,15 & 0,321 & 0,024 & bom \\
\hline 288,57 & 13,07 & 0,282 & 0,022 & bom \\
\hline 336.64 & 12.81 & 0.284 & 0,022 & bom \\
\hline 384.70 & 12,46 & 0.282 & 0.023 & bom \\
\hline \multicolumn{5}{|c|}{ cV médio $=$} \\
\hline \multicolumn{5}{|c|}{ MODELO:JET; REG. FLUXO: BRANCO;BOCAL:AZUL } \\
\hline $\begin{array}{l}\text { Pressão } \\
\text { (kPa) }\end{array}$ & $\begin{array}{c}\text { Vaz.Média } \\
(/ / h) \\
\end{array}$ & $\begin{array}{l}\text { Desvio } \\
\text { padrão }\end{array}$ & C.V.F & $\begin{array}{l}\text { Classificaçăo } \\
\text { ABNT }\end{array}$ \\
\hline 106.03 & 8,25 & 0,531 & 0,064 & bom \\
\hline 124,96 & 9,74 & 0,406 & 0.042 & bom \\
\hline 144,39 & 11,11 & 0,388 & 0,035 & bom \\
\hline 192,45 & 12.72 & 0,330 & 0,026 & bom \\
\hline 240,51 & 13,03 & 0,333 & 0,026 & bom \\
\hline 288.57 & 12.94 & 0,335 & 0,026 & bom \\
\hline 336,64 & 12,65 & 0,338 & 0,027 & bom \\
\hline 384,70 & 12,31 & 0,354 & 0,029 & bom \\
\hline \multicolumn{5}{|c|}{ cv médio $=$} \\
\hline \multicolumn{5}{|c|}{ MODELO:JET; REG. FLUXO: BRANCO; BOCAL:LARANJA } \\
\hline $\begin{array}{l}\text { Pressão } \\
\text { (kPal }\end{array}$ & $\begin{array}{l}\text { Vaz:Média } \\
(\text { (I/h) }\end{array}$ & pesvio & C.V.F. & $\begin{array}{l}\text { Classificação } \\
\text { ABNT }\end{array}$ \\
\hline 106,03 & 8,00 & 0,453 & 0,057 & bom \\
\hline 124,96 & 9,85 & 0,414 & 0,042 & bom \\
\hline 144,39 & 11,17 & 0,417 & 0,037 & bom \\
\hline 192,45 & 12,75 & 0,342 & 0,027 & bom \\
\hline 240,51 & 13,24 & 0,319 & 0,024 & bom \\
\hline 288,57 & 13,15 & 0,291 & 0,022 & bom \\
\hline 336.64 & 12,86 & 0,294 & 0,023 & bom \\
\hline 384,70 & 12,47 & 0,289 & 0,023 & bom \\
\hline \multicolumn{4}{|c|}{ cv médio = } & bom \\
\hline
\end{tabular}


Tabela 9 - Vazão média observada para os bocais spinner com reguladores de fluxo verde a diferentes pressões e respectivos coeficientes de variação.

\section{Piracicaba 1993}

\begin{tabular}{|c|c|c|c|c|}
\hline \multicolumn{5}{|c|}{ MODELO:SPINNER; REG. FLUXO: VERDE; BOCAL:VERMELHO } \\
\hline $\begin{array}{l}\text { Press 3o } \\
\text { (kPal }\end{array}$ & $\begin{array}{l}\text { Vaz Medio } \\
\text { (I) }\end{array}$ & pesvoro & $\mathrm{CVF}$ & Clossificaca \\
\hline 127,51 & 6,48 & 0,509 & 0,079 & bom \\
\hline 147,43 & 7,72 & 0,413 & 0,053 & bom \\
\hline 196,57 & 9,19 & 0,574 & 0,062 & bom \\
\hline 245,12 & 9,59 & 0,360 & 0,038 & bom \\
\hline 294,66 & 9,56 & 0,273 & 0,029 & bom \\
\hline 343,31 & 9,36 & 0,295 & 0,032 & bom \\
\hline 392,35 & 9,15 & 0,444 & 0,049 & bom \\
\hline \multicolumn{3}{|r|}{ cv médio $=$} & 0,049 & bom \\
\hline \multicolumn{5}{|c|}{ MODELO:SPINNER; REG. FLUXO: VERDE; BOCAL:VIOLETA } \\
\hline Prossao & Var Modia & Dosvof & $\mathrm{GQP}$ & Clossificroá \\
\hline 127,51 & 6,47 & 0,429 & 0,066 & bom \\
\hline 147,43 & 7,59 & 0,428 & 0,056 & bom \\
\hline 196.57 & 9.03 & 0,506 & 0,056 & bom \\
\hline 245,12 & 9.46 & 0,352 & 0.037 & bom \\
\hline 294,66 & 9,45 & 0,280 & 0,030 & bom \\
\hline 343,31 & 9,27 & 0,329 & 0,036 & bom \\
\hline 392,35 & 8,94 & 0,447 & 0,050 & bom \\
\hline \multicolumn{3}{|r|}{ cv médio $=$} & 0.047 & bom \\
\hline \multicolumn{5}{|c|}{ MODELO:SPINNER: REG. FLUXO: VERDE: BOCAL:AZUL } \\
\hline $\begin{array}{l}\text { Pressáo } \\
\text { (kpal }\end{array}$ & VazMedia & $\begin{array}{l}\text { Desvio } \\
\text { padrao }\end{array}$ & Q1P & Classificacao \\
\hline 127.51 & 6.56 & 0.338 & 0.052 & bom \\
\hline 147,43 & 7.60 & 0.334 & 0,044 & bom \\
\hline 196.57 & 8,99 & 0.451 & 0,050 & bom \\
\hline 245,12 & 9.41 & 0,314 & 0,033 & bom \\
\hline 294.66 & 9,39 & 0.255 & 0,027 & bom \\
\hline 343.31 & 9,21 & 0.322 & 0.035 & bom \\
\hline 392,35 & 8,95 & 0,389 & 0,043 & bom \\
\hline \multicolumn{3}{|r|}{ cv médio $=$} & 0,041 & bom \\
\hline
\end{tabular}


Tabela 10 - Vazão média observada para os bocais jet com reguladores de fluxo verde a diferentes pressões e respectivos coeficientes de variação. Piracicaba 1993

\begin{tabular}{|c|c|c|c|c|}
\hline \multicolumn{5}{|c|}{ MODELO:JET; REG. FLUXO: VERDE; BOCAL:VERMELHO } \\
\hline $\begin{array}{l}\text { Pressao } \\
\text { lkPol }\end{array}$ & Yav Media & $\begin{array}{l}\text { Dosvio } \\
\text { padrao }\end{array}$ & ச1? & Classilicacas \\
\hline 127,51 & 6,26 & 0,329 & 0,053 & bom \\
\hline 147,43 & 7,41 & 0,297 & 0,040 & bom \\
\hline 196,57 & 8,88 & 0,437 & 0,049 & bom \\
\hline 245,12 & 9,39 & 0,333 & 0,035 & bom \\
\hline 294,66 & 9,35 & 0,260 & 0,028 & bom \\
\hline 343,31 & 9,19 & 0,320 & 0,035 & bom \\
\hline 392,35 & 8,98 & 0,427 & 0,048 & bom \\
\hline \multicolumn{5}{|c|}{ cV médio $=$} \\
\hline \multicolumn{5}{|c|}{ MODELO:JET: REG FLUXO: VERDE; BOCAL:VIOLETA } \\
\hline Pressao & Voz Media & $\begin{array}{l}\text { Dosvo } \\
\text { podrao }\end{array}$ & 9४P & classificacă \\
\hline 127,51 & 6,45 & 0,369 & 0,057 & bom \\
\hline 147,43 & 7,53 & 0,312 & 0,041 & bom \\
\hline 196,57 & 8.96 & 0,463 & 0,052 & bom \\
\hline 245,12 & 9,45 & 0,351 & 0,037 & bom \\
\hline 294,66 & 9,42 & 0,268 & 0,028 & bom \\
\hline 343,31 & 9.24 & 0,336 & 0,036 & bom \\
\hline 392,35 & 8.98 & 0,448 & 0,050 & bom \\
\hline \multicolumn{5}{|c|}{ cv médio $=0,043$} \\
\hline \multicolumn{5}{|c|}{ MODELO:JET; REG. FLUXO: VERDE; BOCAL:AZUL } \\
\hline $\begin{array}{l}\text { Pressa } \\
\text { (KPal }\end{array}$ & VatMedia & $\begin{array}{l}\text { Desuio } \\
\text { padrao }\end{array}$ & GUF & $\begin{array}{c}\text { Classificaca } \\
\text { aBNT }\end{array}$ \\
\hline 127.51 & 6.63 & 0,270 & 0.041 & bom \\
\hline 147.43 & 7.63 & 0.301 & 0.040 & bom \\
\hline 196.57 & 9,01 & 0,441 & 0,049 & bom \\
\hline 245,12 & 9,43 & 0,313 & 0.033 & bom \\
\hline 294.66 & 9,39 & 0,279 & 0,030 & bom \\
\hline 343,31 & 9,21 & 0,340 & 0,037 & bom \\
\hline 392,35 & 8.96 & 0,452 & 0,050 & bom \\
\hline \multicolumn{5}{|c|}{ cv médio $=0,040 \quad$ bom } \\
\hline \multicolumn{5}{|c|}{ MODELO:JET; REG. FLUXO: VERDE; BOCAL:LARANJA } \\
\hline $\begin{array}{l}\text { Prossä } \\
\text { ropal }\end{array}$ & Vaz Media & Dosuio & $\mathrm{CVP}$ & $\begin{array}{l}\text { clossificaca } \\
\text { ABNT }\end{array}$ \\
\hline 127.51 & 6.85 & 0,390 & 0.057 & bom \\
\hline 147,43 & 7,86 & 0,410 & 0,052 & bom \\
\hline 196,57 & 9,10 & 0,473 & 0,052 & bom \\
\hline 245,12 & 9,47 & 0,338 & 0,036 & bom \\
\hline 294,66 & 9,41 & 0,291 & 0,031 & bom \\
\hline 343,31 & 9,08 & 0,741 & 0,082 & bom \\
\hline 392.35 & 8,99 & 0,436 & 0,049 & bom \\
\hline \multicolumn{4}{|c|}{ cv médio = } & bom \\
\hline
\end{tabular}


Tabela 11 - Vazão média observada para os bocais spinner com reguladores de fluxo preto a diferentes pressões e respectivos coeficientes de variação.

Piracicaba 1993

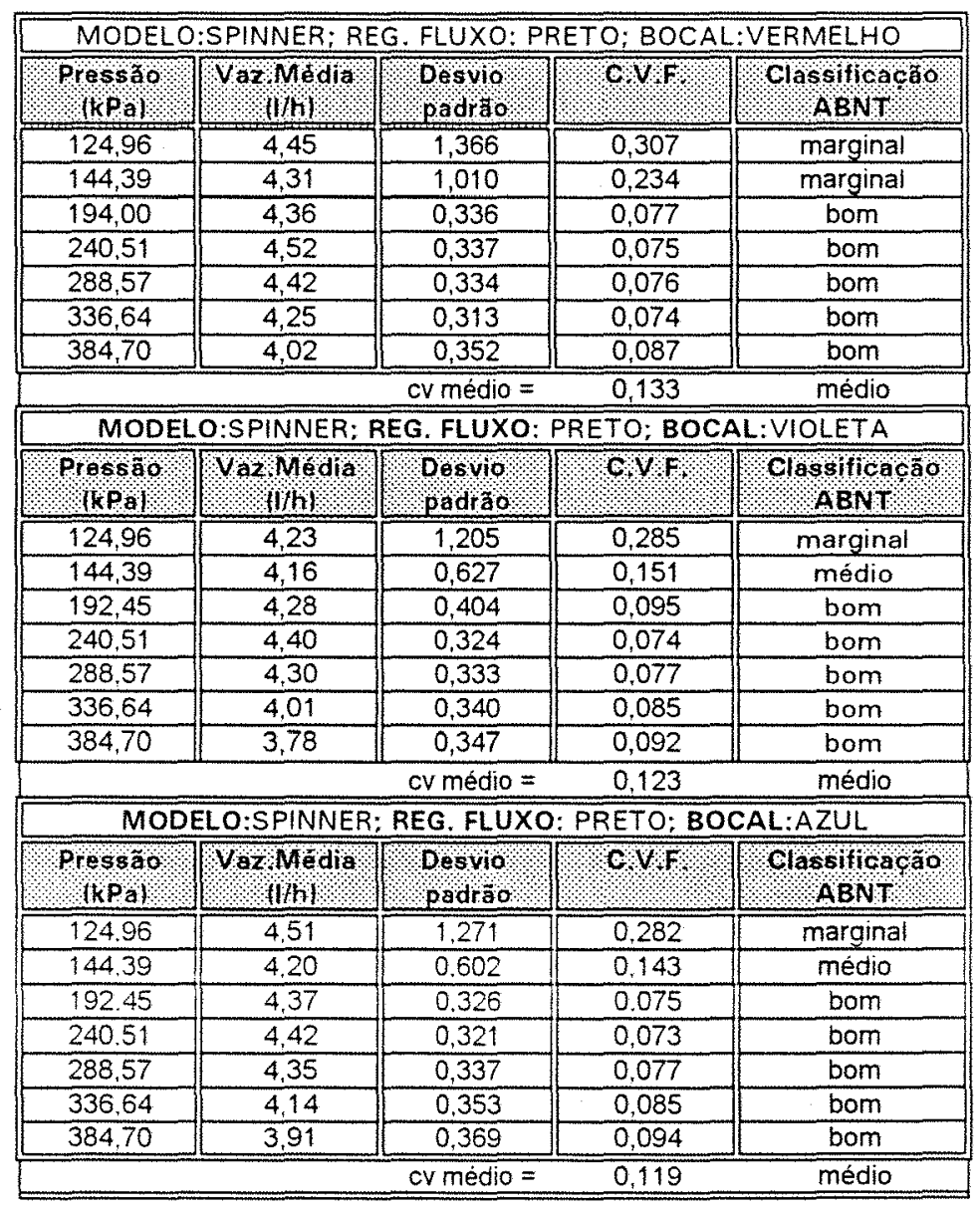


Tabela 12 - Vazão média observada para os bocais jet com reguladores de fluxo preto a diferentes pressões e respectivos coeficientes de variação. Piracicaba 1993

\begin{tabular}{|c|c|c|c|c|}
\hline \multicolumn{5}{|c|}{ MODELO:JET; REG. FLUXO: PRETO; BOCAL:VERMELHO } \\
\hline $\begin{array}{l}\text { Pressa a } \\
\text { (kPa) }\end{array}$ & Yar Media & Desuio & $\mathrm{CP}$ & $\mathrm{Clossificacso}^{\mathrm{ABNT}}$ \\
\hline 127,51 & 4,28 & 1,144 & 0,267 & marginal \\
\hline 147,43 & 4,04 & 0,472 & 0,118 & médio \\
\hline 196,57 & 4,23 & 0,341 & 0,081 & bom \\
\hline 245,12 & 4,39 & 0,325 & 0,074 & bom \\
\hline 294,66 & 4,28 & 0,342 & 0,080 & bom \\
\hline 343,31 & 4,08 & 0,342 & 0,084 & bom \\
\hline 392,35 & 3,85 & 0,345 & 0,090 & bom \\
\hline \multicolumn{5}{|c|}{ cr médio $=$} \\
\hline \multicolumn{5}{|c|}{ MODELO:JET; REG. FLUXO: PRETO; BOCAL:VIOLETA } \\
\hline $\begin{array}{l}\text { Pressao } \\
\text { (kPal }\end{array}$ & Vaz Media & $\begin{array}{l}\text { Desvio } \\
\text { podrao }\end{array}$ & 010 & $\begin{array}{l}\text { classificaca } \\
\text { ABNT }\end{array}$ \\
\hline 127,51 & 4,31 & 1,197 & 0,278 & marginal \\
\hline 147,43 & 4,10 & 0,495 & 0,121 & médio \\
\hline 196,57 & 4,31 & 0,303 & 0,070 & bom \\
\hline 245,12 & 4,36 & 0,298 & 0,068 & bom \\
\hline 294.66 & 4,24 & 0,305 & 0,072 & bom \\
\hline 343,31 & 4,03 & 0,326 & 0,081 & bom \\
\hline 392,35 & 3,82 & 0,338 & 0.088 & bom \\
\hline \multicolumn{5}{|c|}{ cr médio $=\quad 0,111 \quad$ médio } \\
\hline \multicolumn{5}{|c|}{ MODELO:JET: REG. FLUXO: PRETO; BOCAL:AZUL } \\
\hline $\begin{array}{l}\text { Pressao } \\
\text { (kPal }\end{array}$ & Varmedia & $\begin{array}{l}\text { Desulo } \\
\text { padrato }\end{array}$ & CVP & Clossificacso \\
\hline 127.51 & 4.28 & 1.205 & 0.281 & marginal \\
\hline$\$ 47.43$ & 4.12 & 0.533 & 0.129 & médio \\
\hline 196.57 & 4.33 & 0,329 & 0.076 & bom \\
\hline 245.12 & 4,39 & 0.321 & 0.073 & bom \\
\hline 294,66 & 4,28 & 0,327 & 0,076 & bom \\
\hline 343.31 & 4,04 & 0,346 & 0,086 & bom \\
\hline 392.35 & 3,80 & 0.362 & 0,095 & bom \\
\hline \multicolumn{5}{|c|}{ crmédio $=0,117 \quad$ médio } \\
\hline \multicolumn{5}{|c|}{ MODELO:JET; REG. FLUXO: PRETO; BOCAL:LARANJA } \\
\hline $\begin{array}{l}\text { Prossoo } \\
\text { (kpol }\end{array}$ & Yar Medra & $\begin{array}{l}\text { Dosvio } \\
\text { padrao }\end{array}$ & $\mathrm{CVP}$ & $\begin{array}{l}\text { Clossificaca } \\
\text { ABNT }\end{array}$ \\
\hline 127,51 & 4,25 & 1,101 & 0,259 & marginal \\
\hline 147,43 & 4,09 & 0,462 & 0,113 & médio \\
\hline 196,57 & 4,33 & 0,293 & 0,068 & bom \\
\hline 245.12 & 4,36 & 0,305 & 0,070 & bom \\
\hline 294,66 & 4,26 & 0,306 & 0,072 & bom \\
\hline 343,31 & 4,04 & 0,310 & 0,077 & bom \\
\hline 392.35 & 3,79 & 0,321 & 0.085 & bom \\
\hline \multicolumn{5}{|c|}{ cV médio $=\quad 0,106$} \\
\hline
\end{tabular}


Tabela 13 - Vazăo média observada para os reguladores de fluxo branco, verde e preto a diferentes pressões e respectivos coeficientes de variação. Piracicaba 1993

\begin{tabular}{|c|c|c|c|}
\hline \multicolumn{4}{|c|}{ MODELO:REGULADOR DE FLUXO BRANCO } \\
\hline Pressäo & Yaz Media. & pesvio & CVF \\
\hline 117,80 & 8,21 & 0,760 & 0,093 \\
\hline 127,51 & 9,15 & 0,646 & 0,071 \\
\hline 147,43 & 10.73 & 0.557 & 0,052 \\
\hline 196,57 & 12,66 & 0,540 & 0,043 \\
\hline 245,12 & 13,37 & 0,544 & 0,041 \\
\hline 294,66 & 13,40 & 0,644 & 0,048 \\
\hline 343,31 & 13,19 & 0,893 & 0,068 \\
\hline 392,35 & 12,79 & 1,103 & 0,086 \\
\hline \multicolumn{4}{|c|}{ cv médio $=$} \\
\hline \multicolumn{4}{|c|}{ MODELO: REGULADOR DE FLUXO VERDE } \\
\hline Pressấ & Yoz.Medía & Besvio & $\mathrm{OVF}$ \\
\hline$\overline{127,51}$ & $\overline{6,83}$ & 0,686 & 0,100 \\
\hline 147,43 & 7.91 & 0,517 & 0,065 \\
\hline 196,57 & 9,28 & 0,454 & $\overline{0,049}$ \\
\hline 245,12 & 9.66 & 0,319 & 0.033 \\
\hline 294,66 & 9,65 & 0,315 & 0,033 \\
\hline 343.31 & 9.39 & 7.175 & 0,649 \\
\hline 392,35 & 9.23 & 0,443 & 0,048 \\
\hline \multicolumn{4}{|c|}{ CV médio $=$} \\
\hline \multicolumn{4}{|c|}{ MODELO: REGULADOR DE FLUXO PRETO } \\
\hline $\begin{array}{l}\text { Pressão } \\
\text { (kPa) }\end{array}$ & Yaz Media & Desvio & $0 \mathrm{QF}$ \\
\hline 127,51 & 3,39 & 1,269 & 0,375 \\
\hline 147,43 & 3,65 & 1,044 & 0,286 \\
\hline 196,57 & 4,08 & 0,716 & 0,176 \\
\hline 245,12 & 4,32 & 0,556 & 0,129 \\
\hline 294,66 & 4,29 & 0,409 & 0,095 \\
\hline 343,31 & 4,16 & 0,461 & 0,111 \\
\hline 392,35 & 4,08 & 0,489 & 0,120 \\
\hline \multicolumn{4}{|c|}{ CV médio = } \\
\hline
\end{tabular}




\subsection{DETERMINAÇÃO DO PERFIL DE DISTRIBUIÇÃO DA ÁGUA}

Analisando os perfis de distribuição de água pelos microaspersores do tipo spinner com bocais vermelho, violeta e azul, sem o uso de reguladores de fluxo; pode-se verificar que houve uma concentração dos maiores valores de precipitação bem próximo ao microaspersor, reduzindo-se a medida que se afastava destes (Figura 18).

Os valores de precipitação média ponderadas ocorreram a aproximadamente 2,$50 ; 2,30$ e $2,20 \mathrm{~m}$ de distância para os microaspersores com bocais vermelho, violeta e azul respectivamente.

LIMA \& ALVES (1994) estudando diversos difusores e microaspersores fabricados no Brasil, Israel e Estados Unidos concluíram que no caso dos microaspersores houve grande precipitação próximo a haste de sustentação dos mesmos.

Os valores de diâmetros de alcance médio encontram-se na Tabela 14. Verifica-se que os valores encontrados para os bocais sem reguladores de fluxo vermelho, violeta e azul foram inferiores aos divulgados pelo catálogo do fabricante. Sendo que o bocal violeta apresentou o maior valor do diâmetro de alcance. Os valores do diâmetro de alcance médio a $147,43 \mathrm{kPa}$ encontrados foram 6,$50 ; 6,60 \mathrm{e}$ $5,80 \mathrm{~m}$ para os bocais vermelho, violeta e azul, enquanto que os valores anunciados pelo fabricante foram de 7,$6 ; 6,2$ e $6,0 \mathrm{~m}$ respectivamente. 
Tabela 14 - Diâmetro de alcance médio para os microaspersores spinner operando á $147,13 \mathrm{kPa}(15$ m.c.a.)

\begin{tabular}{|c|c|c|c|}
\hline \multicolumn{4}{|c|}{ BOCAIS SPINNER. } \\
\hline REGUIADOR & VERM & YIOIFI & 1740 \\
\hline DE FLUKO & & & \\
\hline \multicolumn{4}{|l|}{ sem regulador } \\
\hline D. alcance (m) & 6,50 & 6,60 & 5,80 \\
\hline \multicolumn{4}{|l|}{ branco } \\
\hline D. alcance $(m)$ & 5,24 & 5,44 & 5,36 \\
\hline \multicolumn{4}{|l|}{ verde } \\
\hline D. alcance (m) & 5,05 & 5,29 & 5,09 \\
\hline \multicolumn{4}{|l|}{ preto } \\
\hline D. alcance (m) & 5,00 & 5,20 & 5,00 \\
\hline
\end{tabular}

Quando operado a $147,13 \mathrm{kPa}$ o microaspersor spinner, com bocal violeta, associado aos reguladores de fluxo branco, verde e preto (Figuras 19, 20 e 21) superou o valor de precipitação média para o bocal vermelho nas mesmas condições, embora segundo dados do fabricante e dos dados obtidos nos ensaios de vazão o bocal vermelho tenha superado os valores de vazão médio do bocal violeta.

Com o regulador de fluxo branco houve uma tendência a estabilização da precipitação em torno dos $0,5 \mathrm{~mm} / \mathrm{h}$ no trecho compreendido entre 0,80 e $2,0 \mathrm{~m}$ de distância do microaspersor para os três bocais enquanto que os diâmetros de alcance efetivo diminuíram para 5,$24 ; 5,44$ e $5,36 \mathrm{~m}$, respectivamente. 
Quando os mesmos bocais operaram com o regulador de fluxo verde, houve uma maior desuniformidade em seus perfis de distribuição, tendendo a haver uma estabilização no valor da precipitação em torno dos $0,4 \mathrm{~mm} / \mathrm{h}$ no trecho compreendido entre 0,6 e 1,6 m de distância do microaspersor. Os diâmetros de alcance desses bocais, diminuíram para 5,05; 5,29 e 5,09 m, nessa seqüência.

$\mathrm{E}$, finalmente, os bocais vermelho, violeta e azul, quando combinados com o regulador de fluxo preto, apresentaram uma queda brusca nos valores médios de precipitação. Tal queda ocorreu a partir de $0,40 \mathrm{~m}$ do microaspersor, com os valores de precipitação oscilando em torno dos 0,1 a $0,2 \mathrm{~mm} / \mathrm{h}$ e com o diâmetro de alcance de 5,$00 ; 5,20$ e $5,00 \mathrm{~m}$, para os bocais antes mencionados, obedecendo a mesma seqüência. 


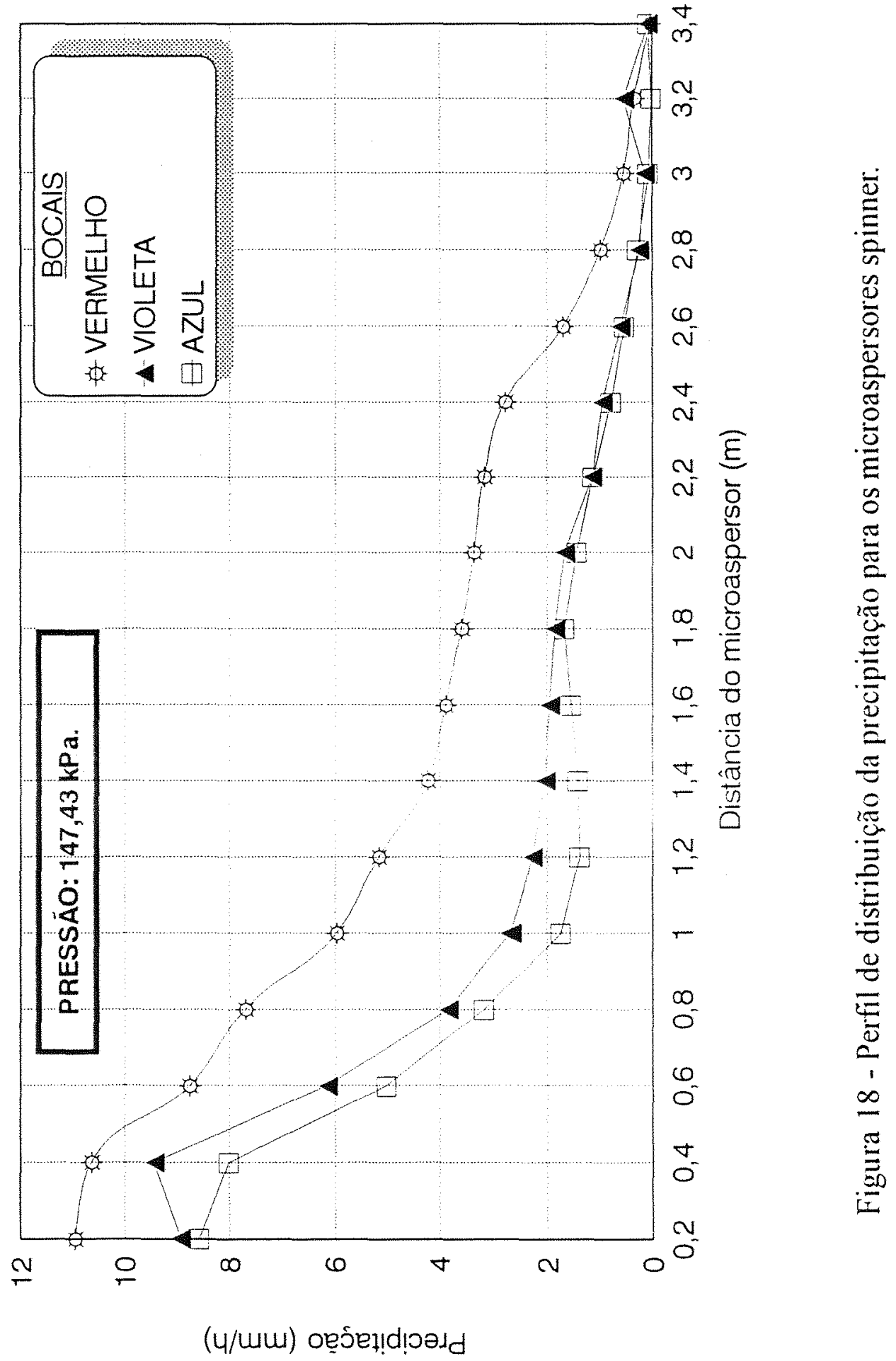




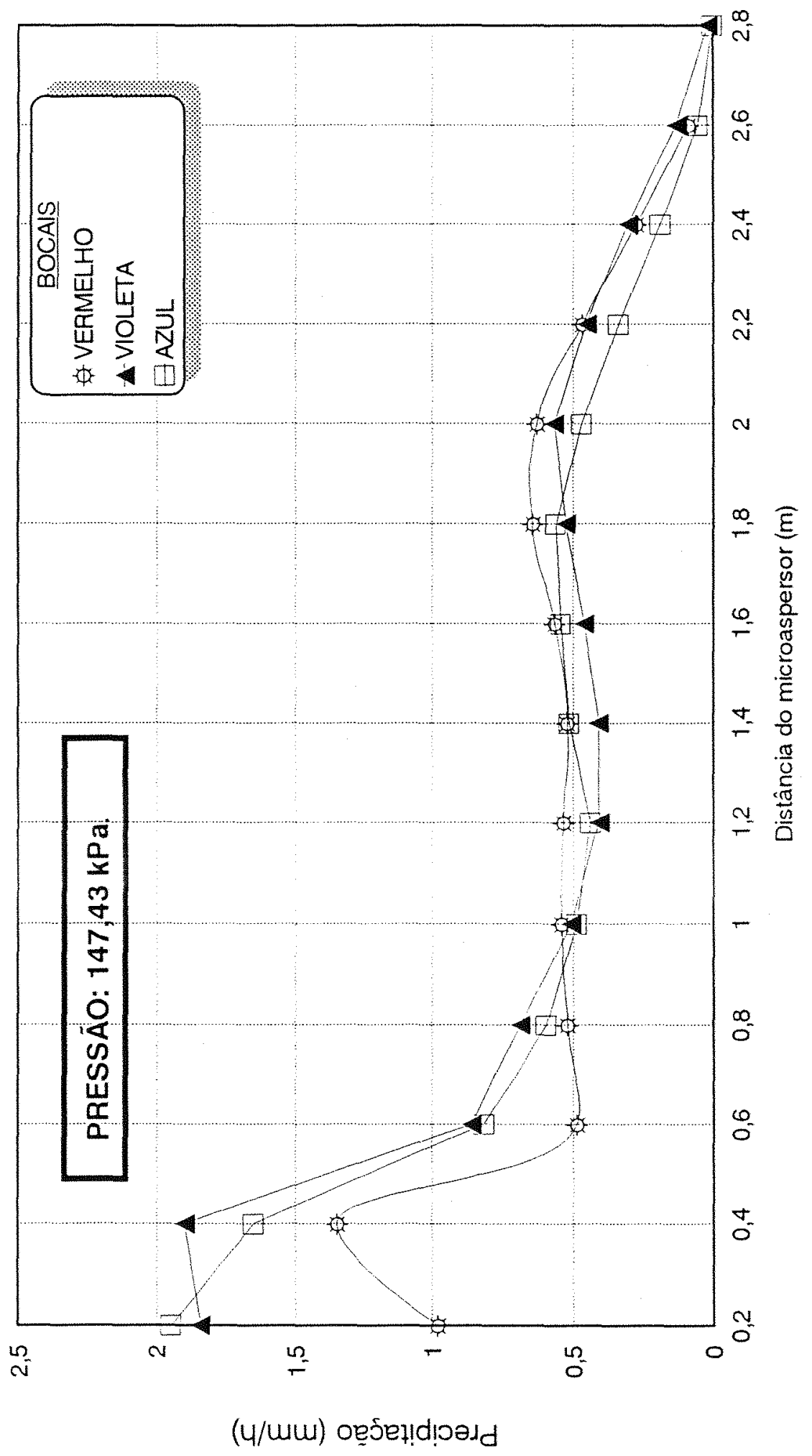

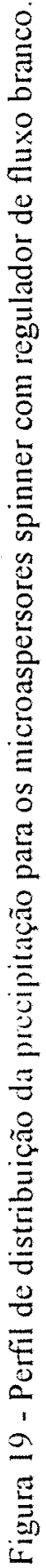




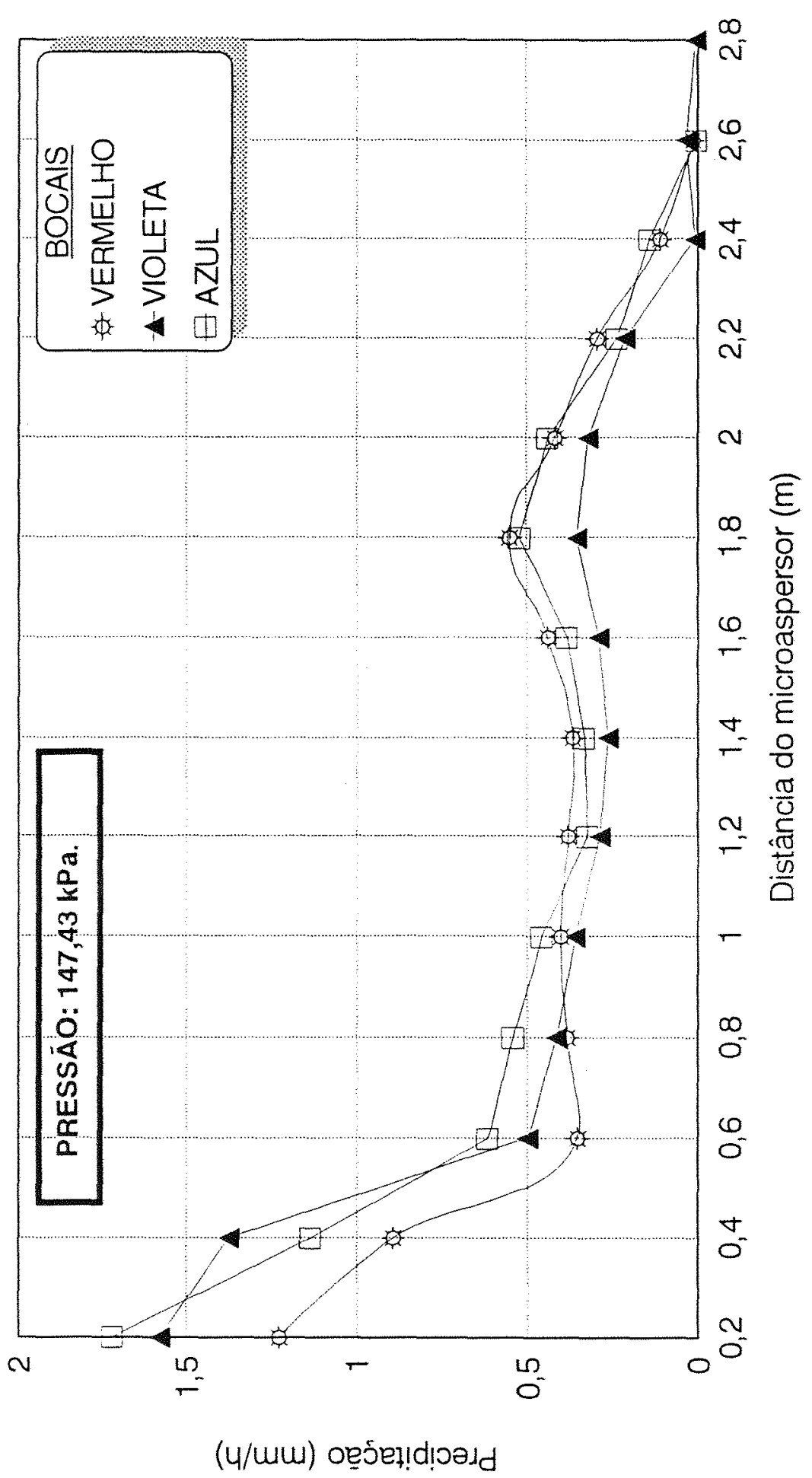

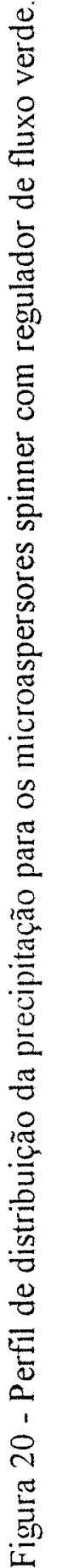




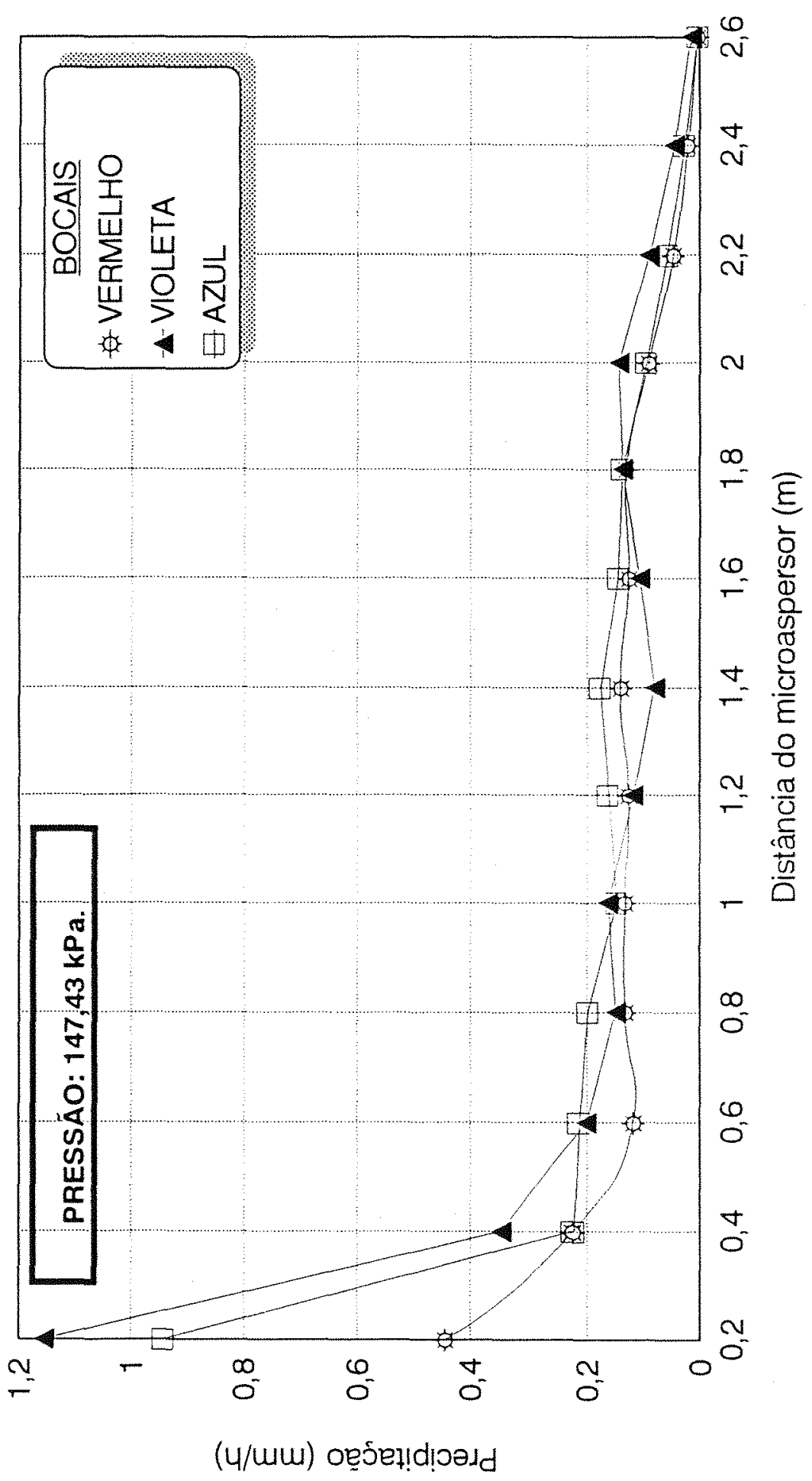

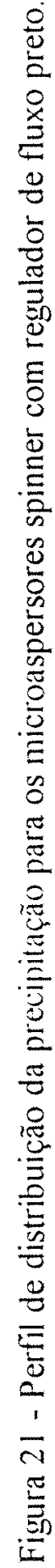




\subsection{DETERMINAÇÃo DA DISTRIBUiÇÃo ESPACIAL DE ÁGUA DOS MICROASPERSORES.}

\subsection{1 - Microaspersor spinner}

Com os dados de precipitação média dos microaspersores tipo spinner utilizou-se um software disponivel no mercado para a elaboração de um gráfico tridimensional onde se pode verificar a distribuição espacial de água pelos mesmos.

Analisando os gráficos de distribuição de água pelo spinner, pode-se verificar a ocorrência de uma concentração maior de água próximo aos microaspersores. Verificou-se que quando se comparava os bocais sem reguladores de fluxo com os bocais associados aos reguladores de fluxo branco, verde e preto, a altura de lamina aplicada. decrescia na seqüência acima citada (Figuras 22 a 33).

Outro aspecto que merece destaque é o fato dos microaspersores vermelho, violeta e azul apresentarem uma diferença, aparentemente, pouco significativa com relação a altura de água precipitada quando esses bocais operavam com os mesmos reguladores de fluxo, sejam eles branco, verde ou preto. 


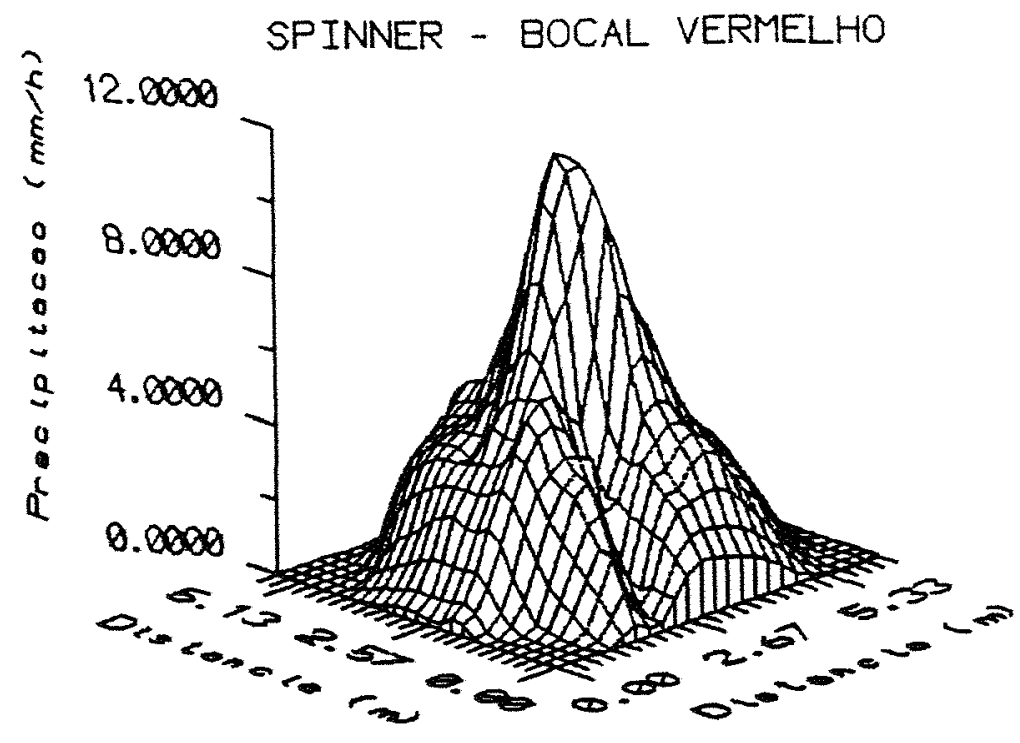

(A)

SPINNER - BOCAL VERMELHO

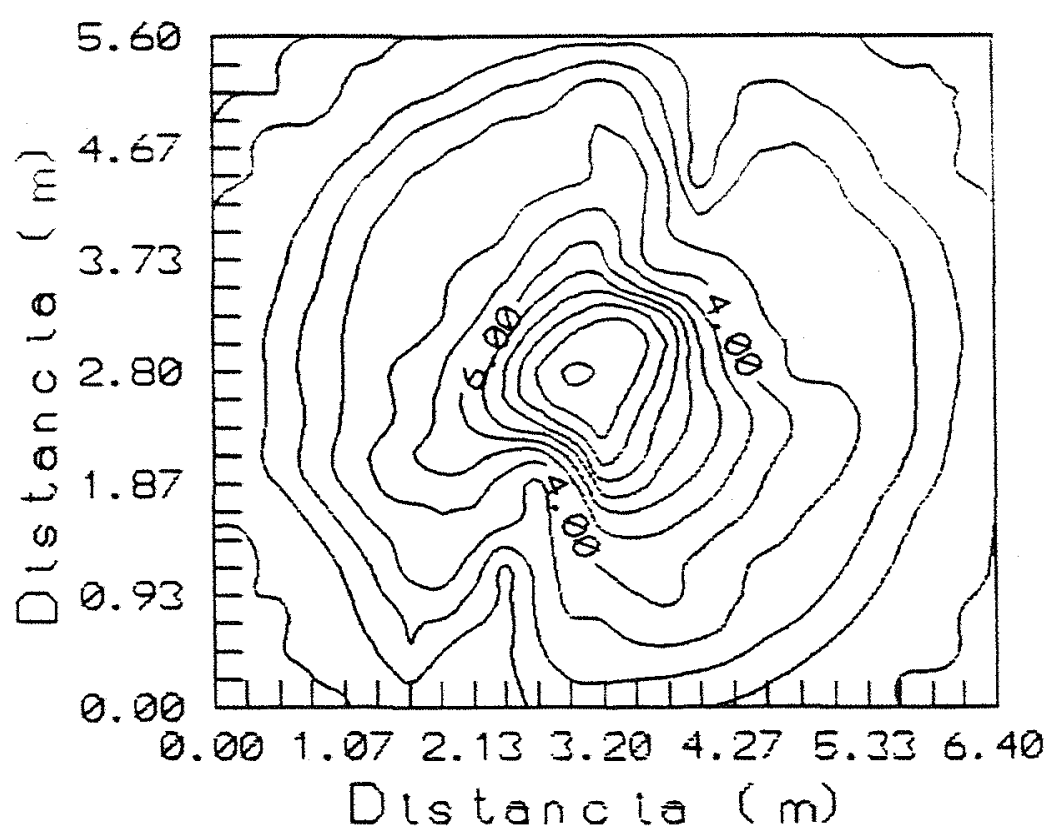

(B)

* Microaspersor nas coordenadas $(3,20 ; 2,80)$

Figura 22 - Distribuição espacial da água apresentada pelo microaspersor spinner com bocal vermelho operando $151,06 \mathrm{kPa}$. - (A) vista tridimensional ; $(B)$ vista superior 


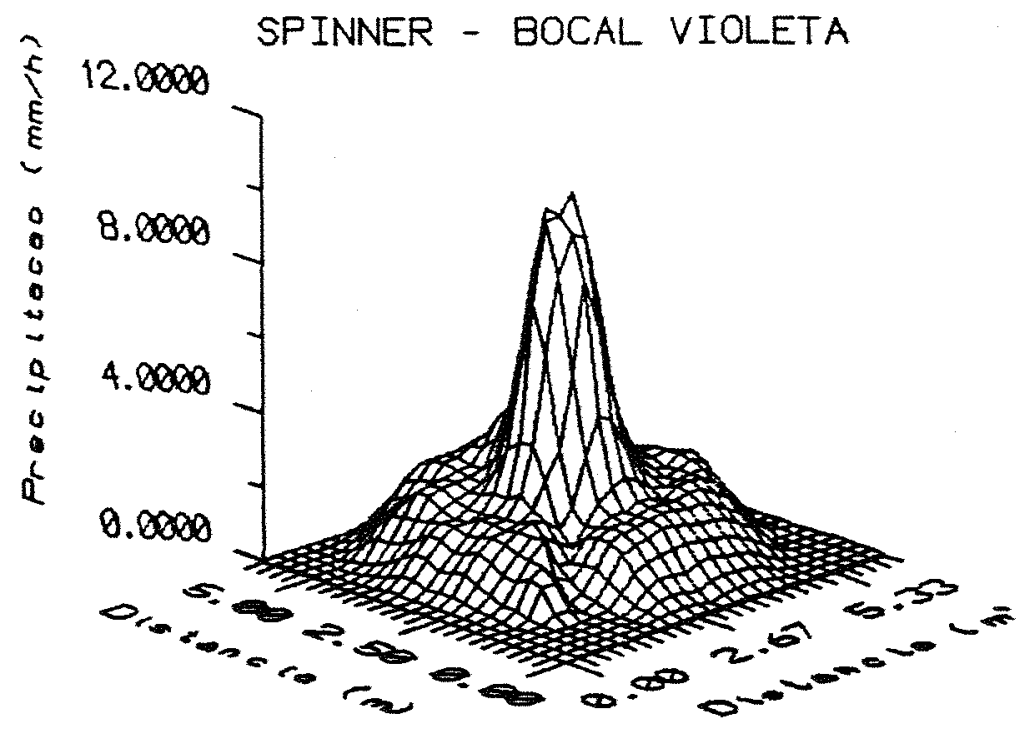

(A)

SPINNER - BOCAL VIOLETA

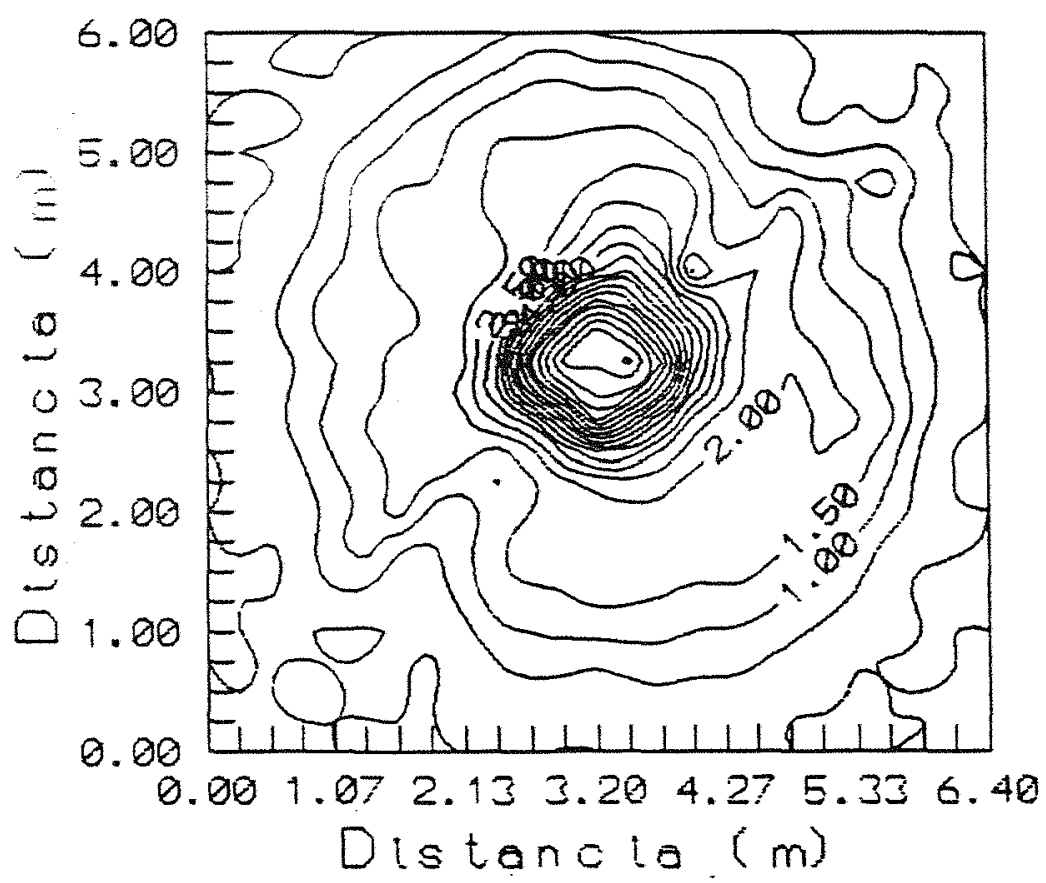

(B)

Figura 23 - Distribuição espacial da água apresentada pelo microaspersor spinner com bocal violeta operando $151,06 \mathrm{kPa}$. - (A) vista tridimensional ; (B) vista superior

* Microaspersor nas coordenadas $(3,20 ; 3,25)$ 


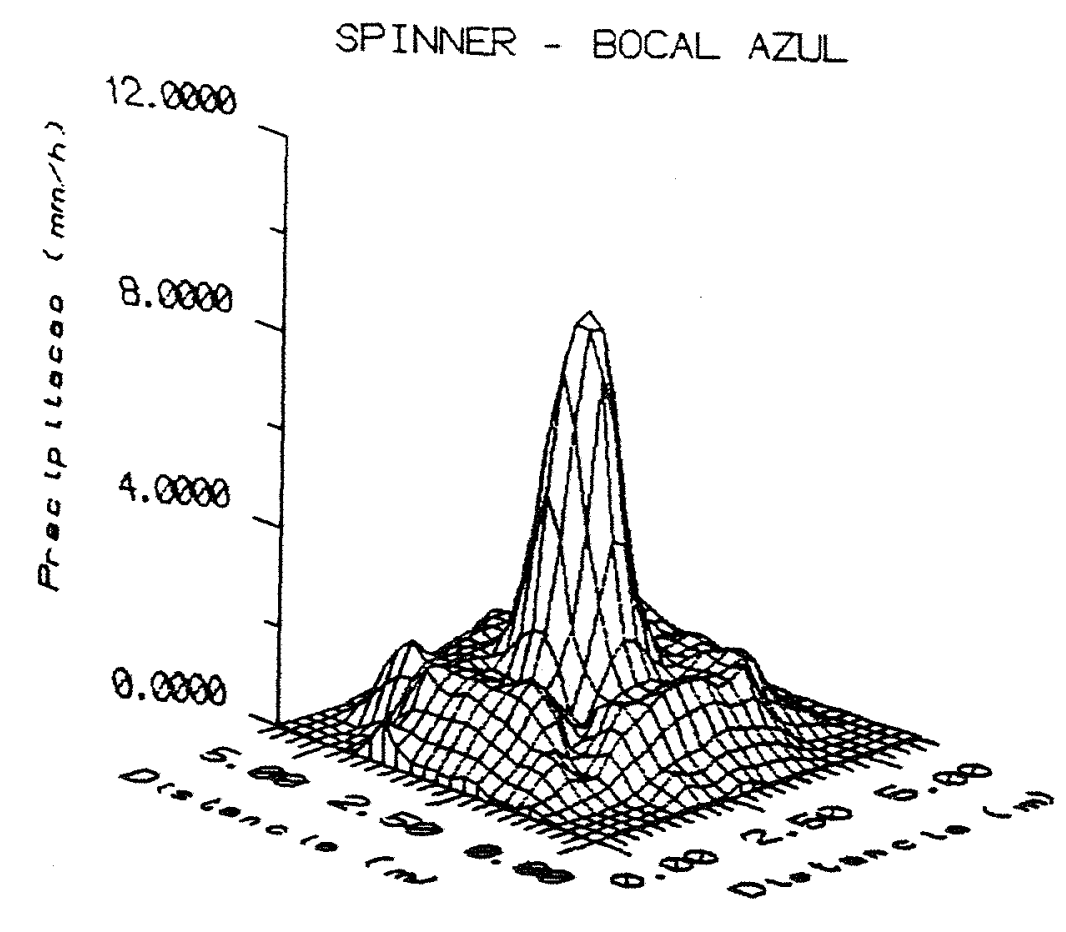

(A)

SPINNER - BOCAL AZUL

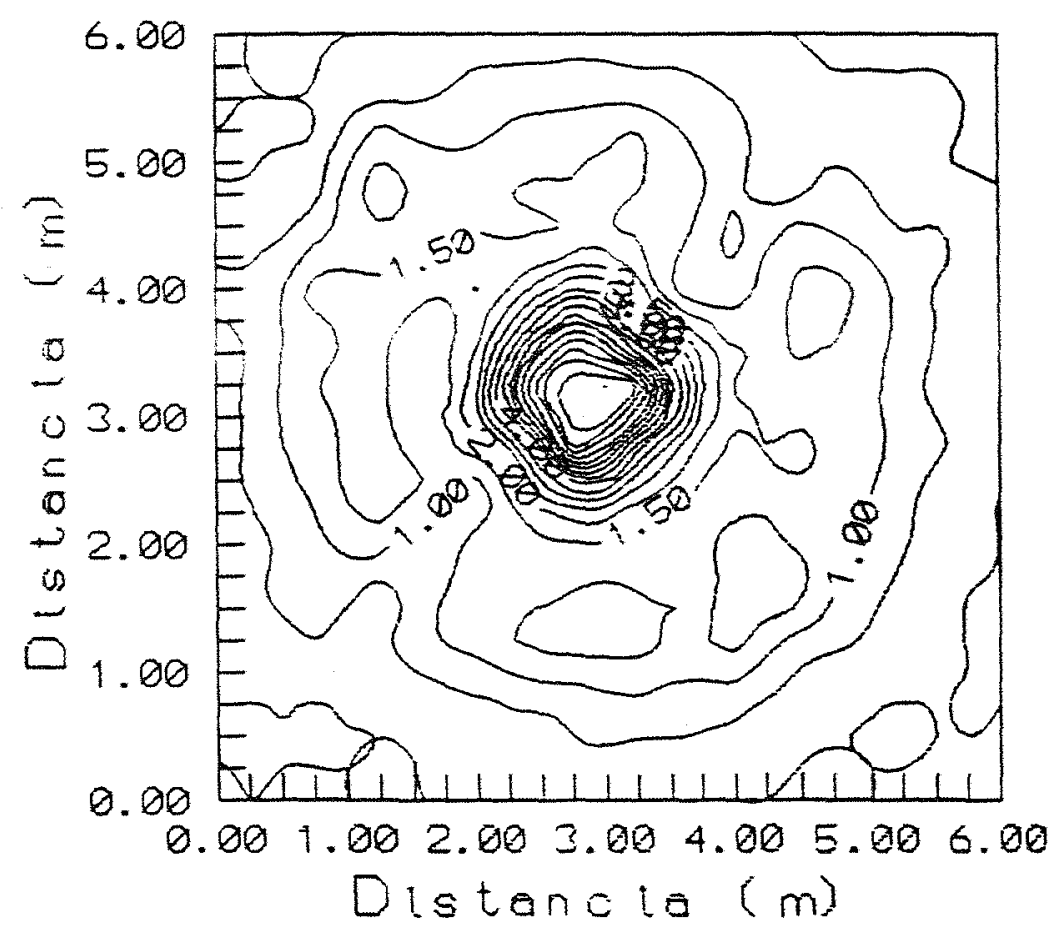

(B)

- Microaspersor nas coordenadas $(2,75 ; 3,25)$

Figura 24 - Distribuição espacial da água apresentada pelo microaspersor spinner com bocal azul operando $151,06 \mathrm{kPa}$. - (A) vista tridimensional ; $(B)$ vista superior 
SPINNER - BOCAL VERMELHO - REG. F. BRANCO

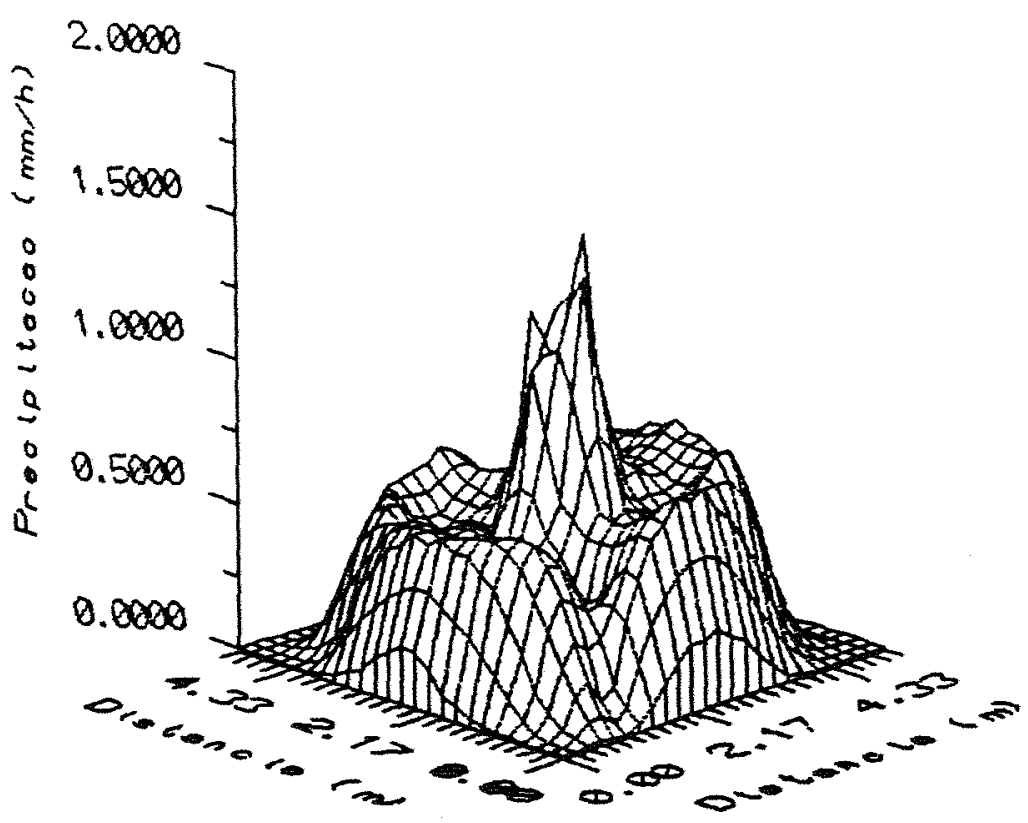

SPINNER - BOCAL VERMELHO - REG. F. BRANCO

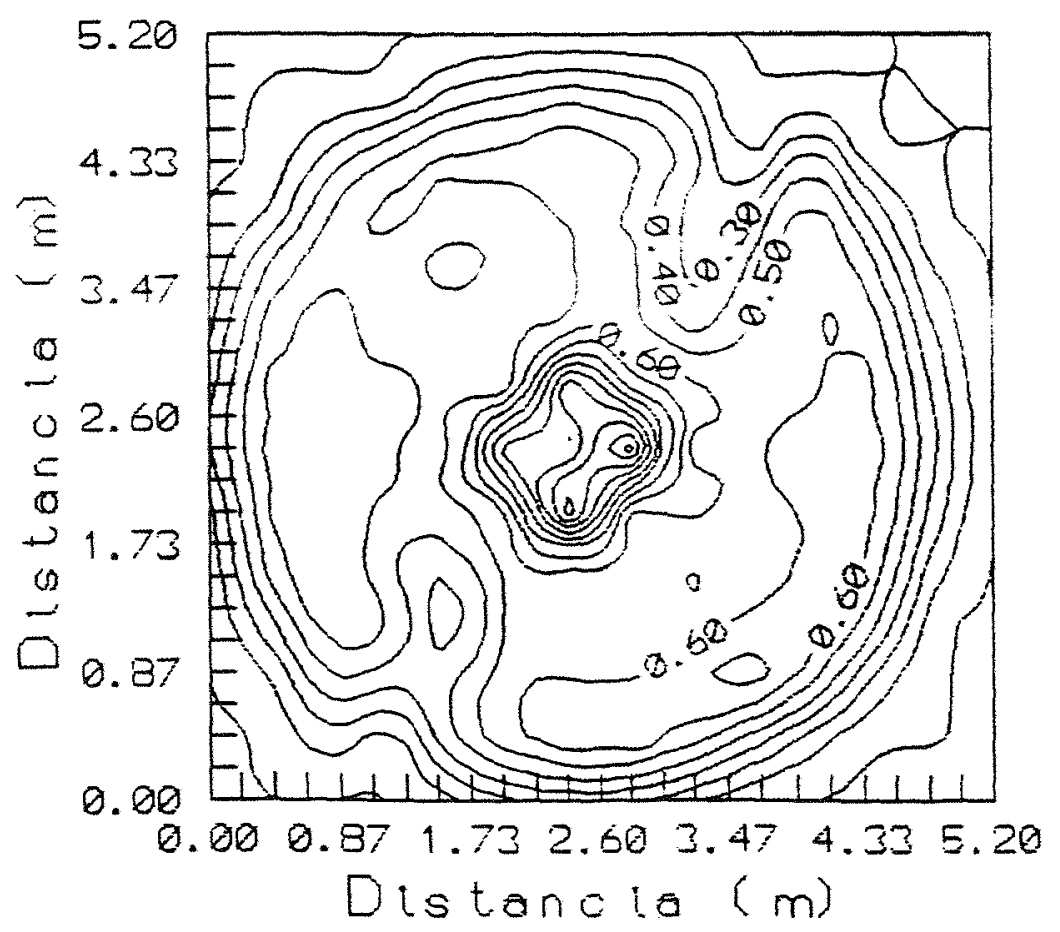

Figura 25 - Distribuição espacial da água apresentada pelo microaspersor spinner com bocal vermelho e regulador de fluxo branco operando 151,06 kPa. - (A) vista tridimensional ; (B) vista superior 
SPINNER - BOCAL VIOLETA - REG. F. BRANCO

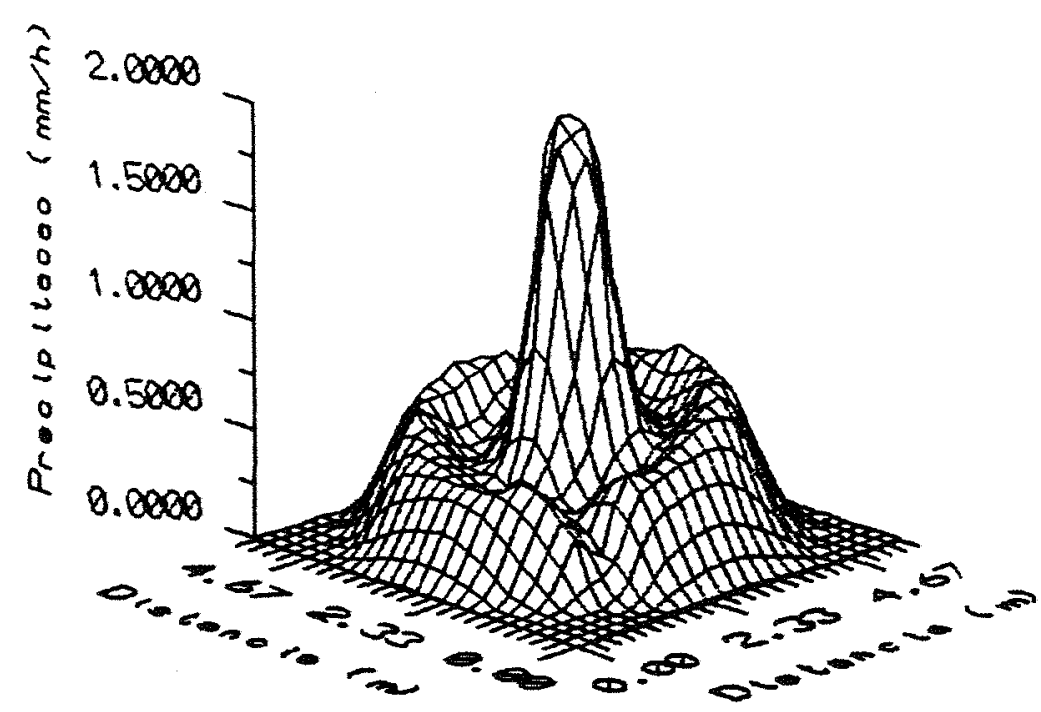

SPINNER - BOCAL VIOLETA - REG. F. BRANCO

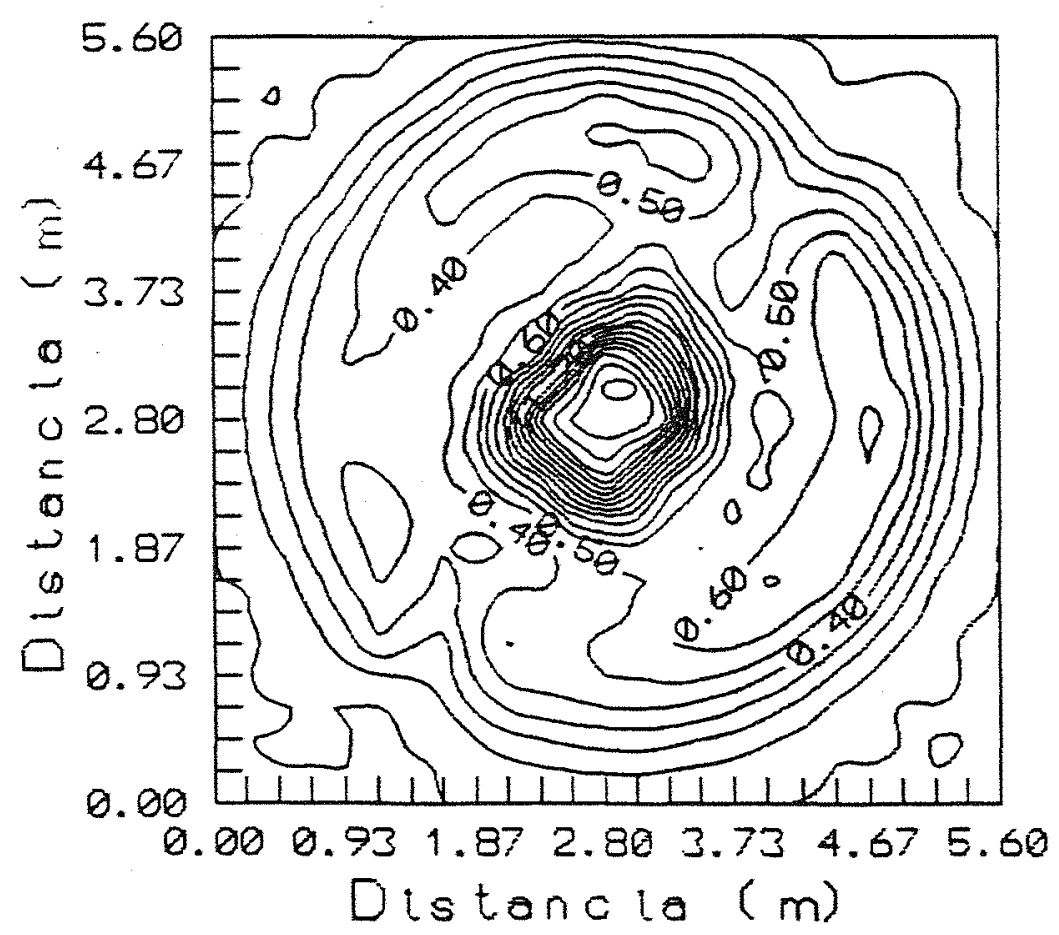

(B)

* Microaspersor nas coordenadas $(2,80 ; 2,80)$

Figura 26 - Distribuição espacial da água apresentada pelo microaspersor spinner com bocal violeta e regulador de fluxo branco operando $151,06 \mathrm{kPa}$. - (A) vista tridimensional ; (B) vista superior 


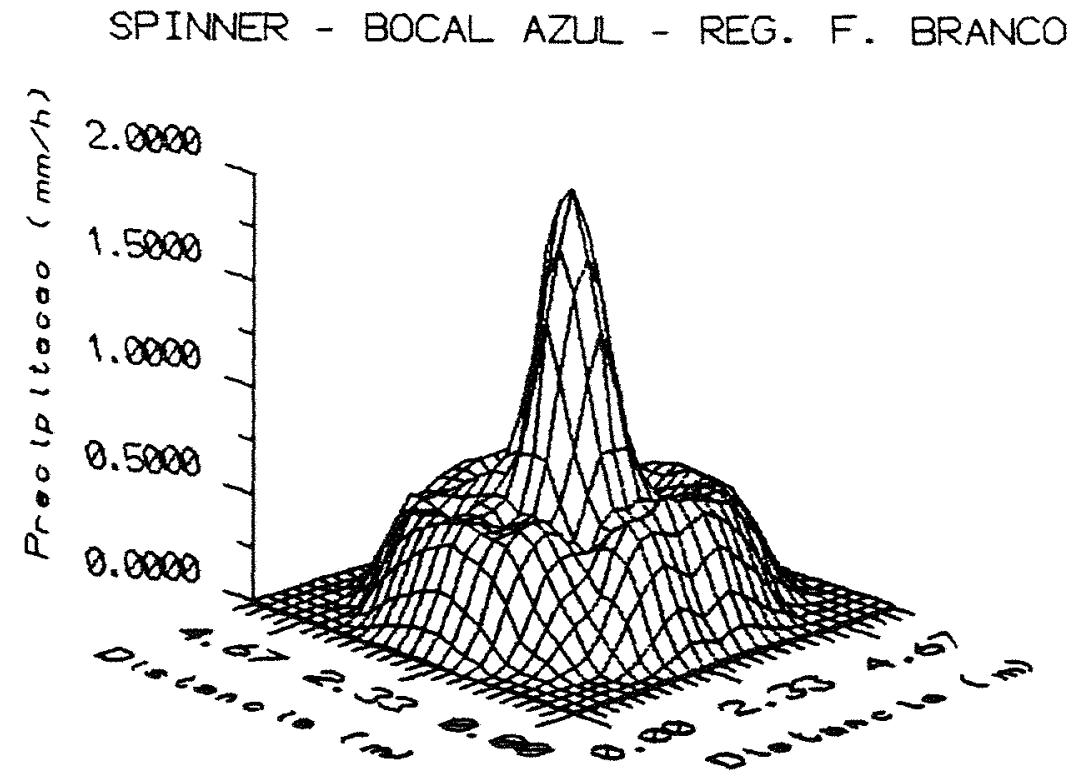

SPINNER - BOCAL AZUL - REG. F. BRANCO

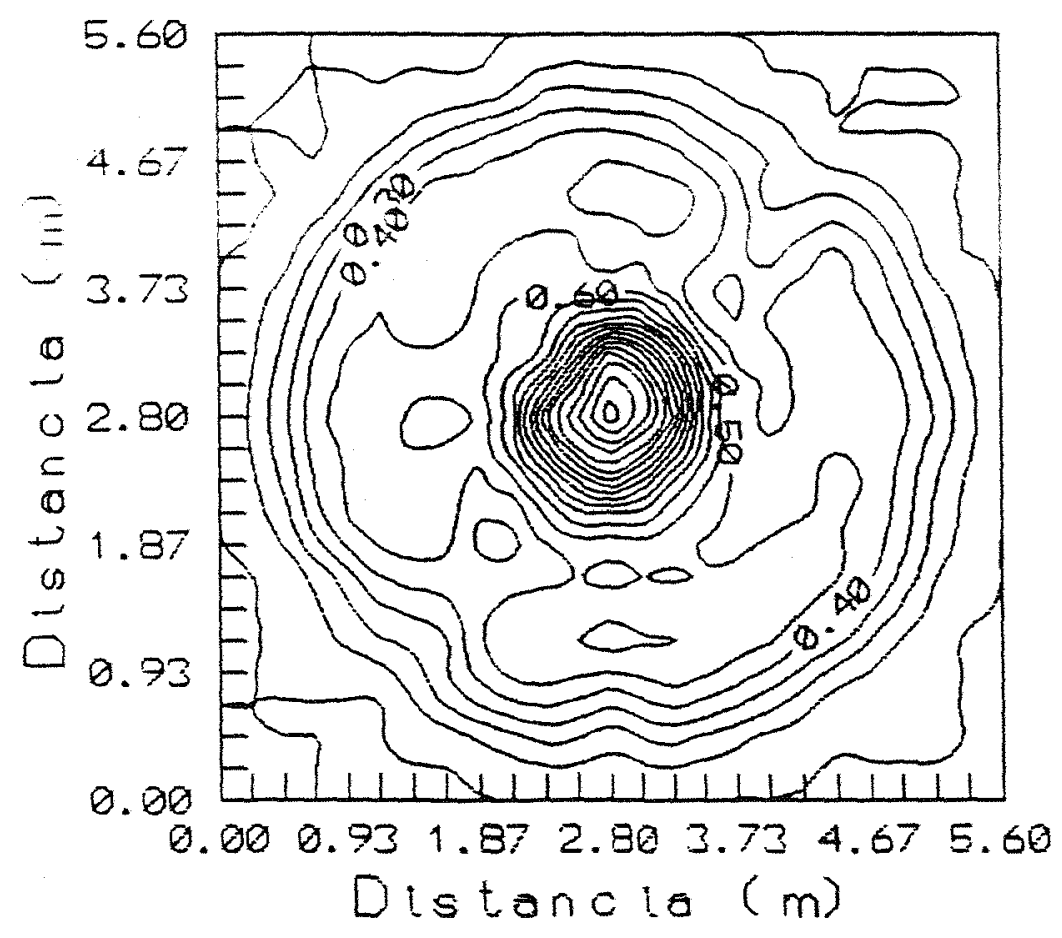

(B)

* Microaspersor nas coordenadas $(2,80 ; 2,80)$

Figura 27 - Distribuição espacial da água apresentada pelo microaspersor spinner com bocal azul e regulador de fluxo branco operando $151,06 \mathrm{kPa}$ - (A) vista tridimensional ; (B) vista superior 


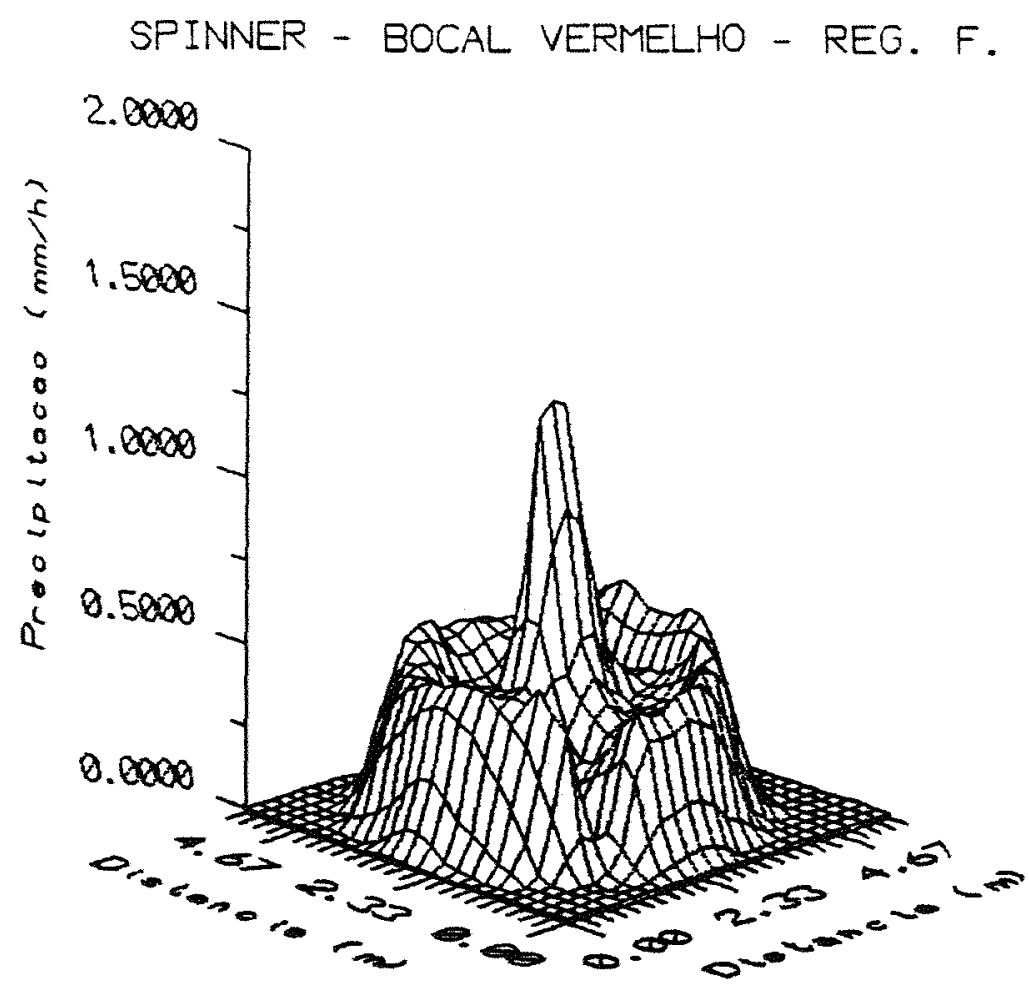

SPINNER - BOCAL VERMELHO - REG. F. VERDE

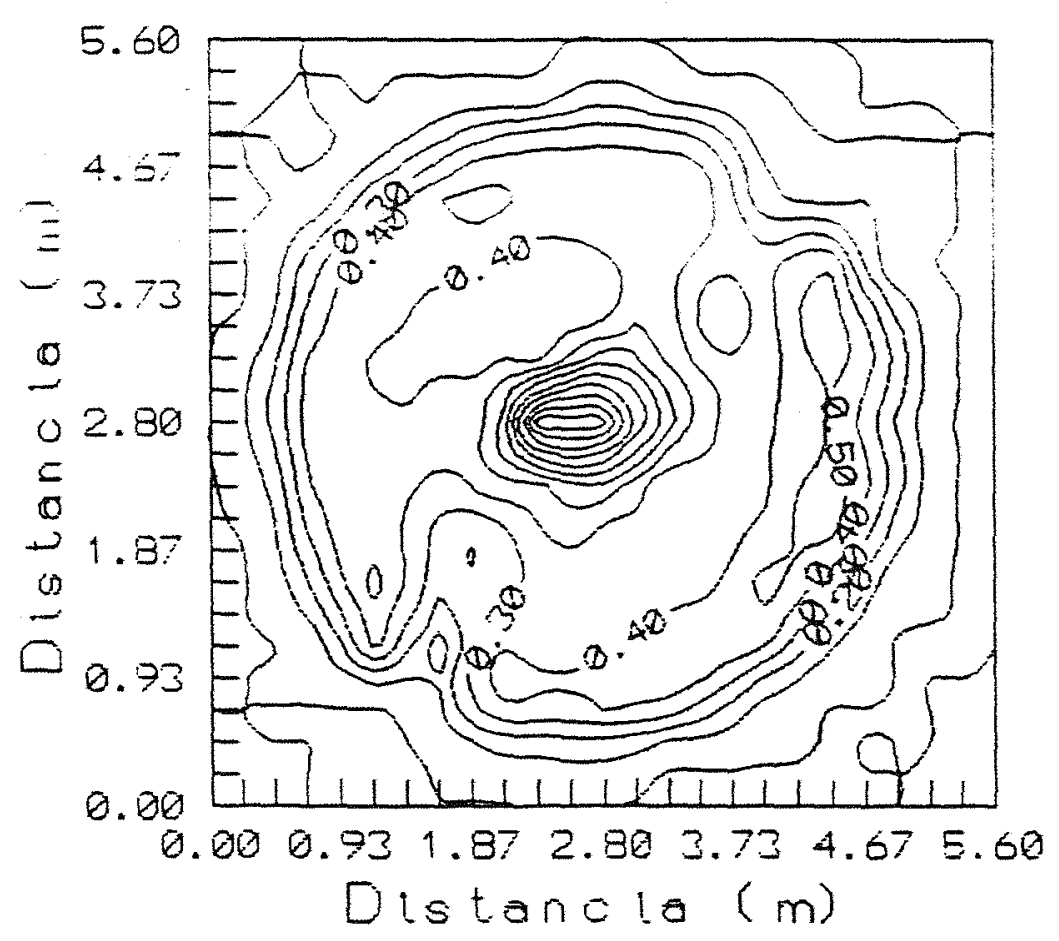

(B)

* Microaspersor nas coordenadas $(2,57 ; 2,80)$

Figura 28 - Distribuição espacial da água apresentada pelo microaspersor spinner com bocal vermelho e regulador de fluxo verde operando $151,06 \mathrm{kPa}$ - (A) vista tridimensional ; (B) vista superior 
SPINNER - BOCAL VIOLETA - REG. F. VERDE

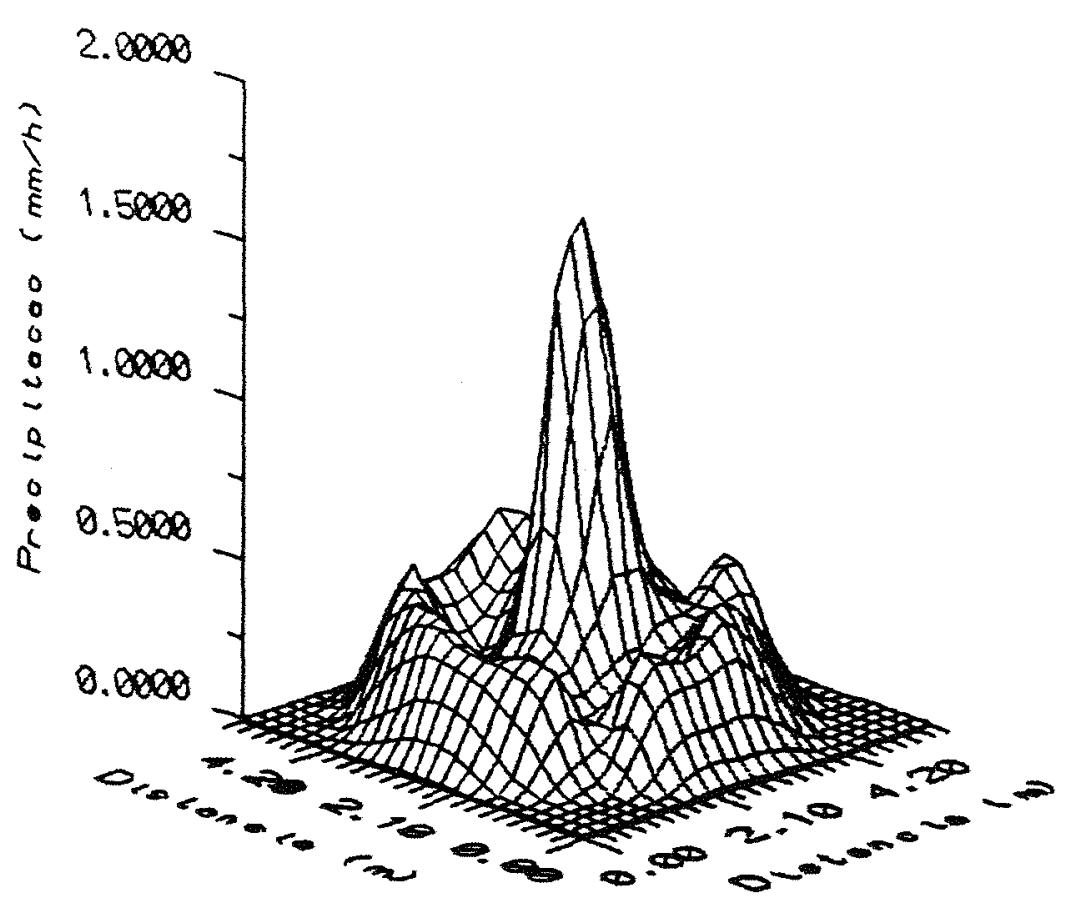

SPINNER - BOCAL VIOLETA - REG. F. VERDE

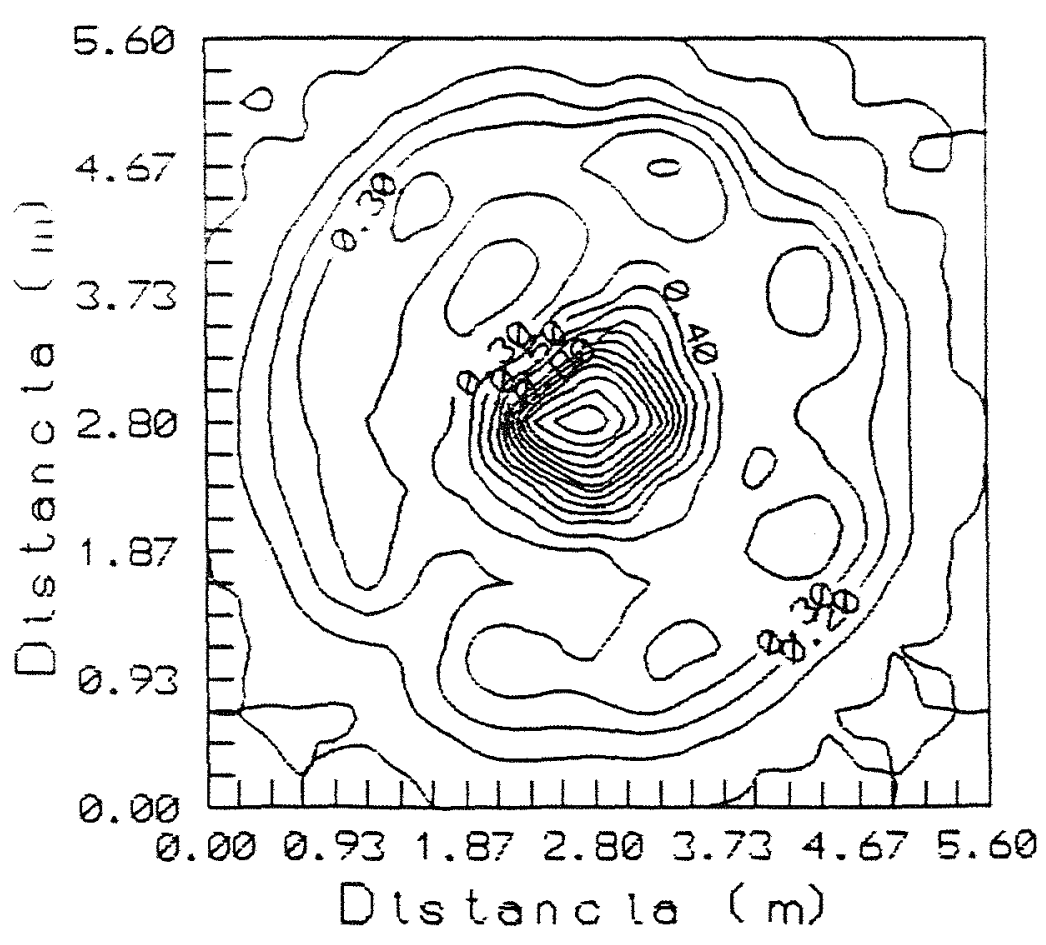

(B)

* Microaspersot nas coordenadas $(2,80 ; 2,80)$,

Figura 29 - Distribuição espacial da água apresentada pelo microaspersor spinner com bocal violeta e regulador de fluxo verde operando $151,06 \mathrm{kPa}$. - (A) vista tridimensional ; (B) vista superior 
SPINNER - BOCAL AZUL - REG. F. VERDE

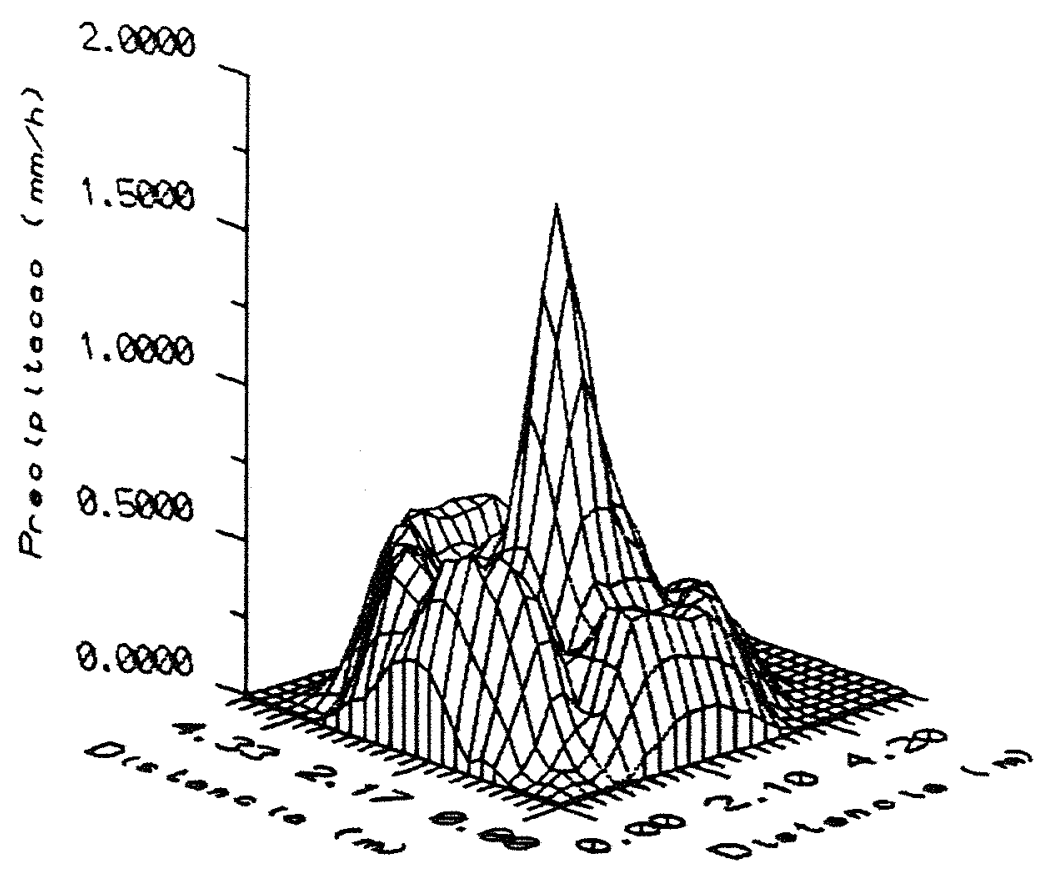

(A)

SPINNER - BOCAL AZUL - REG. F. VERLE

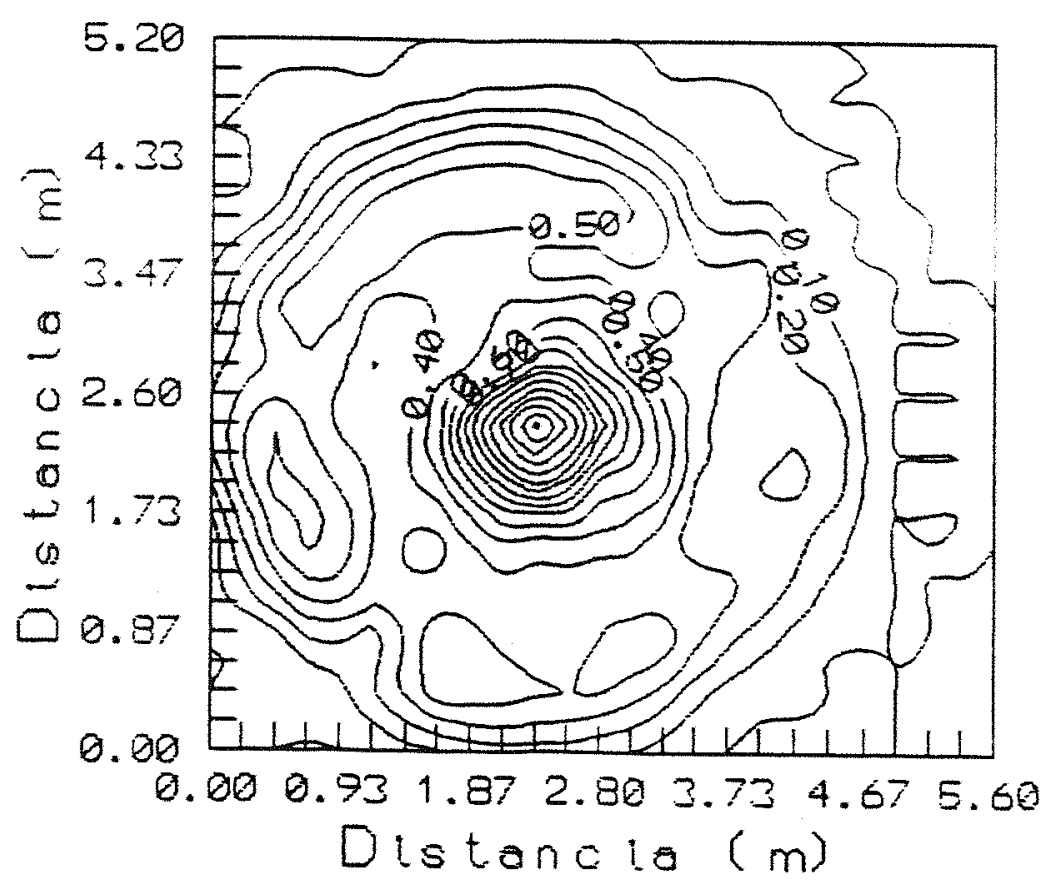

(B)

- Microaspersor: nas coorcienadas i $(2,33 ; 2,38)$

Figura 30 - Distribuição espacial da água apresentada pelo microaspersor spinner com bocal azul e regulador de fluxo verde operando $151,06 \mathrm{kPa}$ - (A) vista tridimensional ; (B) vista superior 


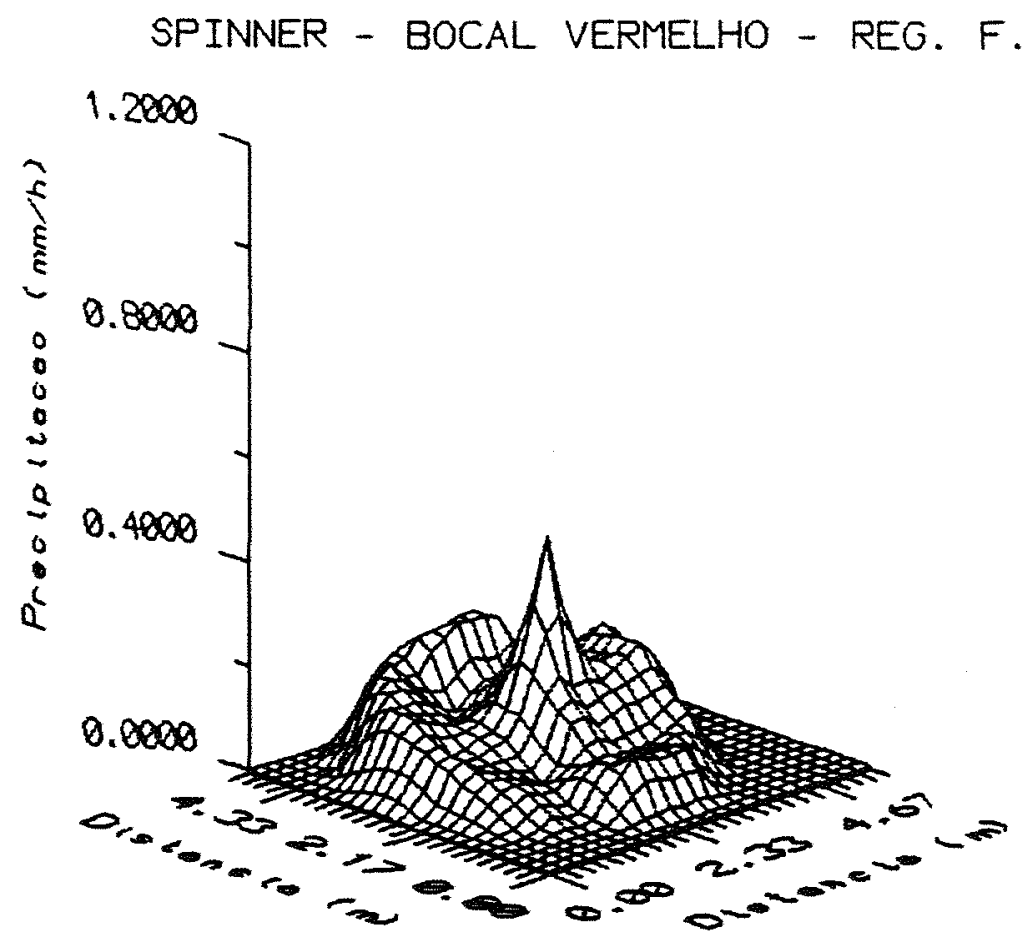

SPINNER - BOCAL VERMELHO - REG. F. FRETO

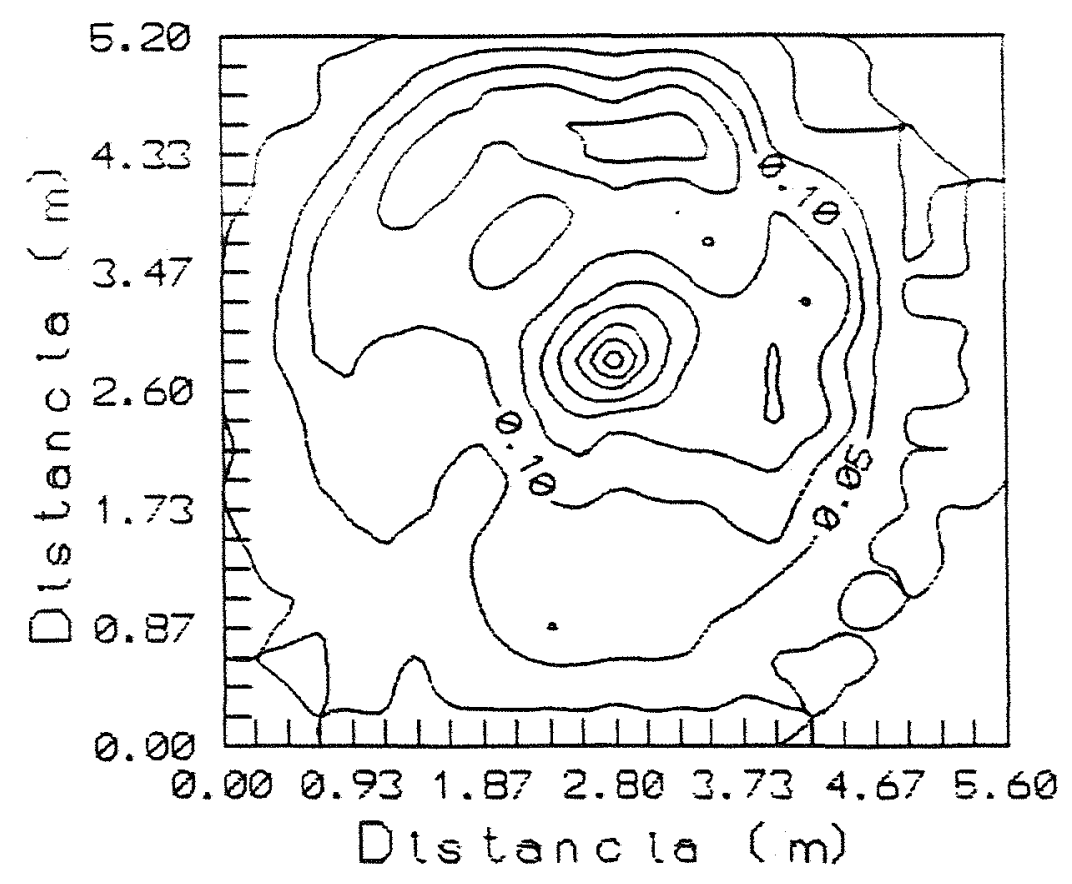

(B)

Figura 31 - Distribuição espacial da água apresentada pelo microaspersor spinner com bocal vermelho e regulador de fluxo preto operando $151,06 \mathrm{kPa}$ - (A) vista tridimensional ; (B) vista superior 
SPINNER - BOCAL VIOLETA - REG. F. PRETO

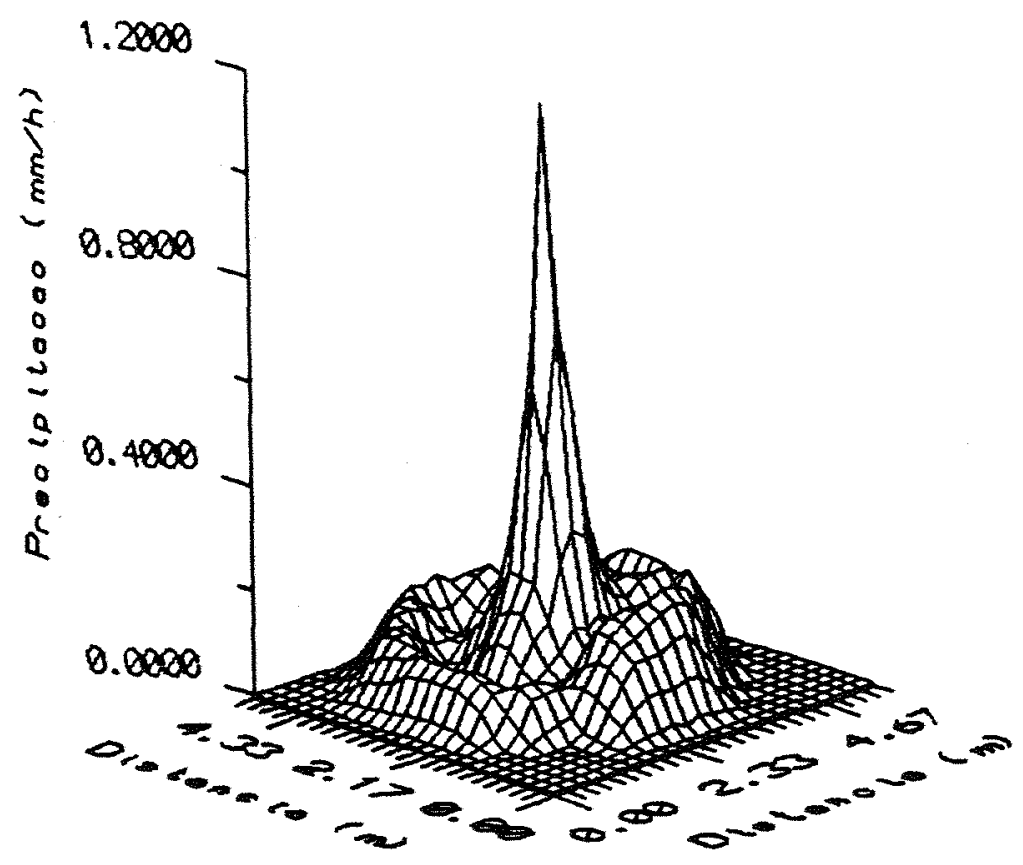

(A)

SPINNER - BOCAL VIOLETA - REG. F. PRETO

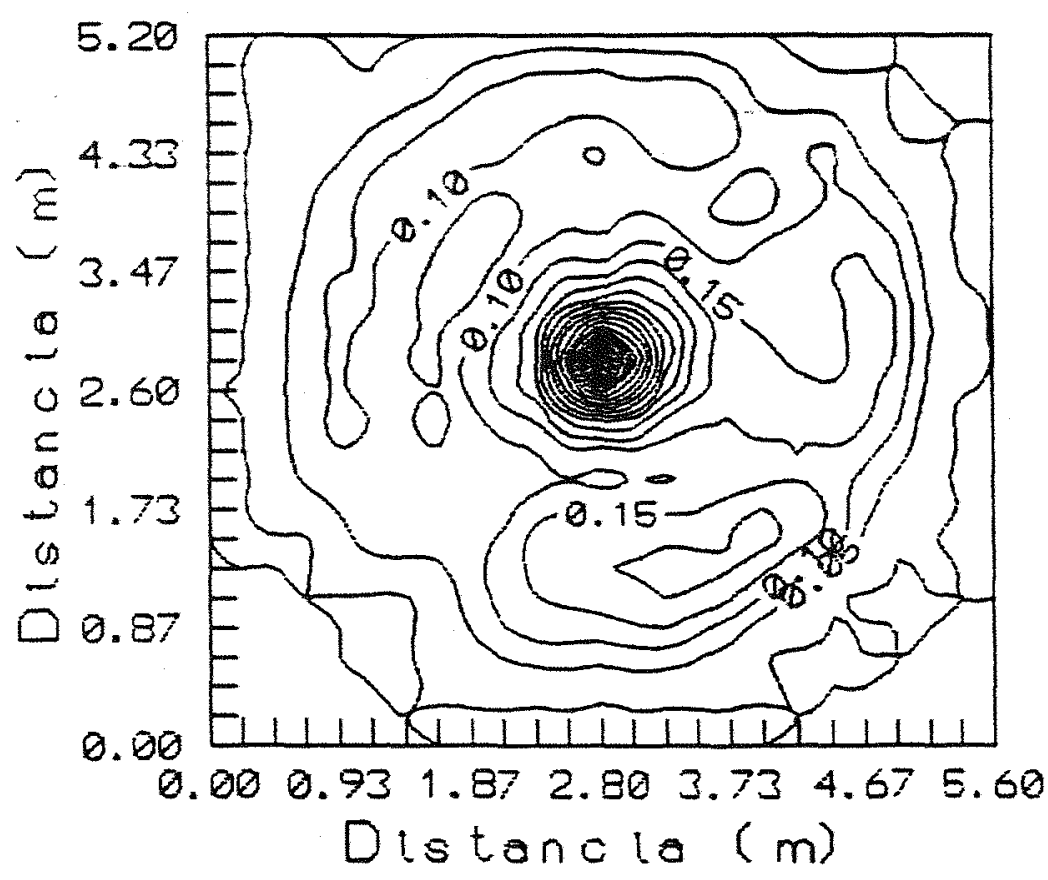

(B)

* Microaspersor nas coordenadas $(2,80 ; 2,82)$

Figura 32 - Distribuição espacial da água apresentada pelo microaspersor spinner com bocal violeta e regulador de fluxo preto operando $151,06 \mathrm{kPa}$. - (A) vista tridimensional ; (B) vista superior 
SPINNER - BOCAL AZUL - REG. F. PRETO

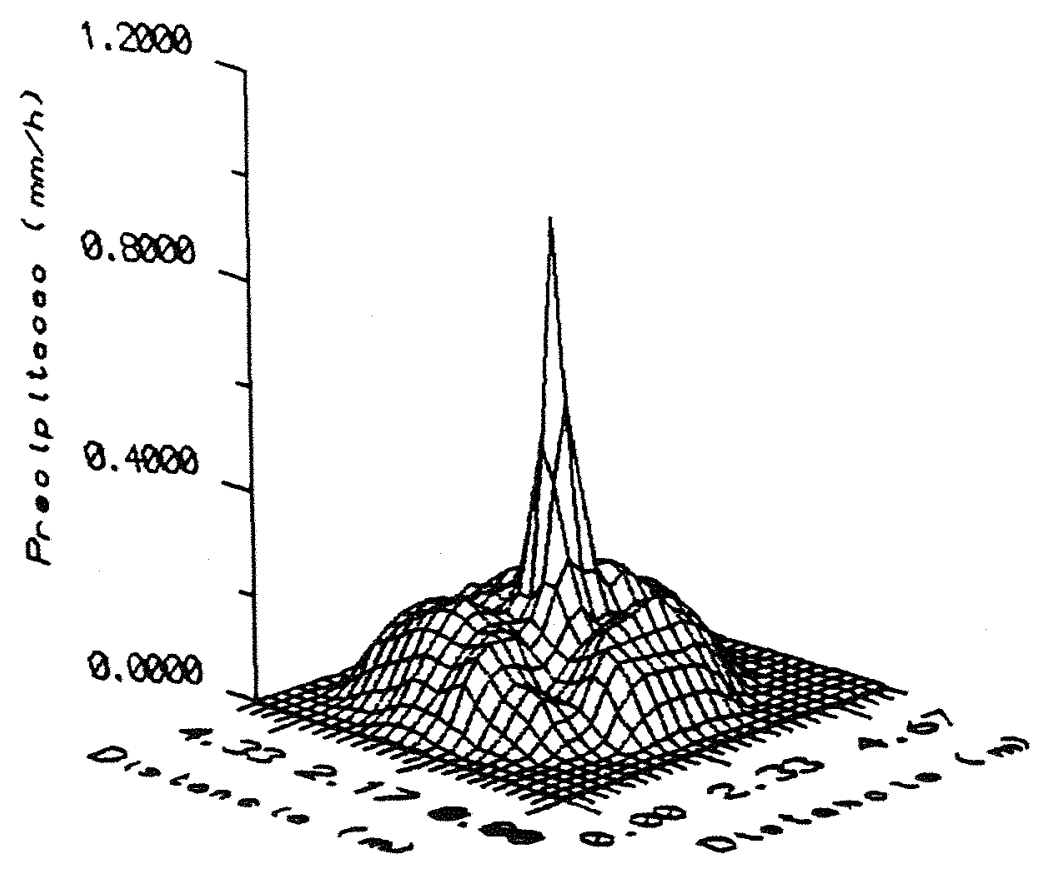

(A)

SPINNER - BOCAL AZUL - REG. F. PRETO

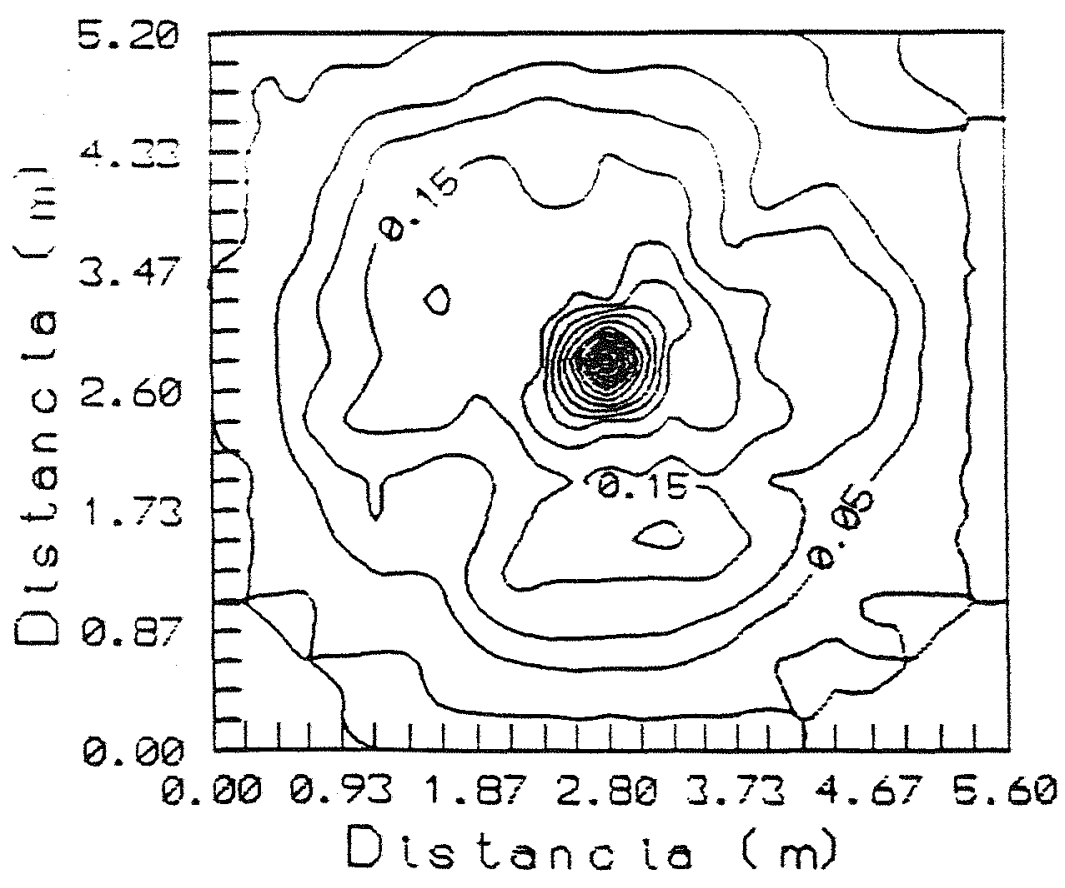

(B)

* Microaspersor nas coordenadas $(2,80 ; 2,82)$

Figura 33 - Distribuição espacial da água apresentada pelo microaspersor spinner com bocal azul e regulador de fluxo preto operando $151,06 \mathrm{kPa}$. - (A) vista tridimensional ; (B) vista superior 


\subsection{2 - Microaspersor jet}

Levando-se em consideração que o microaspersor jet aplica água de forma localizada e em 12 jatos fixos, houve a necessidade de diminuição no espaçamento entre coletores para $10 \times 10 \mathrm{~cm}$. Tal fato trouxe como conseqüência o consumo excessivo de coletores; o que determinou, quando da coleta de precipitação, a escolher, dentre os 12, apenas 3 jatos. Foram escolhidos os jatos de números: 2,8 e

\section{1.( Figura 8).}

Com os dados de precipitação, esquematizou-se um diagrama para as combinações de bocais e reguladores de fluxo, no qual, pode-se observar, cada área molhada.

Analisando as superficies molhadas pelos microaspersores tipo jet, pode-se perceber uma considerável variação na área de alcance entre os jatos de um mesmo microaspersor. Entre os jatos de números 2 e 8 , há semelhança maior do que em relação ao jato 11.( Figuras 34 a 49 em APÊNDICE)

Verificando a Tabela 15 , pode-se observar que houve uma redução nos valores dos diâmetros de alcance dos microaspersores tipo jet, a medida que mudavase de bocal, sendo que a redução ocorreu a partir do bocal vermelho, passando pelos bocais violeta e azul até atingir a queda máxima no bocal laranja.

E quando esses bocais foram combinados com os reguladores de fluxo, o diâmetro molhado decresceu do branco, verde até o preto, como era de se esperar, 
uma vez que os reguladores de fluxo acima citados têm os seguintes valores de vazão nominais: $12 ; 8$ e $4 \mathrm{l} / \mathrm{h}$ respectivamente.

Por outro lado, os valores de diâmetros de alcance dos bocais jet, como os spinner não coincidiram com os fornecidos pelo fabricante (Tabela 2), pois os valores encontrados foram 6,$6 ; 5,42$ e 5,20 para os bocais vermelho, violeta e azul respectivamente. Tendo ocorrido coincidência apenas para o bocal laranja com diâmetro de alcance de $5,0 \mathrm{~m}$, semelhante ao sugerido pelo fabricante.

Tabela 15 - Diâmetro de alcance para os microaspersores jet, operando à $\quad$ 147,13 $\mathrm{kPa}(15$ m.c.a. $)$

\begin{tabular}{|c|c|c|c|c|c|}
\hline \multicolumn{6}{|c|}{ BOCAIS IEIS } \\
\hline $\begin{array}{l}\text { REC. } \\
\text { FIVU }\end{array}$ & YERM. & VIOIET. & 1/2U1 & IARANI. & II? \\
\hline -..--..-- & 3.75 & 2,76 & 2,76 & 3,05 & 2 \\
\hline$-\ldots$ & 3,18 & 2,25 & 2,84 & 2,33 & 8 \\
\hline - & 3,05 & 3.11 & 2,19 & 2,13 & 11 \\
\hline $\begin{array}{c}\text { D. alcance } \\
(m)\end{array}$ & 6,66 & 5,42 & 5,20 & 5,00 & \\
\hline branco & 2,83 & 3,32 & 2,97 & 2,51 & 2 \\
\hline branco & 3,11 & 2,62 & 2,42 & 1,81 & 8 \\
\hline branco & 3,04 & 2,62 & 2,13 & 1,73 & 11 \\
\hline $\begin{array}{c}\text { D. alcance } \\
\text { (m) }\end{array}$ & 5,98 & 5,70 & 5,02 & 4,04 & \\
\hline verde & 2,9 & 3,05 & 2,62 & 2,55 & 2 \\
\hline verde & 3,12 & 2,20 & 2,27 & 1,98 & 8 \\
\hline verde & 2,83 & 2,27 & 2,20 & 1,70 & 11 \\
\hline $\begin{array}{c}\begin{array}{c}\text { D. alcance } \\
\text { (iim) }\end{array} \\
\end{array}$ & 5,9 & 5,02 & 4,72 & 4,16 & \\
\hline preto & 3,04 & 2,90 & 2,41 & 1,94 & 2 \\
\hline preto & 2,59 & 2,13 & 2,00 & 2,06 & 8 \\
\hline preto & 2,91 & 1,12 & 2,00 & 1,63 & 11 \\
\hline $\begin{array}{c}\begin{array}{c}\text { D. alcance } \\
(\mathrm{m})\end{array} \\
\end{array}$ & 5,70 & 4,76 & 4,28 & 3,76 & \\
\hline
\end{tabular}




\section{CONCLUSÕES}

Tendo como base os resultados obtidos, nos métodos aplicados e nas condições em que os testes foram realizados, chegou-se as seguintes conclusões:

a) As equações caraterísticas para os microaspersores spinner - com bocais vermelho, violeta e azul - e os microaspersores jet, com distribuição de $360^{\circ}$ - com bocais vermelho, violeta, azul e laranja - sem reguladores de fluxo, apresentaram equações caracteristicas do tipo potencial, semelhantes a descrita por KELLER \& KARMELI (1974).

b) Os microaspersores com reguladores de fluxo operando na faixa 120 a $400 \mathrm{kPa}$, năo se ajustaram ao modelo potencial, recomenda-se a utilização da representação gráfica de suas respectivas curvas caracteristicas observadas como representativas das relações vazão-pressão para as condições nas quais os testes foram realizados.

c) A classificação dos emissores segundo o projeto de normas $12: 02.08-022$ da ASSOCIAÇÃO BRASILEIRA DE NORMAS E TÉCNICAS e de acordo com os coeficientes de variação de vazão obtidos, enquadram os emissores de médio a bom.

d) Os valores médios de vazão para os microaspersores do tipo spinner ou jet, independentemente do bocal utilizado, operando na faixa de 200 a $400 \mathrm{kPa}$, 
apresentaram-se estáveis e próximos a $13 \mathrm{l} / \mathrm{h} ; 9 \mathrm{l} / \mathrm{h}$ e $4 \mathrm{l} / \mathrm{h}$, quando associados aos reguladores de fluxo branco, verde e preto respectivamente.

e) Os diâmetros de alcance para os microaspersores spinner operando a $147,13 \mathrm{kPa}$, foi de 5,00 a $6,60 \mathrm{~m}$, variação esta que dependia do bocal utilizado e do regulador de fluxo, ao qual o bocal estava associado. O microaspersor do tipo jet com ângulo de cobertura de $360^{\circ}$ proporcionou um diâmetro de alcance médio de 3,76 a $6,66 \mathrm{~m}$.

f) Os perfis de distribuição mostraram-se bastante variados entre os microaspersores; a distribuição pluviométrica por sua vez apresentou-se concentrada próximo do emissor para os microaspersores spinner e mais afatadas desses para os microaspersores do tipo jet. 


\section{REFERÊNCIAS BIBLIOGRÁFICAS}

ARMONI, S. Micro-sprinkler irrigation. Kibbutz Dam, Dam Sprinklers, 1986. $88 \mathrm{p}$.

ASSOCIAÇÃO BRASILEIRA DE NORMAS TÉCNICAS. Emissores para sistemas de sistema de irrigação localizada - avaliação das características operacionais; PNBR 12:02.08-021. Rio de Janeiro, 1986. 7p.

AZEVEDO, H. M. \& LIMA, V. L. A. Caracterização hidráulica do emissor microaspersor/microtubo. In: CONGRESSO BRASILEIRO DE IRRIGAÇÃO E DRENAGEM, 9., Natal, 1991. Anais. Fortaleza, ABID, 1992. v.1, t.1, p.317.

BERNARDO, S. Manual de irrigação. 3. ed. Viçosa, Imprensa Universitária UFV, 1984. 463p.

BOMAN, B. J. Emitter and spaghetti tubing effects on microsprinkler flow uniformity. Transactions of The ASAE, St. Joseph, 32(1):168-72, 1989.

BOTREL, T.A. Hidráulica de microaspersores e linhas laterais para irrigação localizada. Piracicaba, 1984. 78p. (Mestrado - Escola Superior de Agricultura "Luiz de Queiroz"/USP). 
CHRISTIANSEN, J.E. Irrigation by sprinkling. Logan, California Agricultural Experimental Station, 1942. 124p. (Bulletin, 670).

ESTADOS UNIDOS. Departament of Agriculture. Soil Conservation Service.

Trickle irrigation. Washington, 1979. 129p. (USDA. Irrigation, 15).

FRIZZONE, J. A. Irrigação por aspersão; uniformidade e eficiência. Piracicaba, USP/ Departamento de Engenharia Rural, 1992. 53p. (Série Didática, 3).

GUIMARÃES JÚNIOR, J. A. Dimensionamento econômico de uma parcela de irrigação por gotejamento. Campina Grande, 1993. 158p. (Mestrado Universidade Federal da Paraíba).

HERNÁNDEZ ABRÉU , J. M.; RODRIGO LÓPEZ, J.; PÉREZ REGALADO, A.; GONZÁLEZ HERNÁNDEZ, J. F. . El riego localizado. Madrid, Instituto de Investigaciones Agrarias, 1987. 320p.

JONAS, S.; SPIESS, L. B.; RAPP, E.. Evaluation of emitters for trickle irrigation, Canadian Agricultural Engineering, Ottawa, 17,(1):28-3, 1975.

KELLER, J. \& KARMELI, D. Trickle irrigation design. Glendora, Rain Bird Sprinkler Manufacturing Corporation, 1975. 133p.

MARTÍ, S.P. Diseño y manejo agronomico de instalaciones. In: SEMINÁRIO SOBRE PROJETO DE IRRIGAÇÃO POR GOTEJAMENTO, Campinas, 1993. Campinas, Unicamp/Faculdade de Engenharia Civil, 1993. p. irreg. 
MERRIAM, J. L. \& KELLER, J. Farm irrigation system evaluation;: a guide for management. 2. ed. Logan, Califórnia Polytechnic State University/ Departament of Agricultural Engineering, 1978. 271p.

MORAES, O. Determinação do coeficiente de variação de gotejadores e sua influência na uniformidade de emissão em linhas laterais de irrigação por gotejamento. Piracicaba, 1984. 196p. (Mestrado - Escola Superior de Agricultura "Luiz de Queiroz"/USP).

NAKAYAMA, F. S. \& BUCKS, D.A. Trickle irrigation for crop production. Phoenix, Elsevier, 1986. 383p.

NOGUEIRA, A.M. Características hidráulicas e de distribuição de água por microaspersores. Piracicaba, 1989. 57p. (Mestrado - Escola Superior de Agricultura "Luiz de Queiroz"/USP).

NUEVO, F.A.S. Modelo computacional para dimensionamento da rede hidráulica em sistemas de irrigação localizada. São Carlos, 1992. 139p. (Mestrado Escola de Engenharia de São Carlos/USP)

OLITTA, A.F.L. Os métodos de irrigação. São Paulo, Nobel, 1984. 267p.

PAES, L.A.D. Características hidráulicas dos microaspersores DANTAS MA-120 e IRTEC e das linhas laterais em sistemas de irrigação por microaspersão. Viçosa, 1985. 85p. (M.S. - Universidade Federal de Viçosa). 
PINTO, J. M.; SOARES, J.M.; NASCIMENTO, T. Análise de coeficiente uniformidade de distribuição de água em sistemas de irrigação localizada. In: CONGRESSO BRASILEIRO DE IRRIGAÇÃO E DRENAGEM, 8., Florianópolis, 1988. Anais. Florianópolis, ABID, 1988. v.1, p 309-26.

PIZARRO, F. Riegos localizados de alta frecuencia; goteo, microaspersion, exudación. 2. ed. Madri, Ediciones Mundi-Prensa, 1990. 46lp.

PLANAS, S. \& SOLANELLES, F. La microaspersion como sistema antiheladas en frutales. In: JORNADAS DE PLÁSTICOS EN AGRICULTURA, 3., Lleida, 1993. Lleida, Estaciõ de Mecânica Agrícola, 1993. pl-8.

PUEYA, L. A. N. \& FORCADA, J. M. G. Irrigação por microaspersão em bananeiras. ITEM, Brasilia, 11:30-4, 1982.

RENQUIST, R. Evapotranspiration calculations for young peach trees and growth responses to irrigation amount and frequency. HortScience/St. Joseph/ 22(2):221-3, 1987.

RODRIGUEZ, A. R. \& LOZANO, A. B. Effects of three system and levels of irrigating aplle trees., Scientia Horticulturae, Amsterdam, 47 :67-75, 1991.

SAN JUAN, M. J. A. Riego por goteo; teoría y práctica. 2. ed. Madri, MundiPrensa, 1981. 219p.

SAVALDI, D. Material de estudio sobre microaspersion. Tel Aviv, Centro de Cooperación Internacional para el Desarrollo Agricola, 1991. 99p. 
SHANI, M. \& SAPIR, S. EI riego por aspersion; equipos y metodos. Tel Aviv, SESCIS, 1984. 67p.

SILVA, A. P. Manual de irrigação localizada. Fortaleza, DNOCS, 1989. 57p.

SOLOMON, K. Manufacturing variation of Trickle emitters. Tansactions of the ASAE, St. Joseph, 22(5):1034-8, 1979

TELLES, D. D. Irrigação localizada. In: TELLES, D. D; VIEIRA, D.B.; OLITTA, A. F.; SCALOPPI, E. J.. Curso básico de irrigação. Brasília, ABID , 1986. 360 p.

VERMEIREN, I. \& JOBLING, G.A. Localized irrigation. Roma, FAO, 1980. $203 p$.

VIEIRA, D. B. \& TRINDADE, V. Avaliação hidráulica em linha de gotejamento. In: CONGRESSO BRASILEIRO DE IRRIGAÇÃO E DRENAGEM, 8., Florianópolis, 1988. Anais. Florianópolis ABID, 1988, v.1, p. 431-56.

ZEKRI, M. \& PARSONS, L. R. Grapefruit leaf and fruit growth in response to drip, microsprinkler, and overhead sprinkler irrigation. Journal of American Society Agricultural HortScience, Alexandria, 114(1):25-9, 1989 
APÊNDICE 
JET - BOCAL VERMELHO

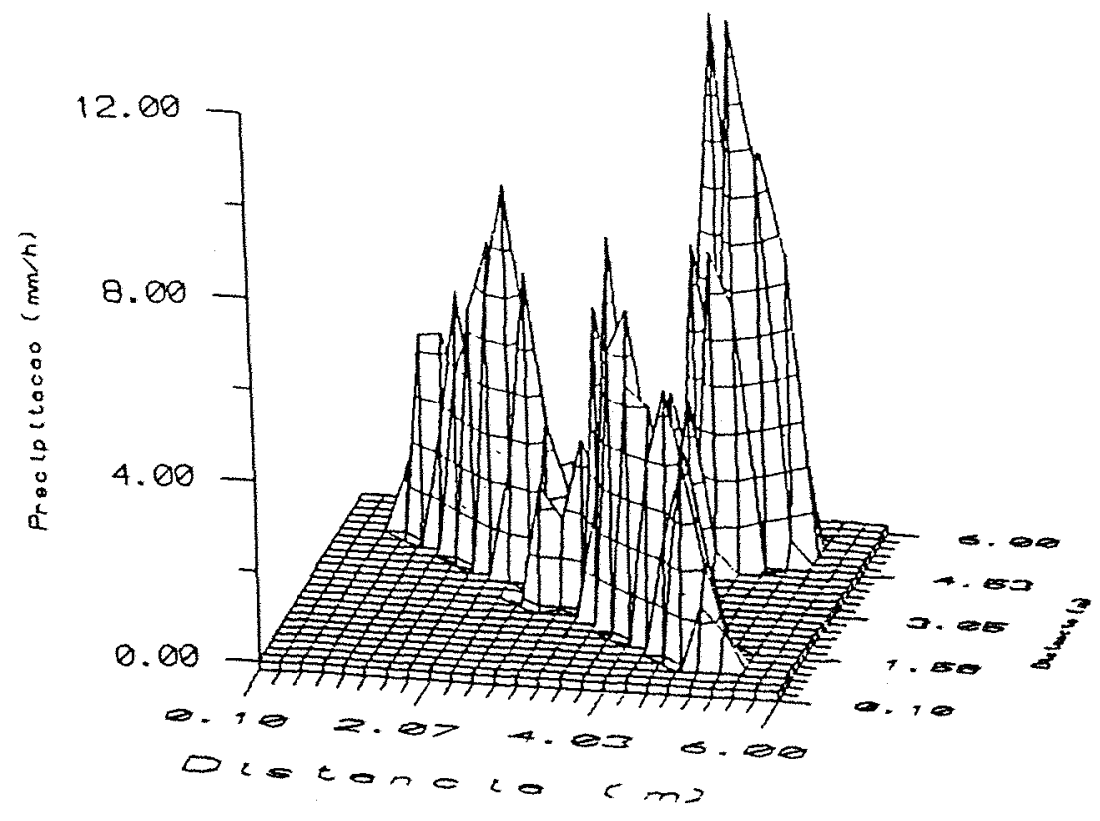

(A)

JET - BOCAL VERMELHO

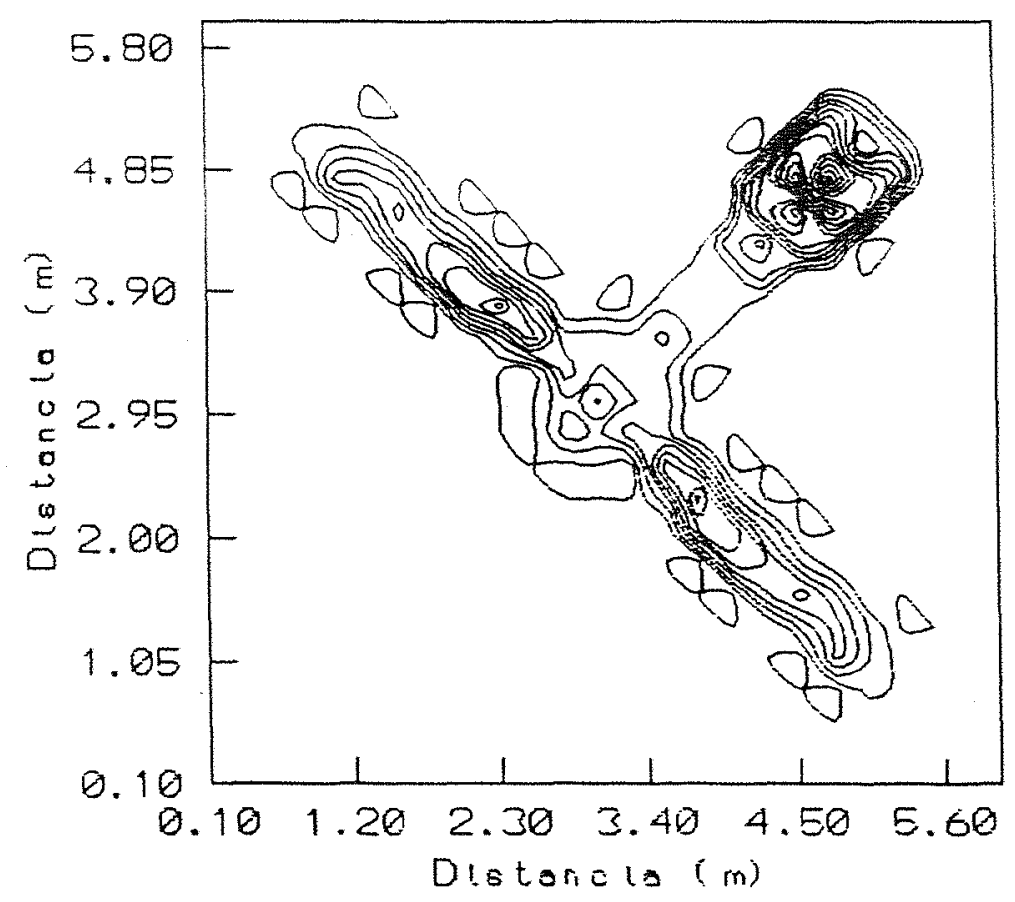

(B)

* Microasversor nas coordenadas $(3,03 ; 3,02)$

Figura 34 - Distribuição espacial da água apresentada por três jatos do microaspersor jet com bocal vermelho operando 151,06 kPa. - (A) vista tridimensional ; $(B)$ vista superior 


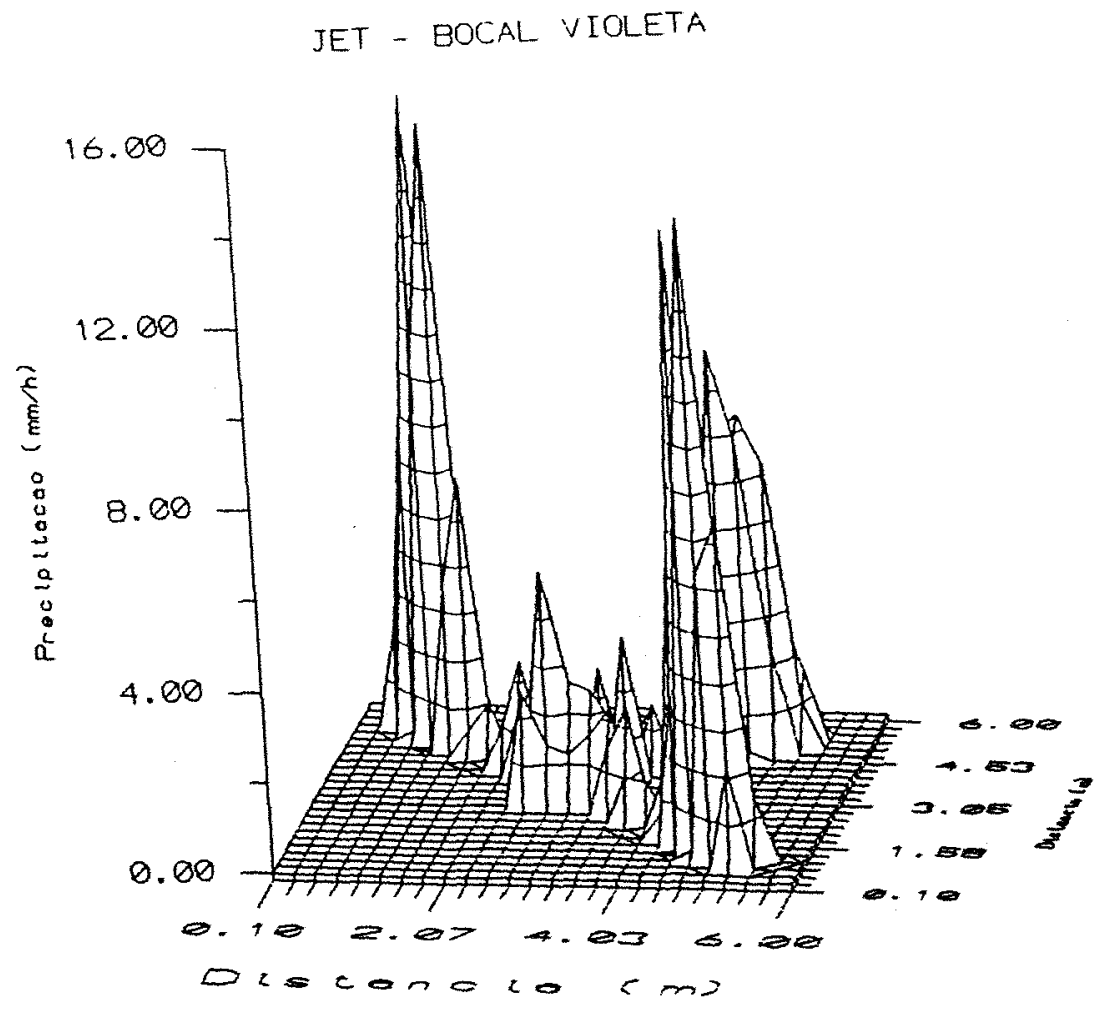

(A)

\section{JET - BOCAL VIOLETA}

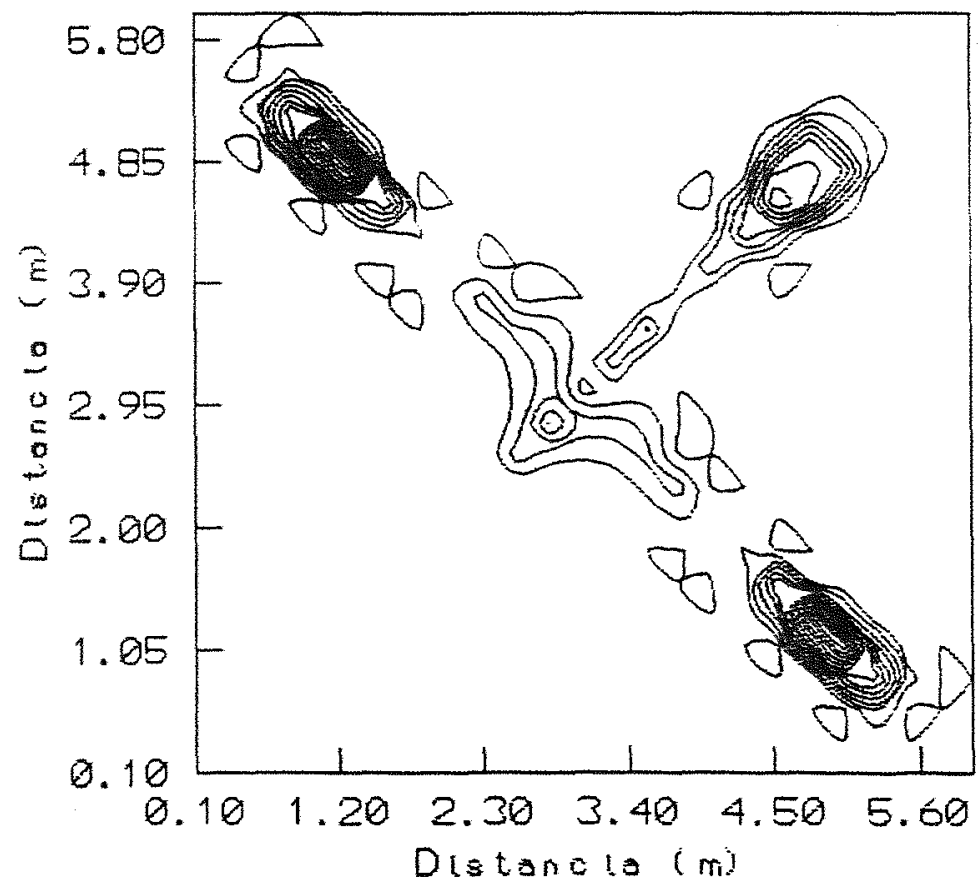

(B)

* Microaspersor nas coordenadas $(2,81 ; 2,73)$

Figura 35 - Distribuição espacial da água apresentada por três jatos do microaspersor jet com bocal violeta operando $151,06 \mathrm{kPa}$ - (A) vista tridimensional ; (B) vista superior 


\section{JET - BOCAL AZUL}

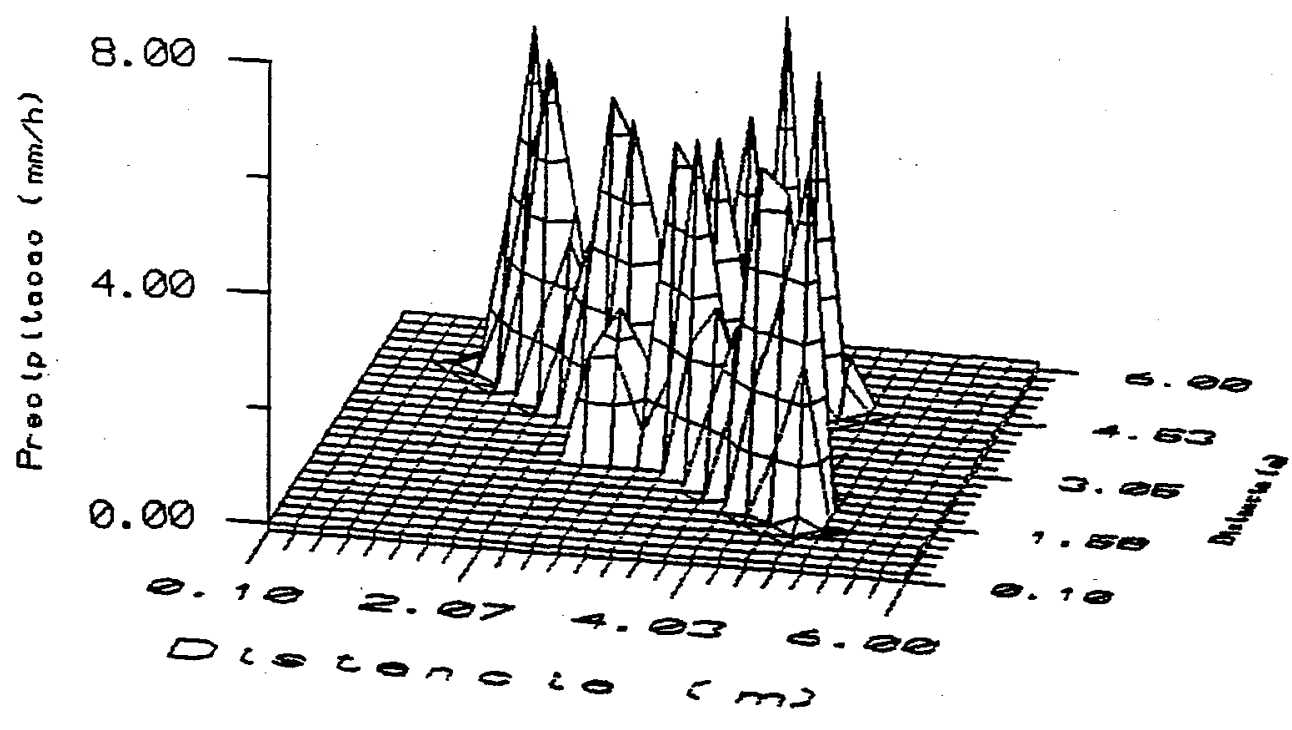

(A)

JET - BOCAL AZUL

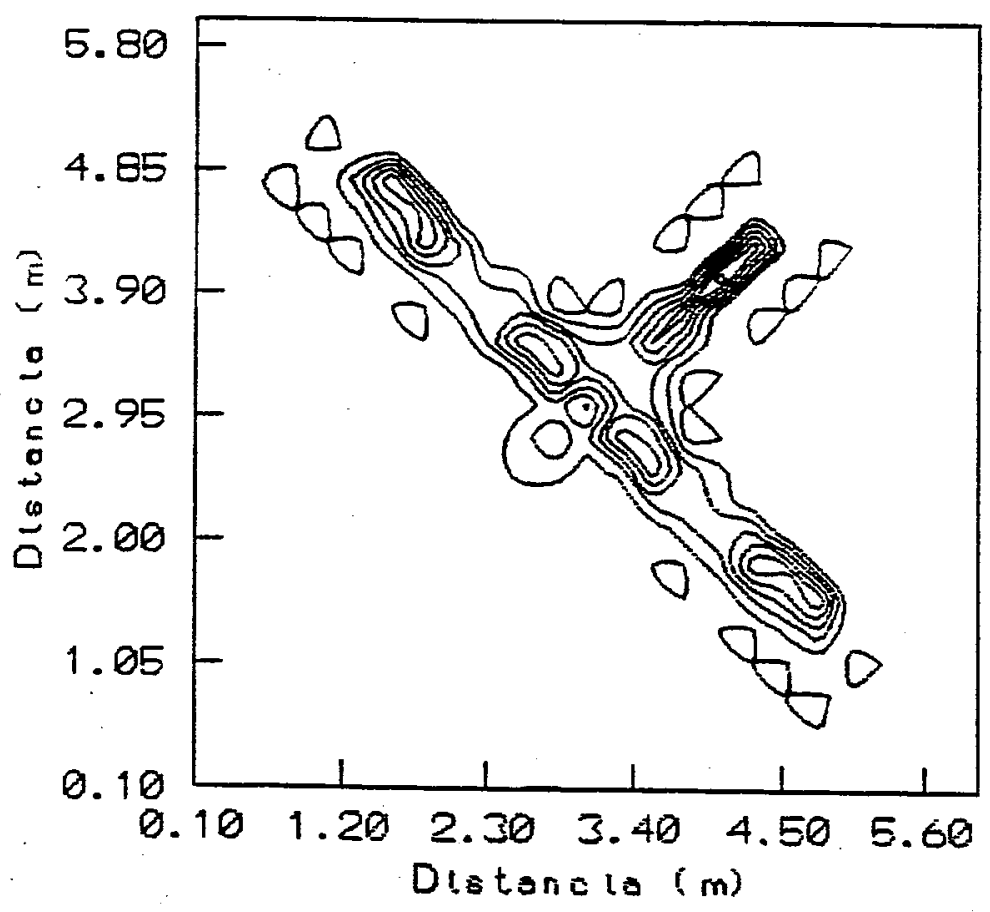

(B)

* Microaspersor nas coordenadas $(3.03 ; 3,02)$

Figura 36 - Distribuição espacial da água apresentada por três jatos do microaspersor jet com bocal azul operando $151,06 \mathrm{kPa}$. - (A) vista tridimensional; (B) vista superior 
JET - BOCAL LARANJA

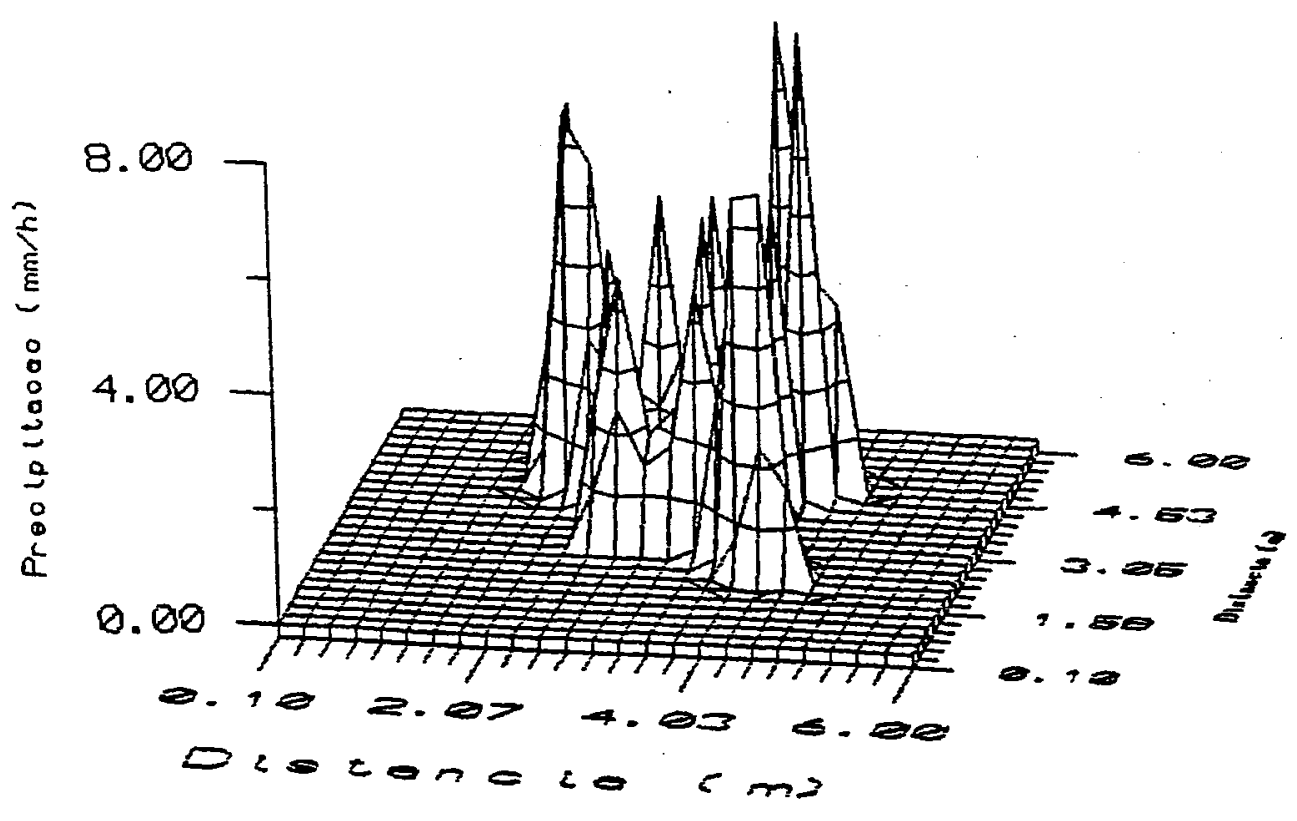

(A)

JET - BOCAL LARANJA

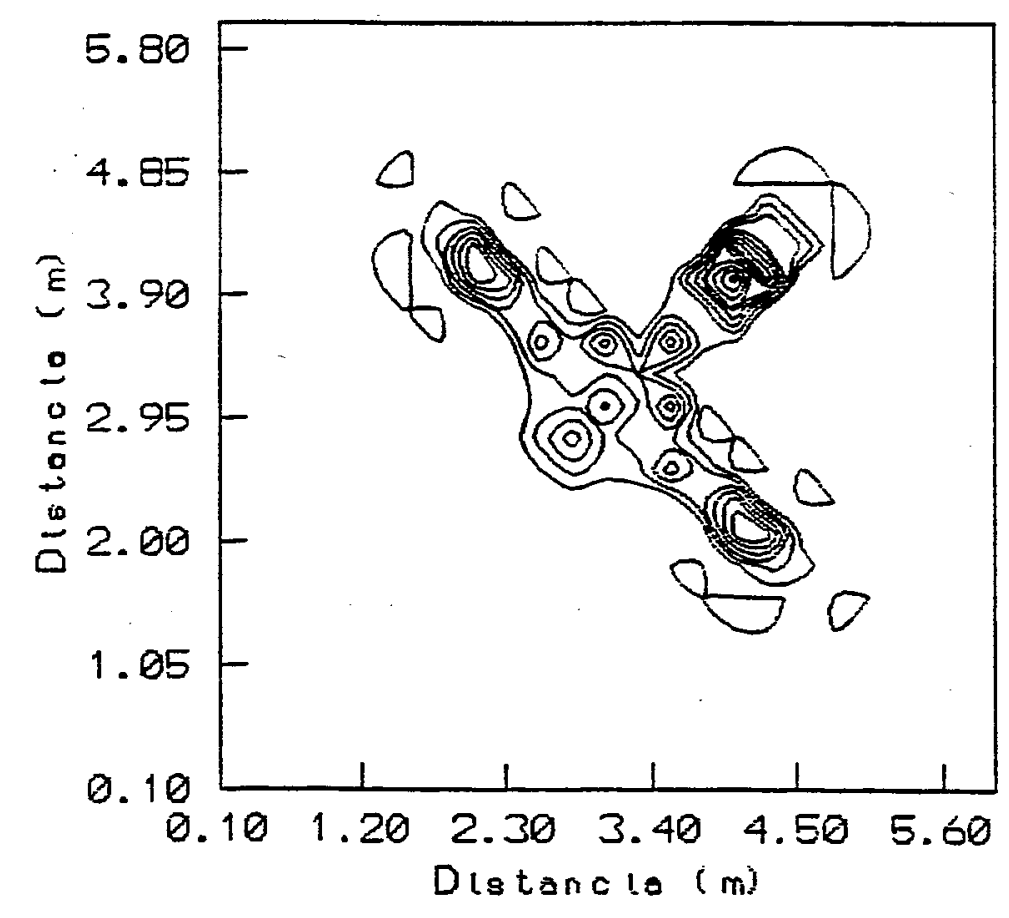

(B)

* Microaspersor nas coordenadas $(2,96 ; 3,02)$

Figura 37 - Distribuição espacial da água apresentada por três jatos do microaspersor jet com bocal laranja operando $151,06 \mathrm{kPa}$ - (A) vista tridimensional ; $(B)$ vista superior 
JET - BOCAL VERMELHO - REg. F. BRANCO

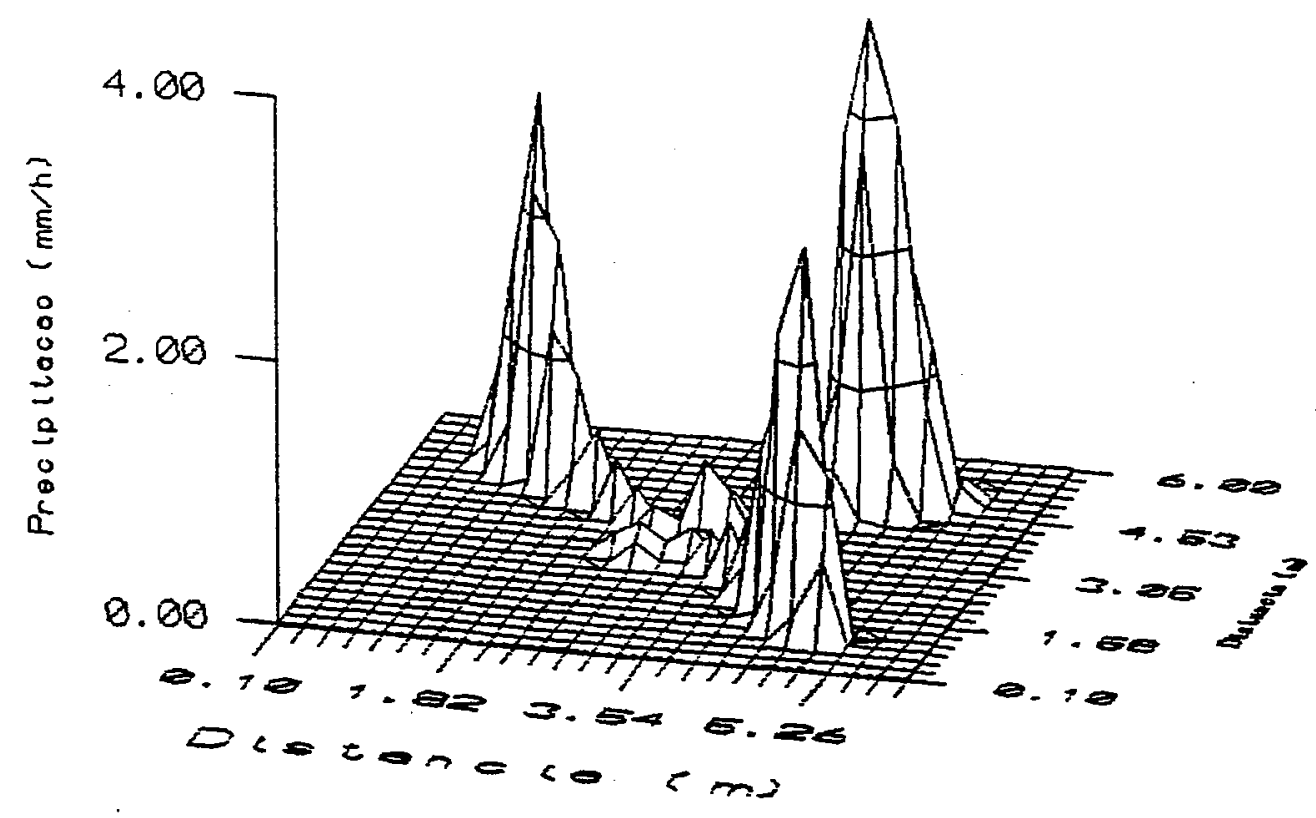

JET - BOCAL VERMELHO - REG. F. BRANCO

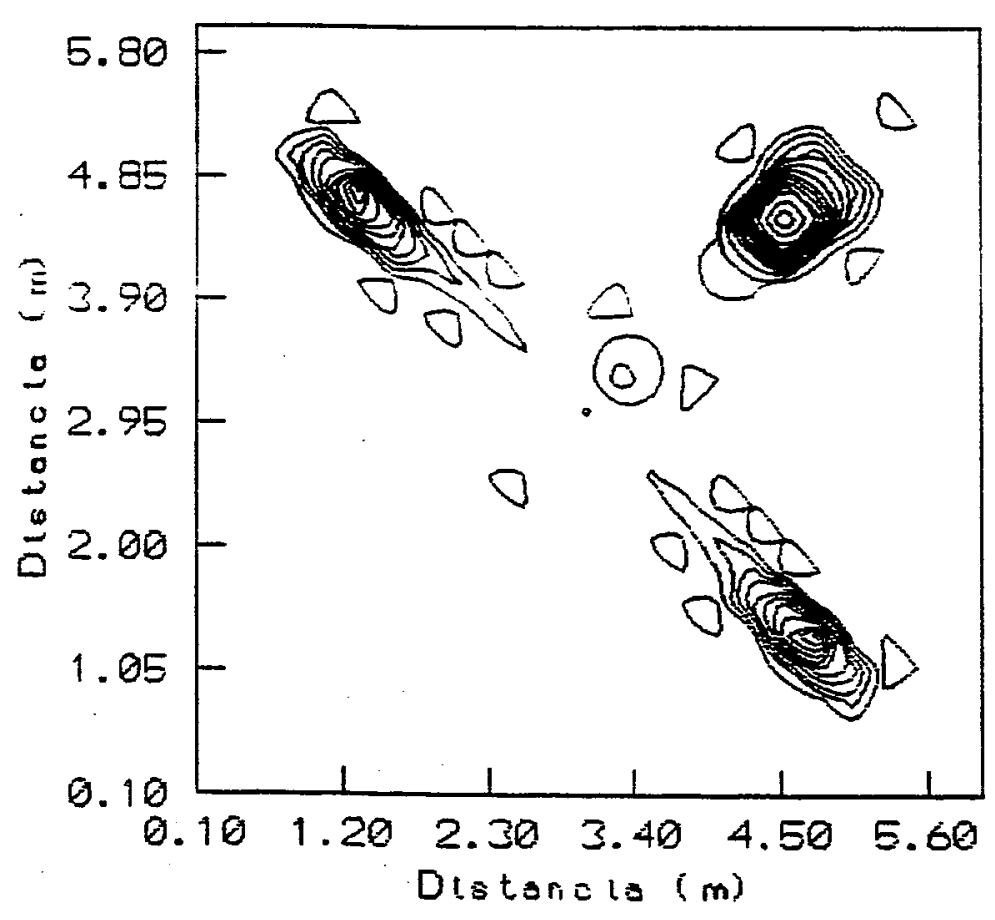

* Microaspersor nas coordenadas $(3,03 ; 3,02)$

Figura 38 - Distribuição espacial da água apresentada por três jatos do microaspersor jet com bocal vermelho e regulador de fluxo branco operando 151,06 kPa. - (A) vista tridimensional ; (B) vista superior 
JET - BOCAL VIOLETA - REG. F. BRANCO

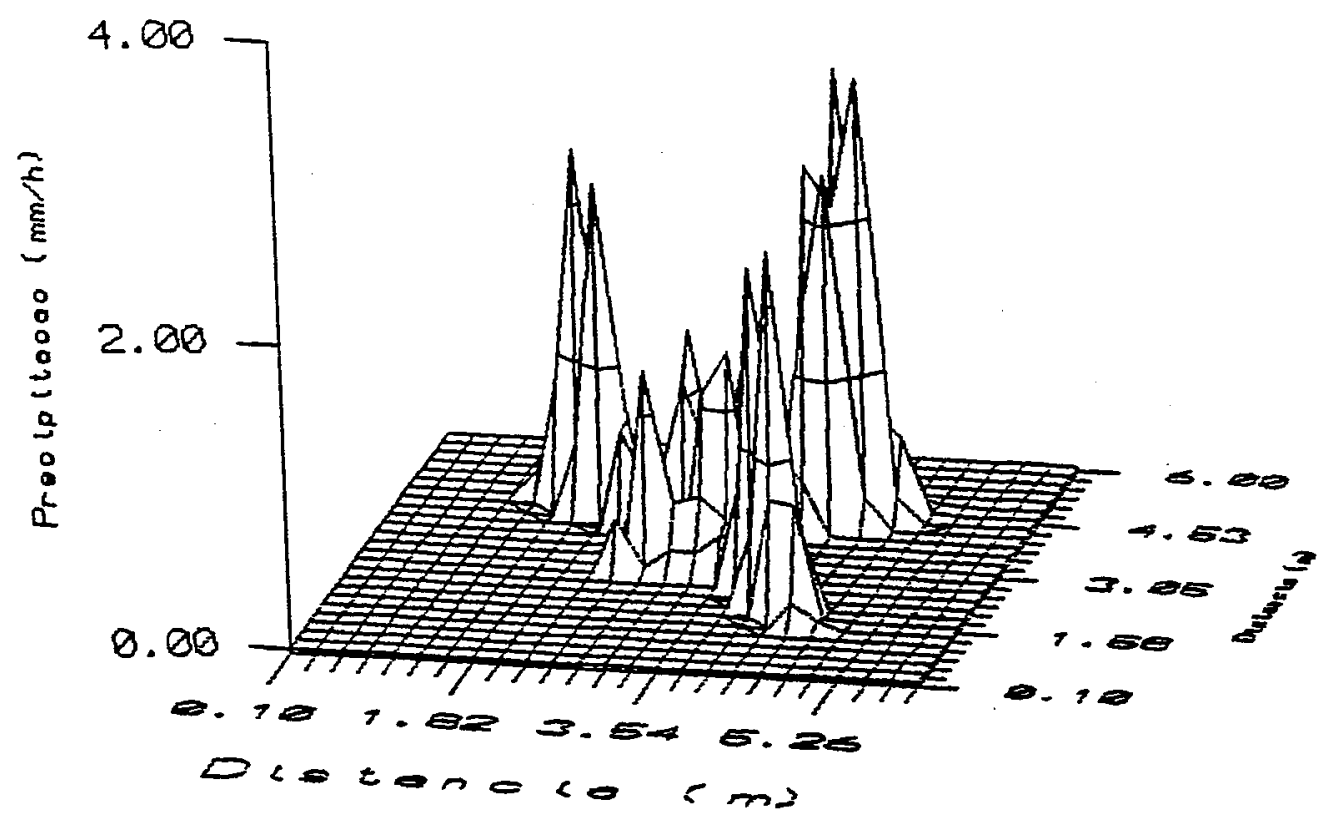

JET - BOCAL VIOLETA - REG. F. BRANCO

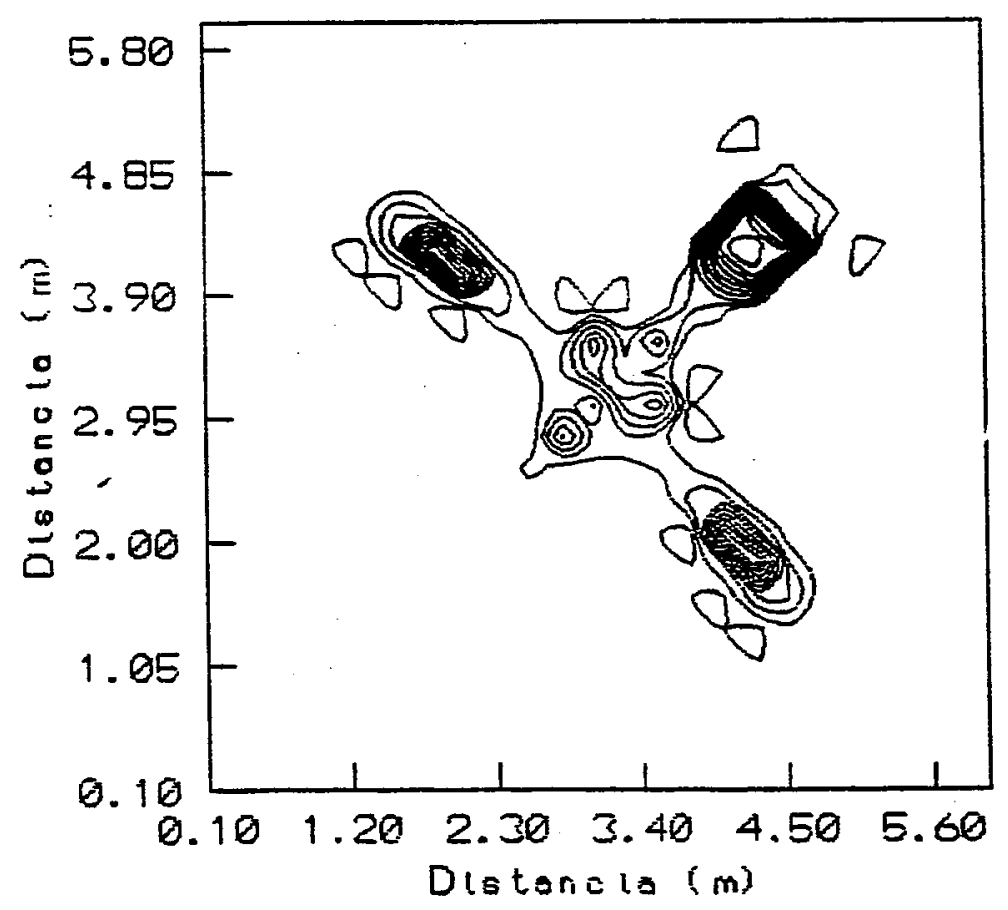

Figura 39 - Distribuição espacial da água apresentada por três jatos do microaspersor jet com bocal violeta e regulador de fluxo branco operando 151,06 kPa. - (A) vista tridimensional ; (B) vista superior 
JET - BOCAL AZUL - REG. F. BRANCO

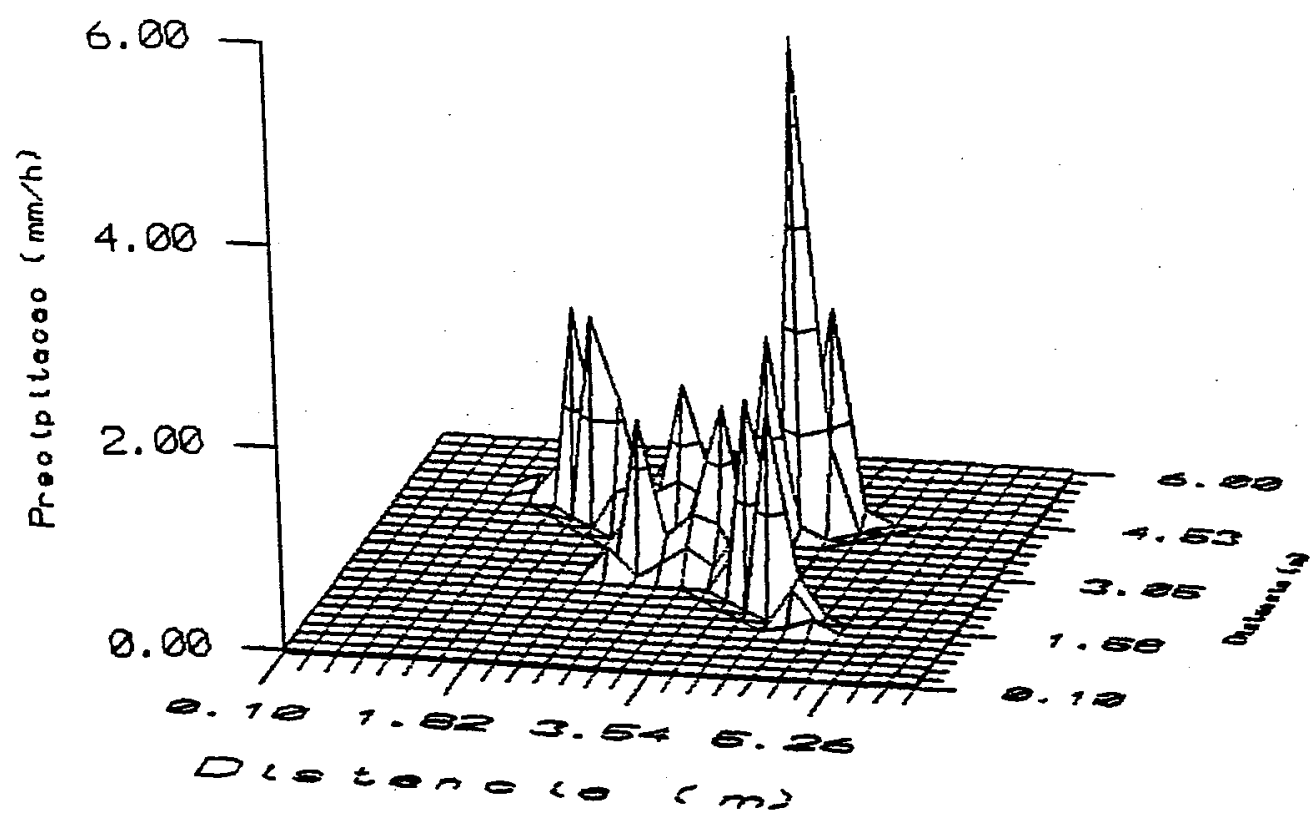

(A)

JET - BOCAL AZUL - REG. F. BRANCO

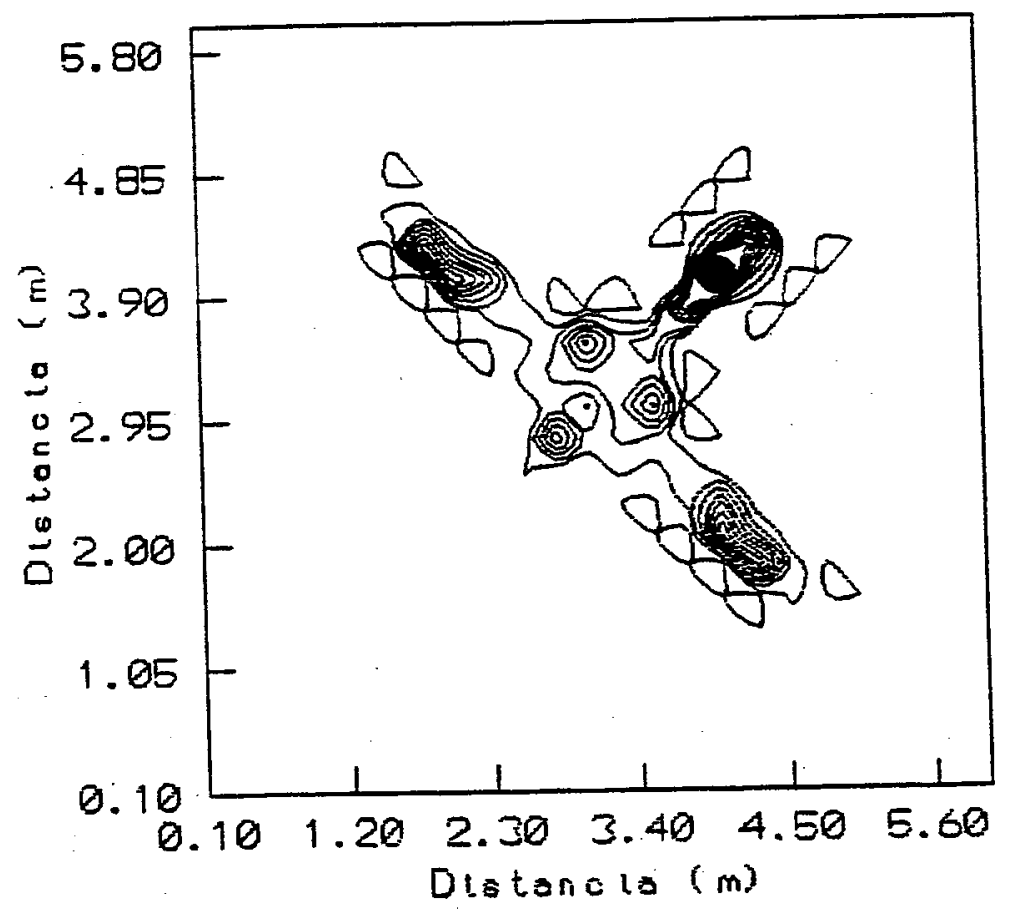

(B)

* Microaspersor nas coordenadas $(3,03 ; 3,02)$

Figura 40 - Distribuição espacial da água apresentada por três jatos do microaspersor jet com bocal azul e regulador de fluxo branco operando $151,06 \mathrm{kPa}$. - (A) vista tridimensional ; (B) vista superior 
JET - BOCAL LARANJA - REG. F. BRANCO

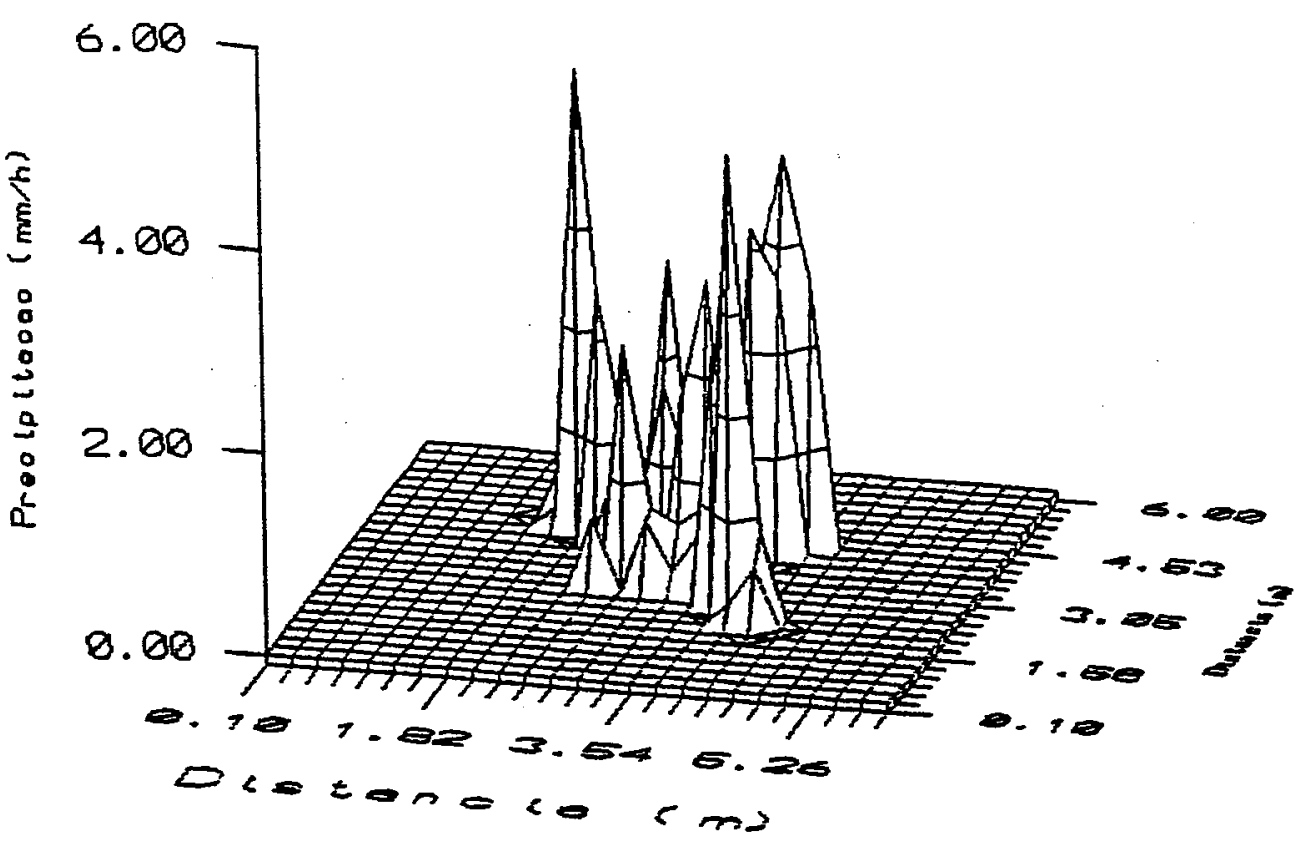

JET - BOCAL LARANJA - REG. F. BRANCO

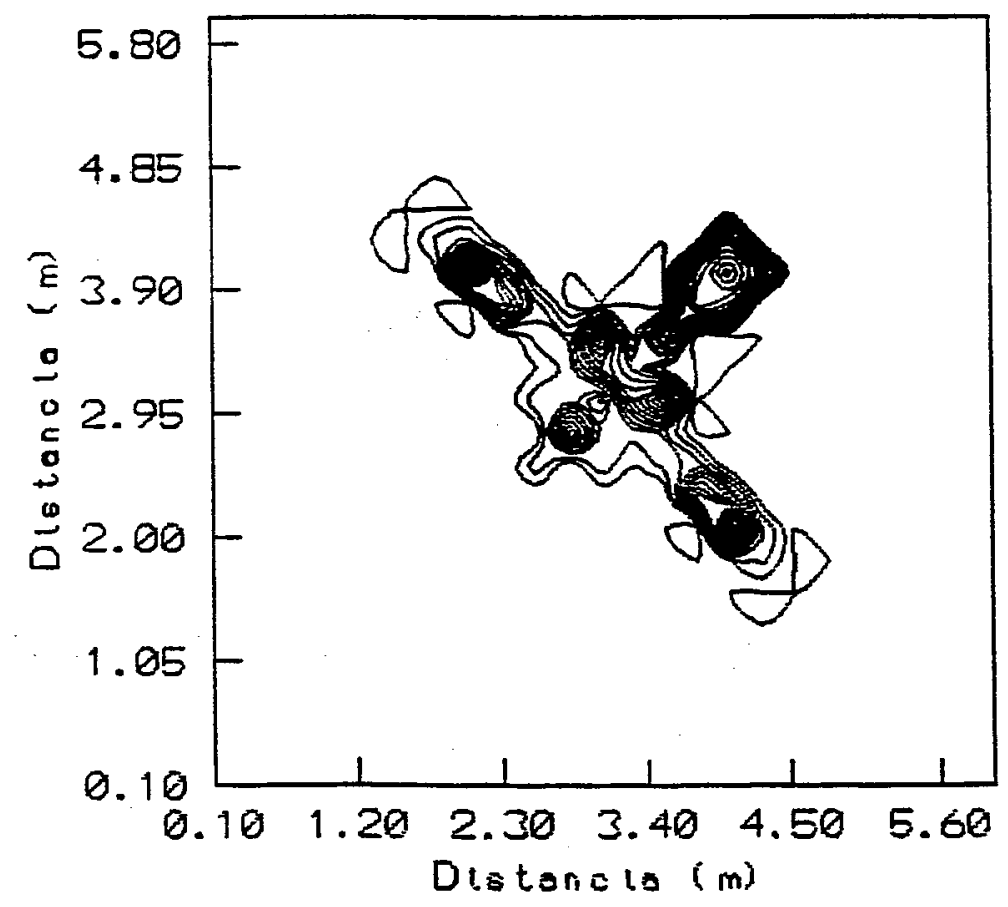

(B)

* Microaspersor nas coordenadas $(3,03 ; 3,02)$

Figura 41 - Distribuição espacial da água apresentada por três jatos do microaspersor jet com bocal laranja e regulador de fluxo branco operando 151,06 kPa. - (A) vista tridimensional ; (B) vista superior 
JET - BOCAL VERMELHO - REG. F. VERDE

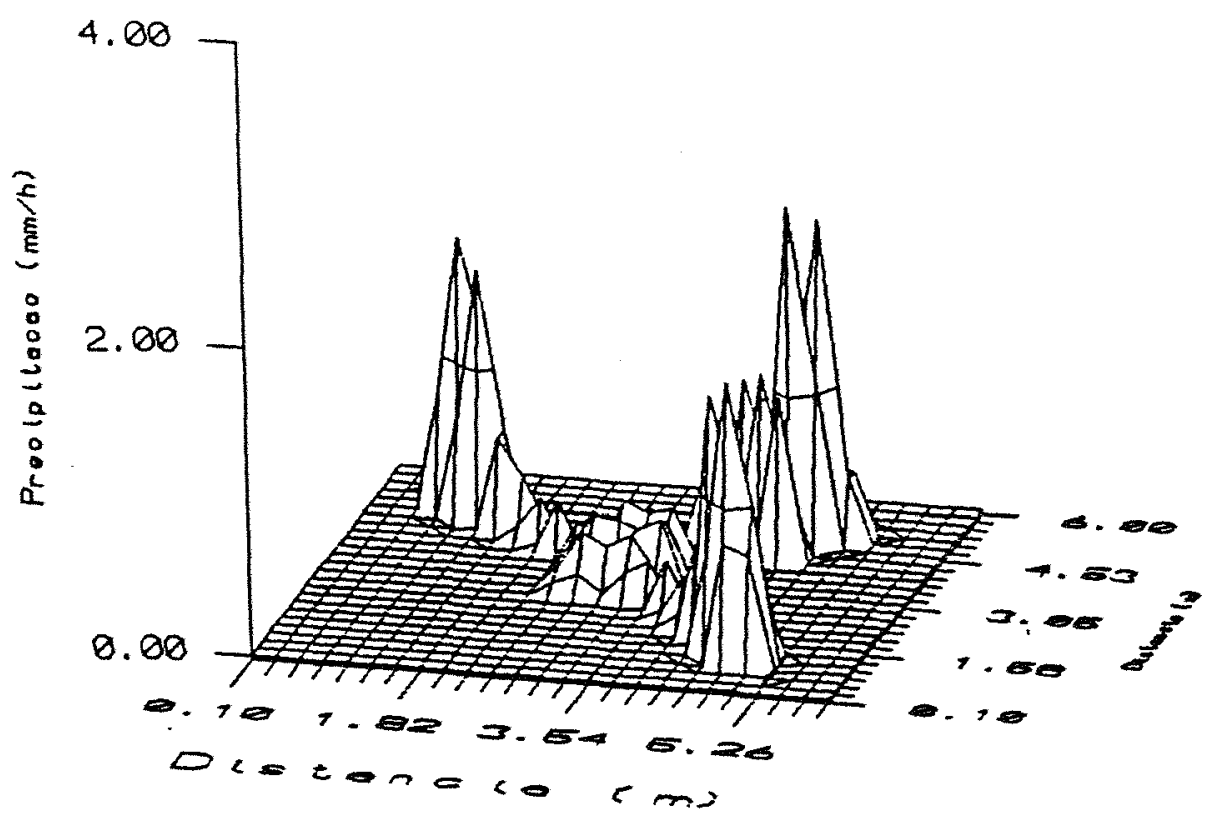

JET - BOCAL VERMELHO - REG. F. VERDE

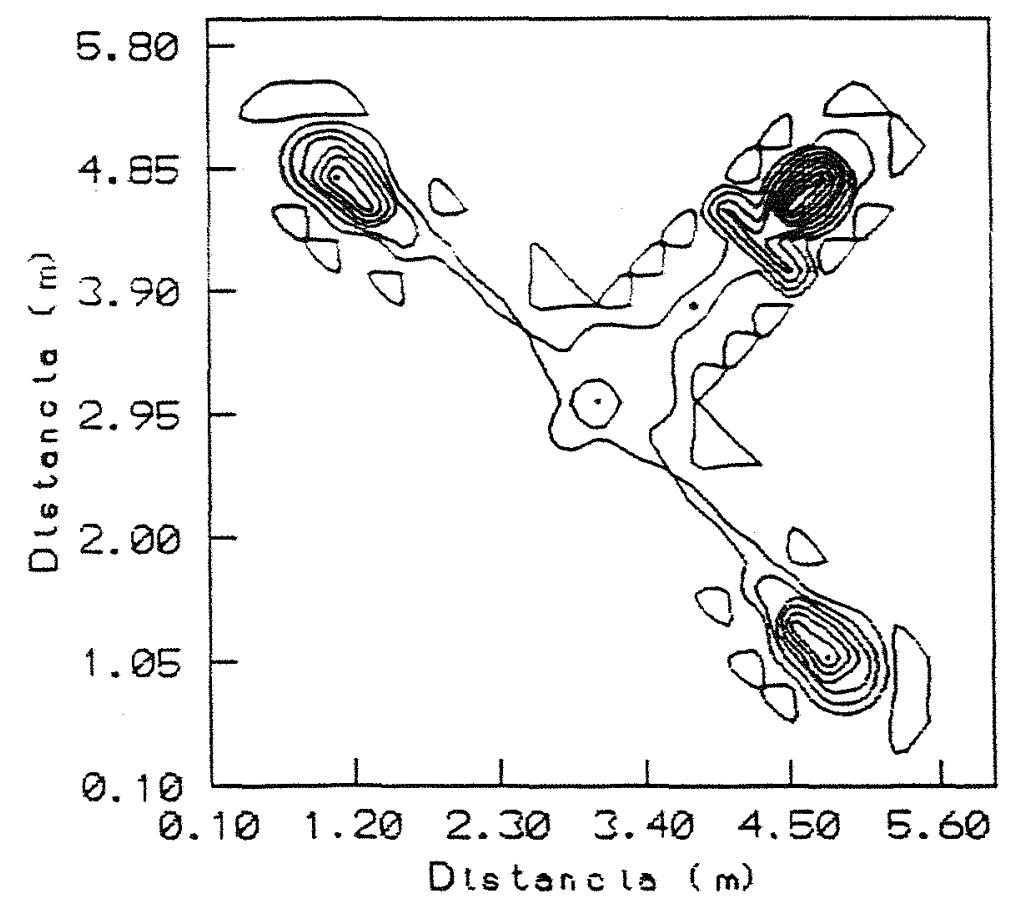

* Microaspersor nas coordenadas $(3,03 ; 3,02)$

Figura 42 - Distribuição espacial da água apresentada por três jatos do microaspersor jet com bocal vermelho e regulador de fluxo verde operando $151,06 \mathrm{kPa}$. - (A) vista tridimensional ; (B) vista superior 
JET - BOCAL VIOLETA - REG. F. VERDE

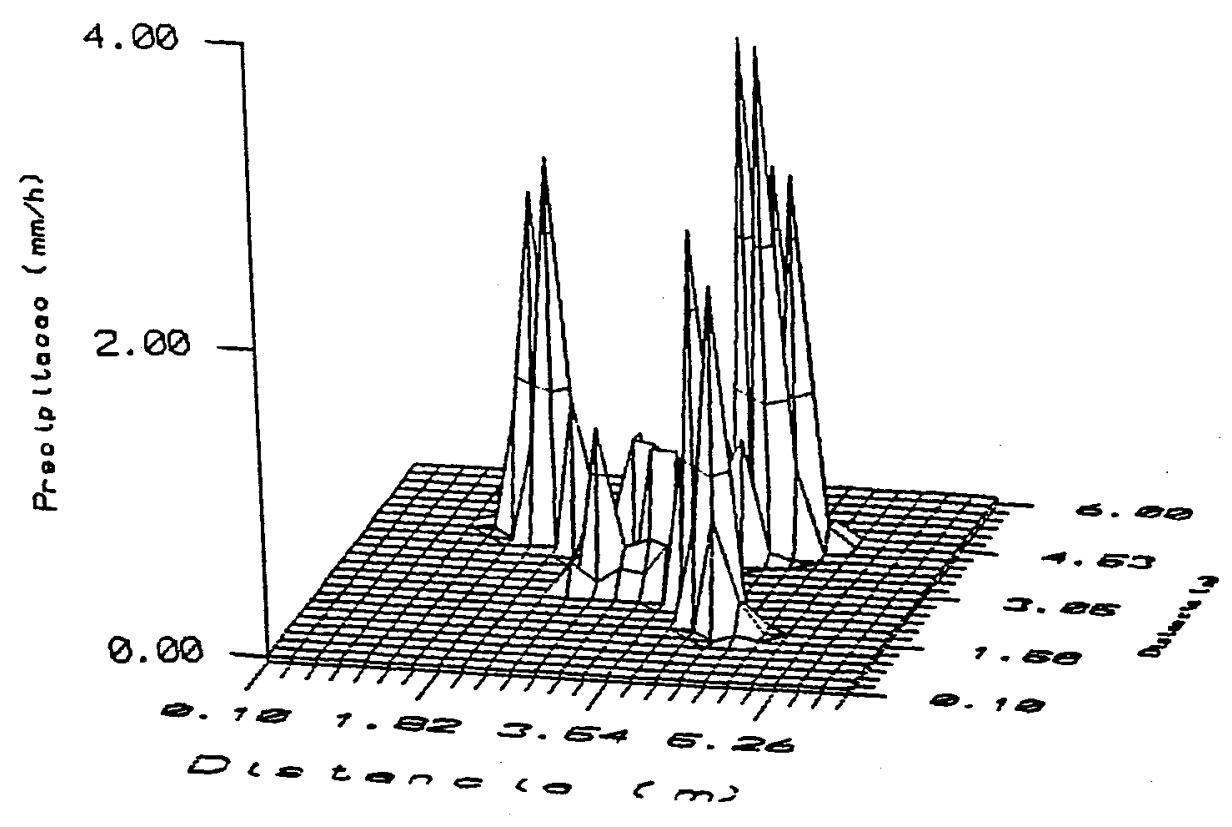

JET - BOCAL VIOLETA - REG. F. VERDE

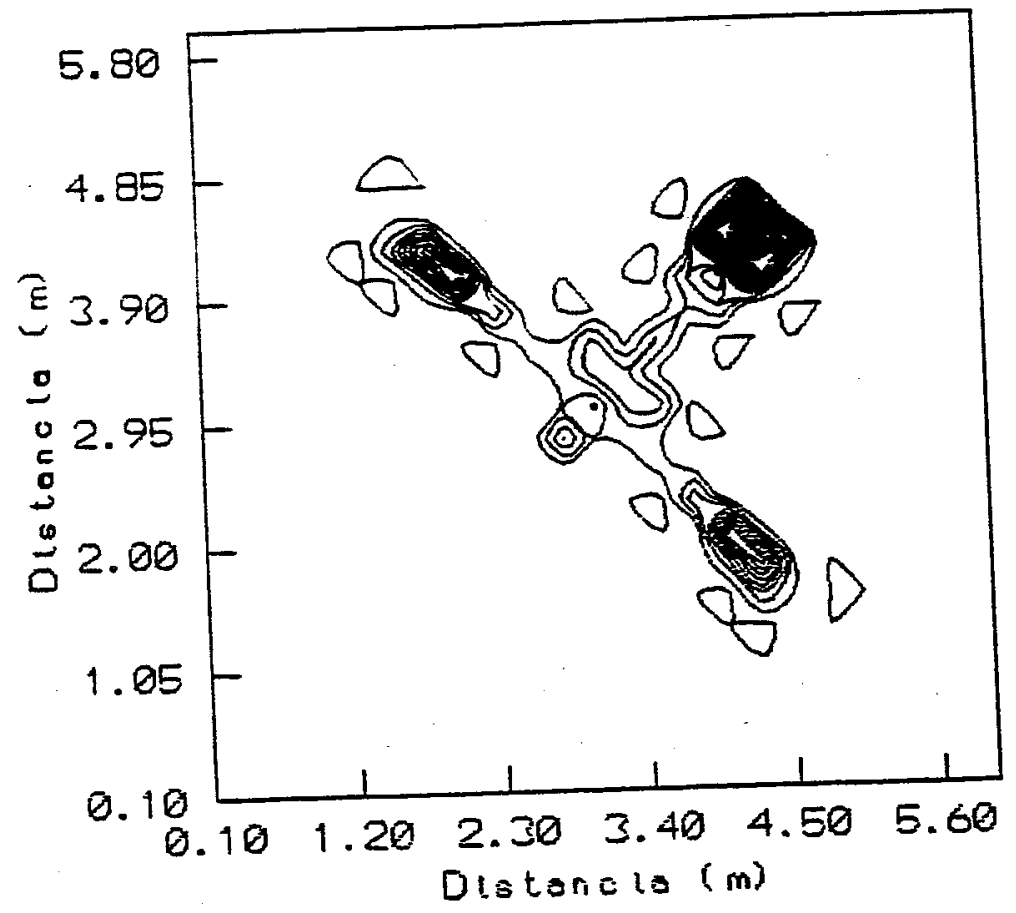

(B)

* Microaspersor nas coordenadas $(3,03 ; 3,02)$

Figura 43 - Distriburição espacial da água apresentada por três jatos do microaspersor jet com bocal violeta e regulador de fluxo verde operando 151,06 kPa. - (A) vista tridimensional ; (B) vista superior 


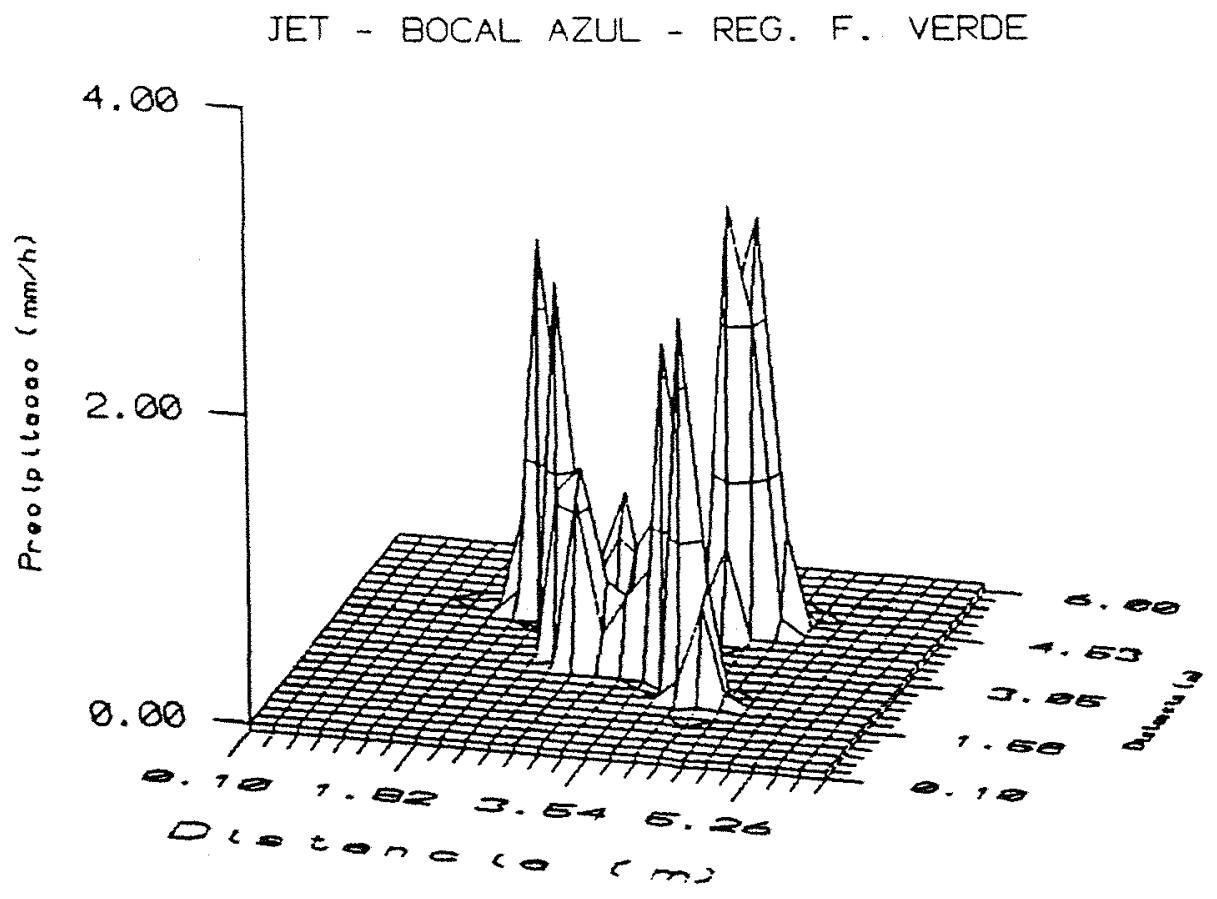

(A)

JET - BOCAL AZUL - REG. F. VERDE

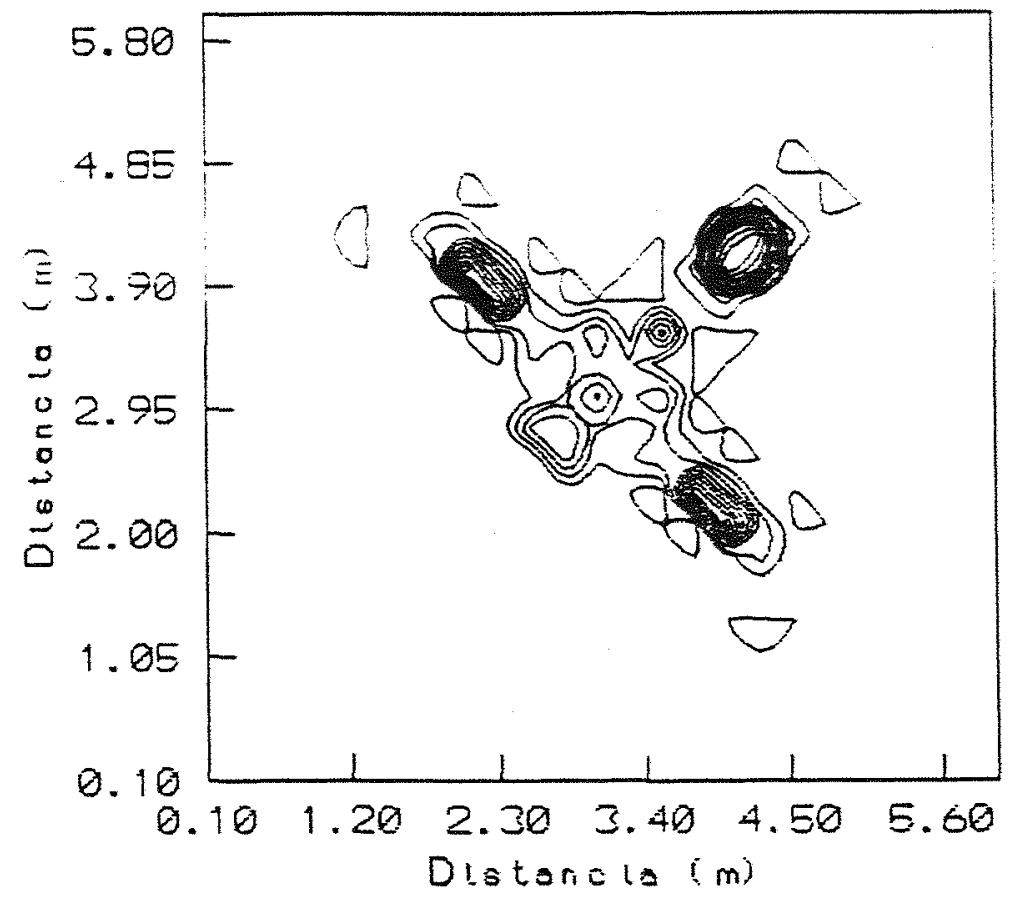

(B)

* Microaspersor nas coordenadas

$(3,03 ; 3,02)$

Figura 44 - Distribuição espacial da água apresentada por três jatos do microaspersor jet com bocal azul e regulador de fluxo verde operando $151,06 \mathrm{kPa}$. - (A) vista tridimensional ; (B) vista superior 


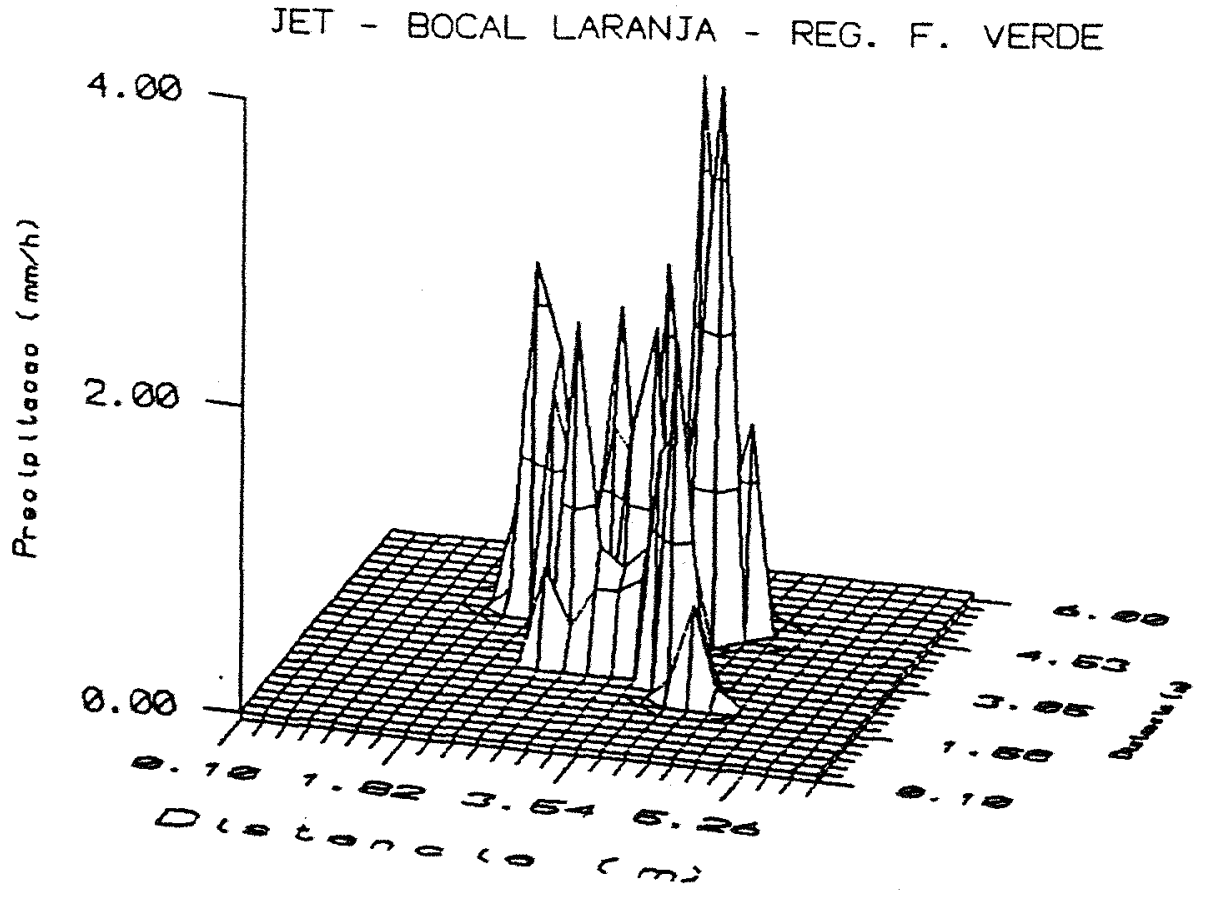

(A)

JET - BOCAL LARANJA - REG. F. VERDE

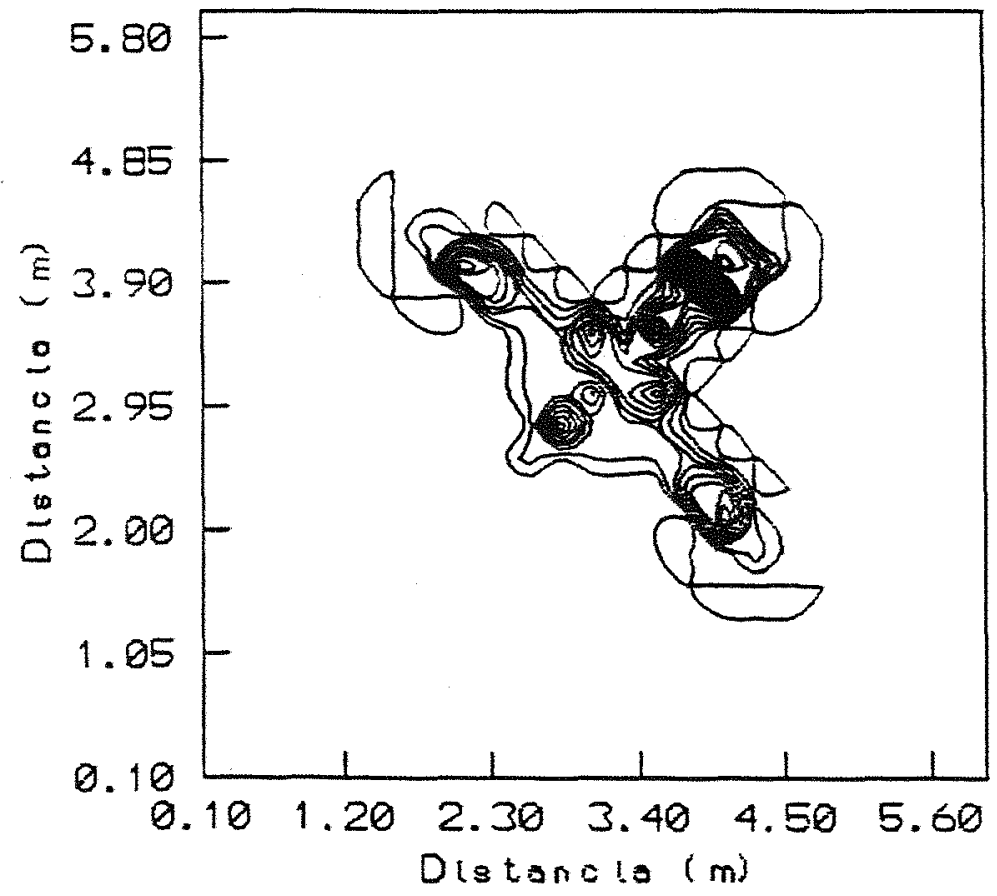

(B)

* Microaspersor nas coordenadas $(3,03 ; 3,02)$

Figura 45 - Distribuição espacial da água apresentada por três jatos do microaspersor jet com bocal laranja e regulador de fluxo verde operando $151,06 \mathrm{kPa}$. - (A) vista tridimensional ; (B) vista superior 
JET - BOCAL VERMELHO - REG. F. PRETO

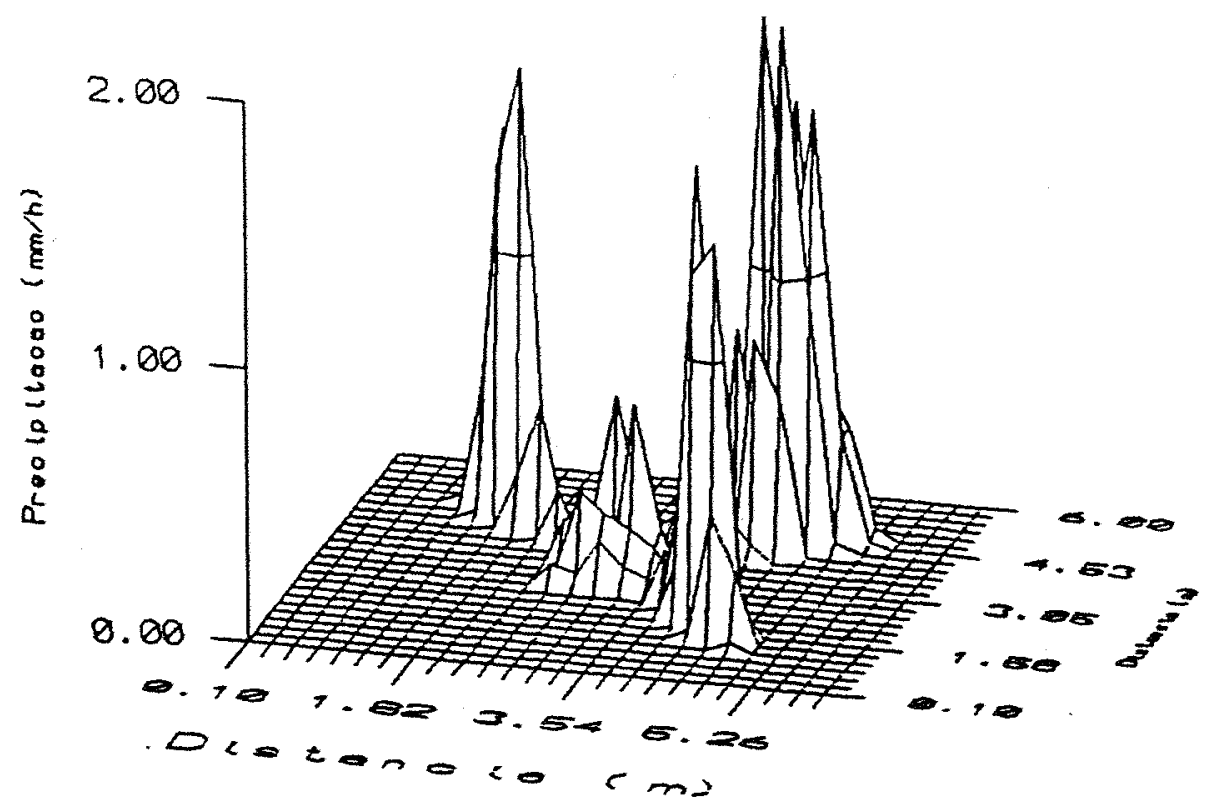

JET - BOCAL VERMELHO - REG. F. PRETO

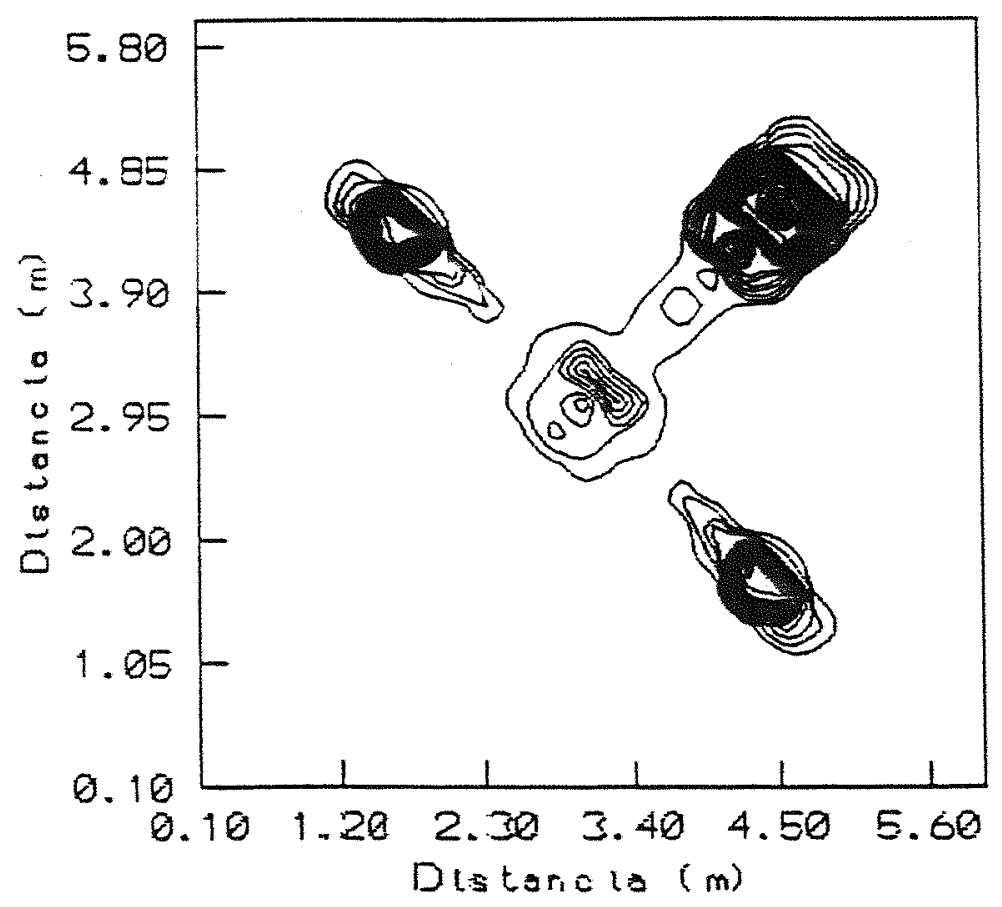

(B)

* Microaspersor nas coordenadas $(3,03 ; 3,02)$

Figura 46 - Distribuição espacial da água apresentada por três jatos do microaspersor jet com bocal vermelho e regulador de fluxo preto operando $151,06 \mathrm{kPa}$. - (A) vista tridimensional ; (B) vista superior 
JET - BOCAL.VIOLETA - REG. F. PRETO

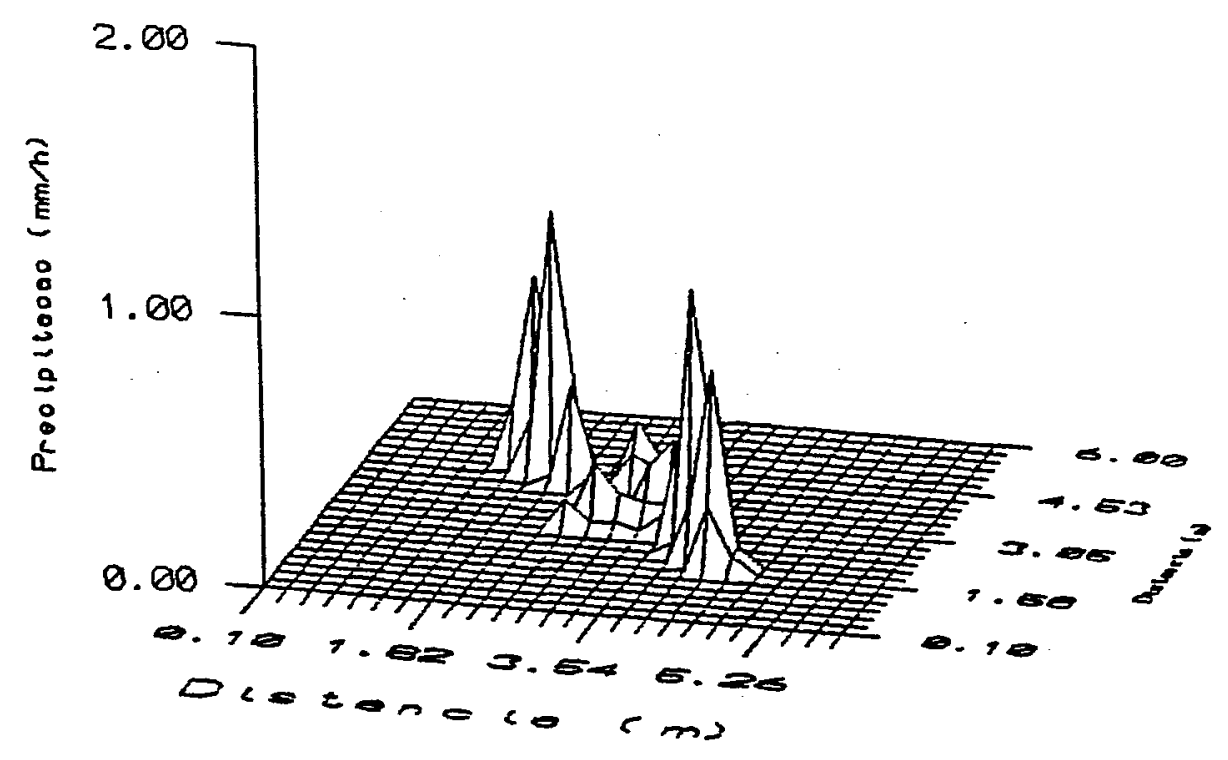

(A)

JET - BOCAL VIOLETA - REG. F. PRETO

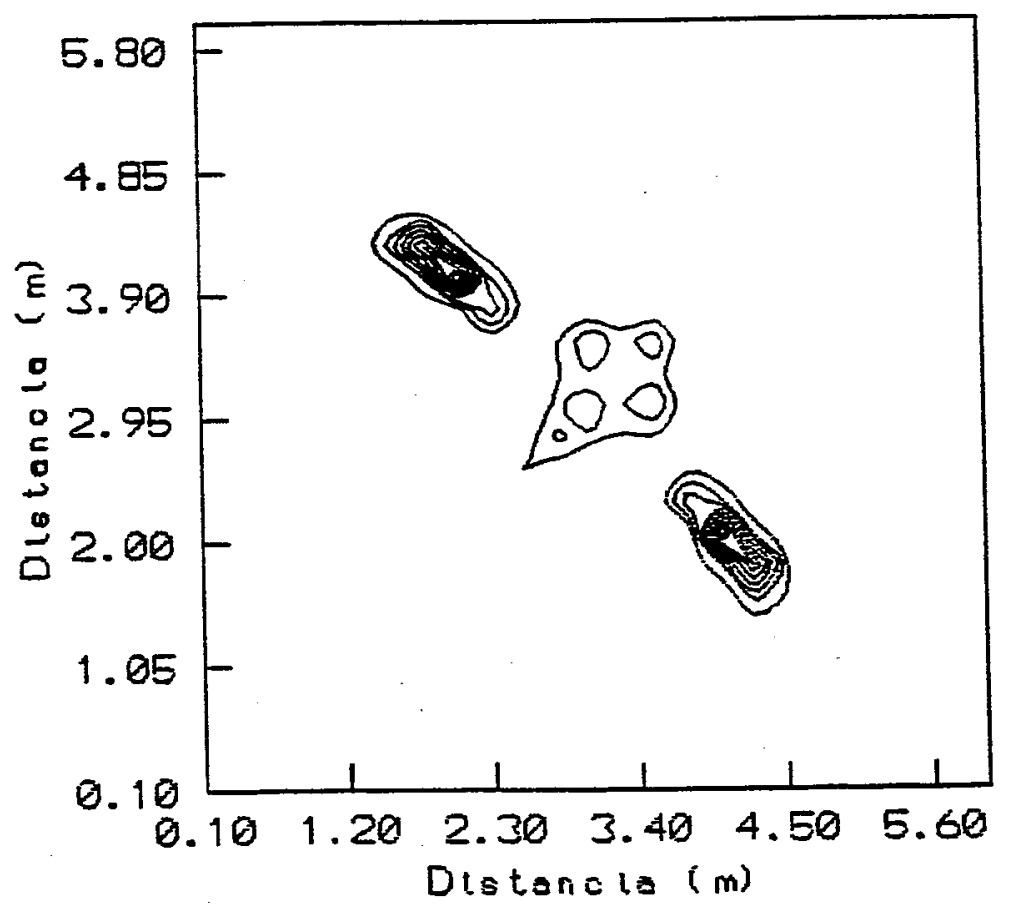

(B)

* Microaspersor nas coordenadas $(3,03 ; 3,02)$

Figura 47 - Distribuição espacial da água apresentada por três jatos do microaspersor jet com bocal violeta e regulador de fluxo preto operando $151,06 \mathrm{kPa}$. - (A) vista tridimensional ; (B) vista superior 
Jët - bulal alul - keg. f. pretu

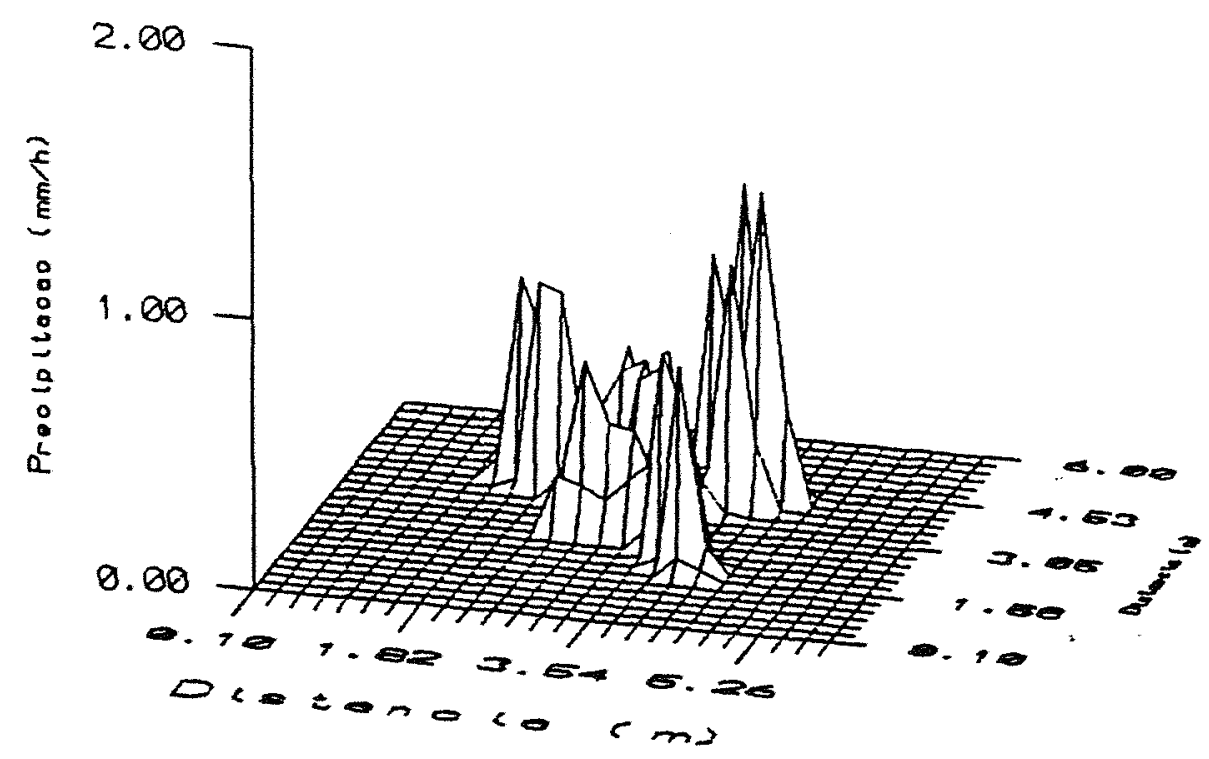

(A)

JET - BOCAL AZUL - REG. F. PRETO

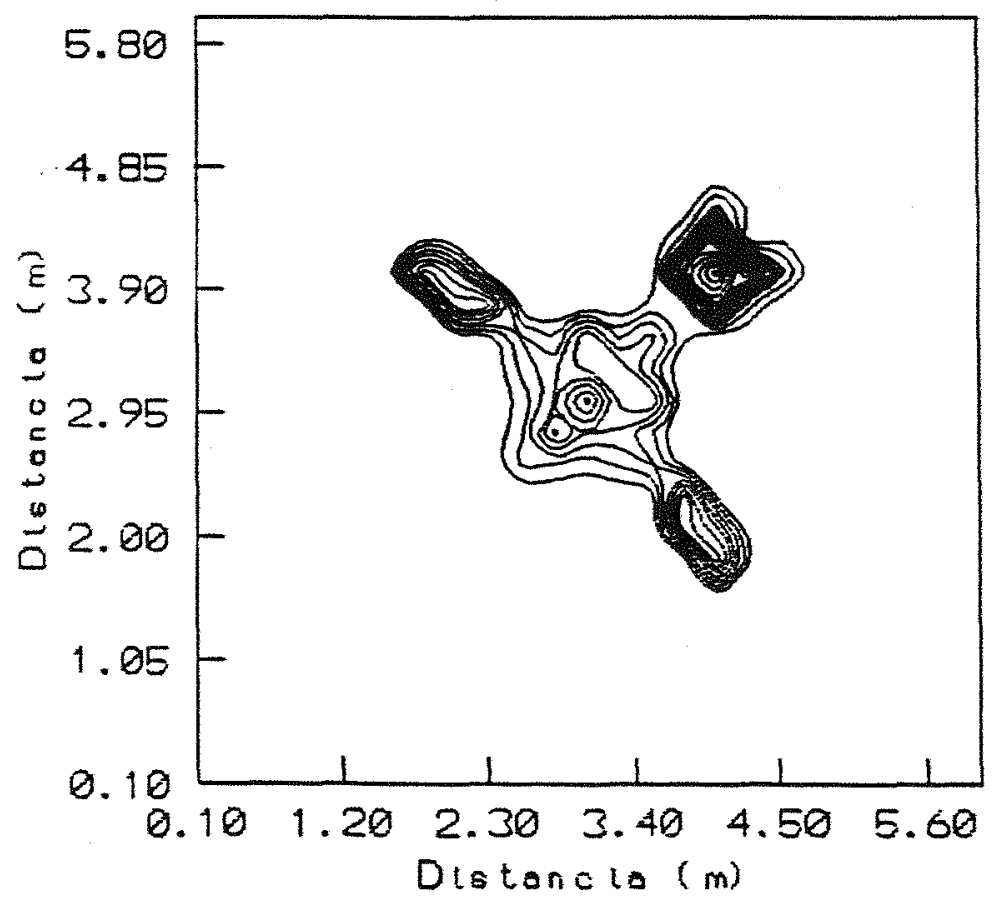

(B)

* Microaspersor nas coordenadas $(3,03 ; 3,02)$

Figura 48 - Distribuição espacial da água apresentada por três jatos do microaspersor jet com bocal azul e regulador de fluxo preto operando $151,06 \mathrm{kPa}$. - (A) vista tridimensional ; (B) vista superior 
JET - BOCAL LARANJA - REg. F. PRETO

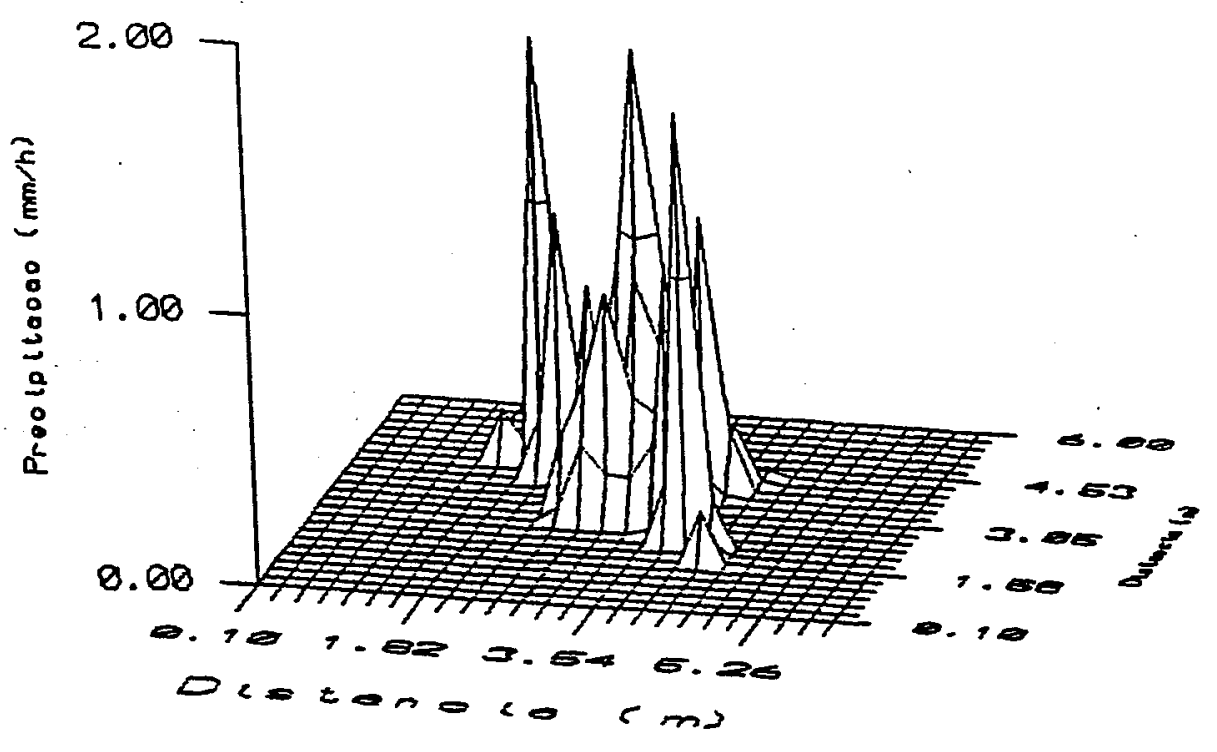

(A)

JET - BOCAL LARANJA - REG. F. PRETO

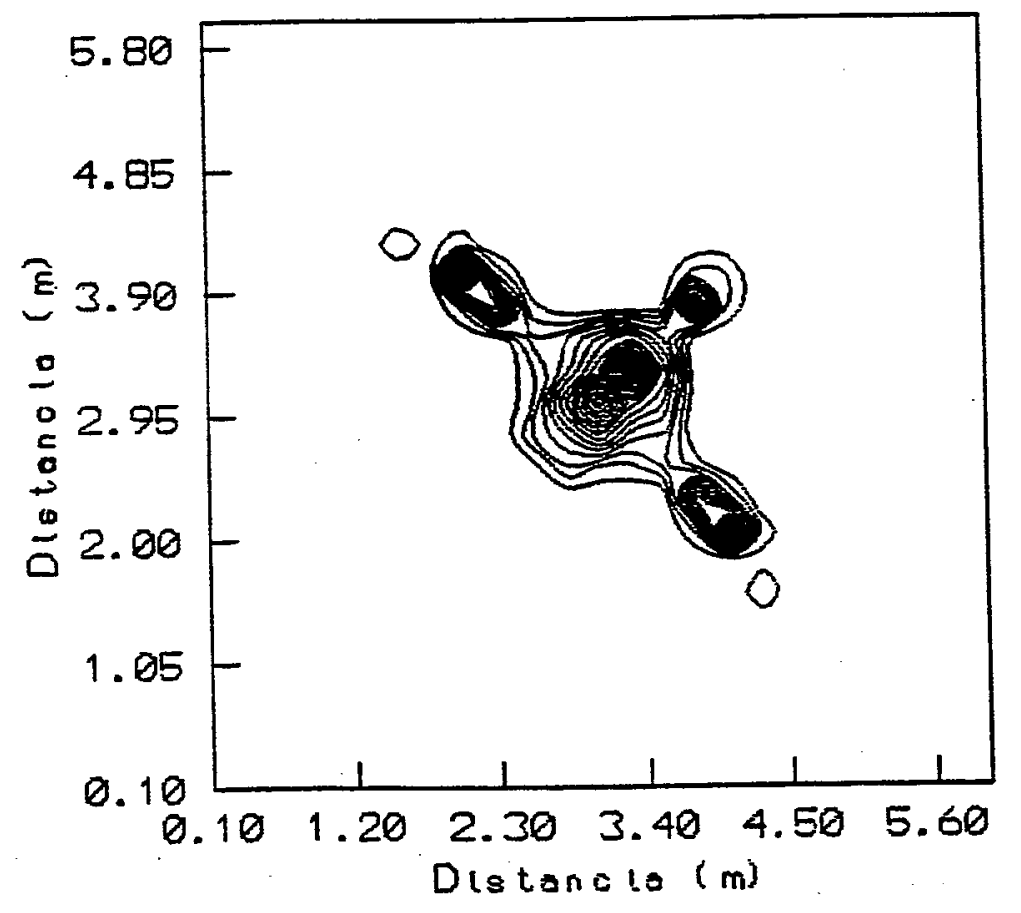

(B)

* Microaspersor nas coordenadas $(3,03 ; 3,02)$

Figura 49 - Distribuição espacial da água apresentada por três jatos do microaspersor jet com bocal laranja e regulador de fluxo preto operando 151,06 kPa. - (A) vista tridimensional ; (B) vista superior 